\title{
Protein Engineering in the Ubiquitin System: Tools for Discovery and Beyond
}

Bo Zhao, Yien Che Tsai, Bo Jin, Bufan Wang, Yiyang Wang, Han Zhou, Tomaya Carpenter, Allan M. Weissman, and Jun Yin Engineering Research Center of Cell and Therapeutic Antibody, Ministry of Education, and School of Pharmacy, Shanghai Jiao Tong University, Shanghai, China (B.Z., B.J., B.W.); Department of Pathophysiology, School of Medicine, Jinan University, Guangzhou, China (Y.W.); Laboratory of Protein Dynamics and Signaling, Center for Cancer Research, National Cancer Institute, Frederick, Maryland (Y.C.T., A.M.W.); and Department of Chemistry, Center for Diagnostics and Therapeutics, Georgia State University, Atlanta, Georgia (Y.W., H.Z., T.C., J.Y.)

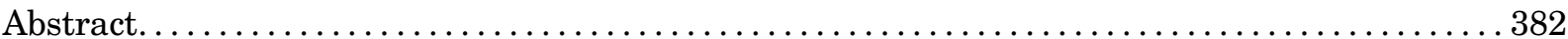

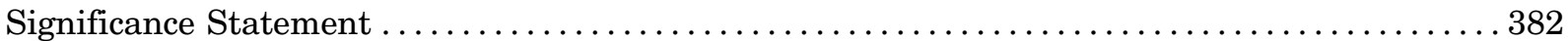

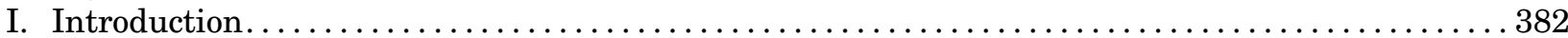

A. The E1-E2-E3 Cascade as the Writer, Deubiquitinating Enzyme as the Editor, and

Ubiquitin-Binding Domain as Reader of Protein Ubiquitination Signals . . . . . . . . . . . . 384

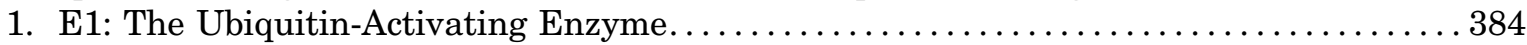

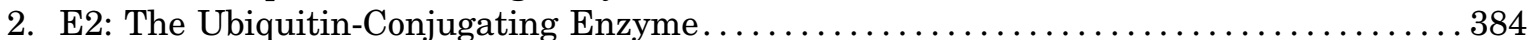

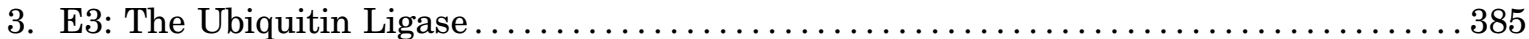

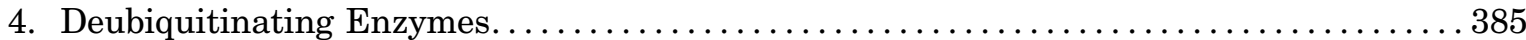

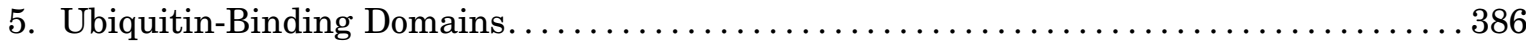

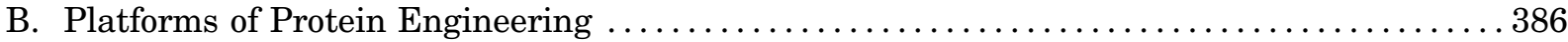

1. Divergent Versus Directed Evolution ................................ 386

2. Screen Versus Selection ......................................... 386

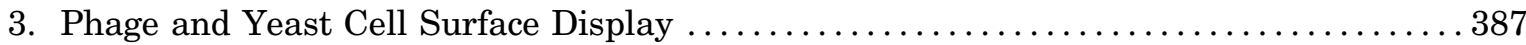

4. Protein Semisynthesis by Expressed Protein Ligation $\ldots \ldots \ldots \ldots \ldots \ldots \ldots \ldots \ldots \ldots \ldots$

5. Site-Specific Incorporation of Unnatural Amino Acids . . . . . . . . . . . . . . . . 388

II. Probing the Mechanism of Ubiquitin Transfer by Protein Engineering ................. 388

A. Designer Ubiquitin Conjugates To Probe the Catalytic Mechanism of Ubiquitin

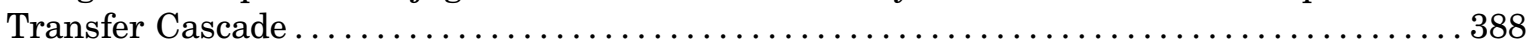

1. Ubiquitin-E1 and E1-E2 Conjugates To Capture the Conformational Change of E1 . . . 388

2. Ubiquitin-E2 Conjugates To Elucidate the Conformation of Ubiquitin Passing

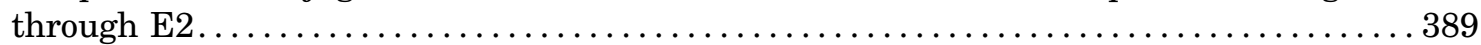

3. Ubiquitin-E3 Conjugates To Elucidate the Conformation of Ubiquitin Passing from

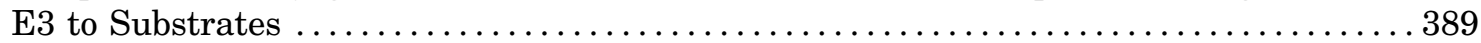

B. Activity-Based Probes for Ubiquitin-Transferring Enzymes and Deubiquitinating

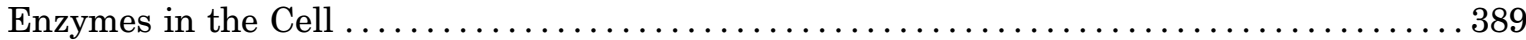

1. Ubiquitin with C-Terminal Electrophiles as Probes of Deubiquitinating Enzyme ...... 389

2. Ubiquitin-E2 Conjugates as Probes of E1 and E3 Enzymes ................... 391

3. diUB Probes with Cys Traps To Target Deubiquitinating Enzyme and E3s .......... 391

C. Linkage-Specific Ubiquitin Chains Enabled by Solid-Phase Peptide Synthesis and

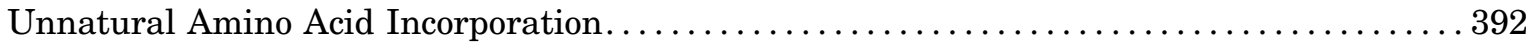

1. Total Peptide Synthesis of Ubiquitin Chains ............................... 392

2. Ubiquitin Chain Synthesis Enabled by Unnatural Amino Acid Incorporation.......... 393

3. Engineered Ubiquitin Chains of Non-native Linkages ...................... 393

Address correspondence to: Dr. Bo Zhao, Shanghai Jiao Tong University, Shanghai 200240, China. E-mail: bozhao@sjtu.edu.cn; Dr. Allan M. Weissman, National Cancer Institute, Frederick, MD 21702. E-mail: weissmaa@mail.nih.gov; or Dr. Jun Yin, Georgia State University, Atlanta, GA 30302. E-mail: junyin@gsu.edu

This work was supported by the National Natural Science Foundation of China [Grants 31770921 and 31971187 ] to B.Z.; National Institutes of Health [Grant R01GM104498] and National Science Foundation [Grant 1710460] to J.Y.; as well as the Intramural Research Program of the National Institutes of Health National Cancer Institute, Center for Cancer Research [Y.C.T. and A.M.W.].

https://doi.org/10.1124/pr.118.015651. 


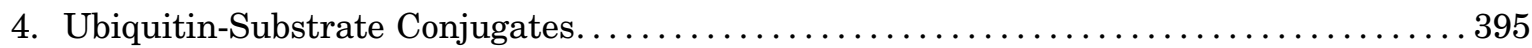

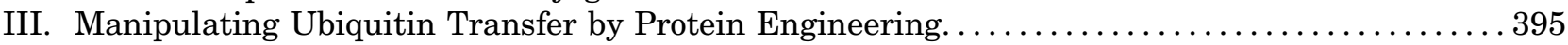

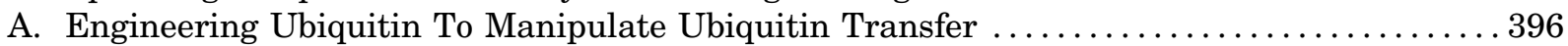

1. Ubiquitin and Ubiquitin-Like Protein-Mimicking Peptides................... 396

2. Ubiquitin Variants That Regulate the Activity of Deubiquitinating Enzyme and E3

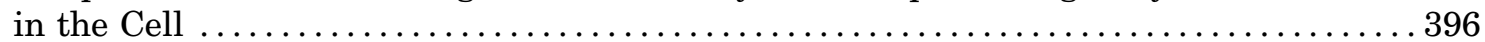

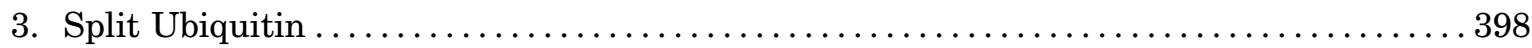

B. Engineering E3s To Regulate New Cellular Targets ......................... 398

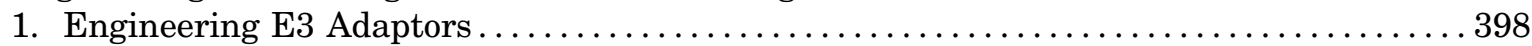

2. E3 Fusions To Redirect the Ubiquitination Targets $\ldots \ldots \ldots \ldots \ldots \ldots \ldots \ldots \ldots \ldots \ldots$

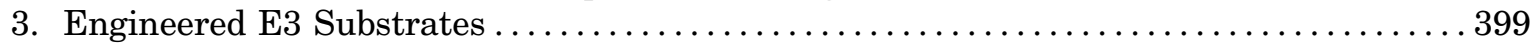

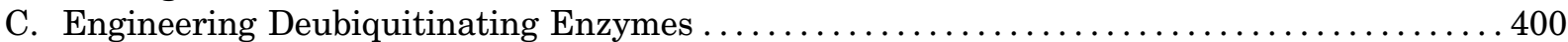

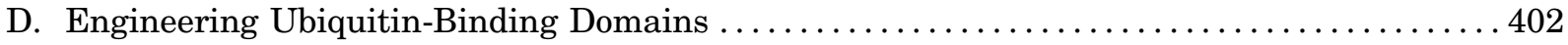

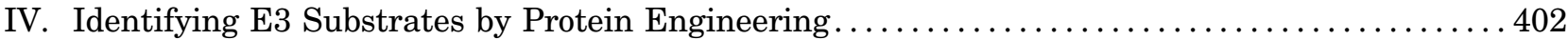

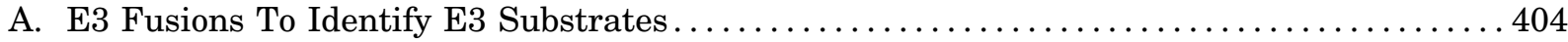

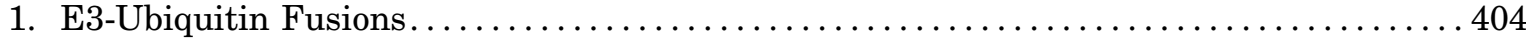

2. E3-Ubiquitin-Associated Domain Fusions............................. 404

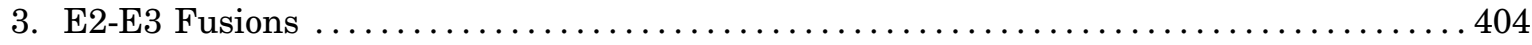

B. Identifying E3 Substrates by a Reporter Gene or Chemical Cross-Linking. ............ 404

1. Split Dihydrofolate Reductase Assays To Screen E3 Substrates in E. coli........... 404

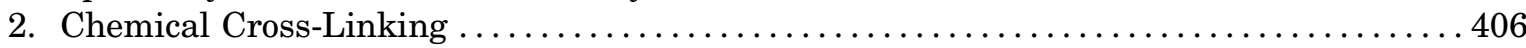

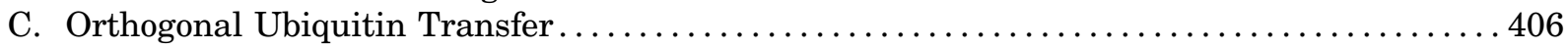

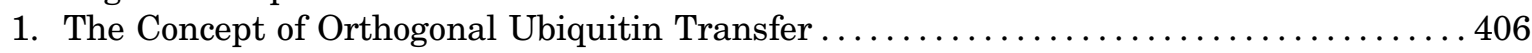

2. Engineering the $x U B-x E 1$ and $x E 1-x E 2$ Pairs for the Orthogonal Ubiquitin Transfer

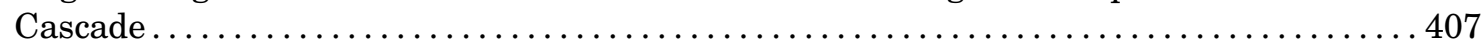

3. Constructing the Orthogonal Ubiquitin Transfer Cascade with HECT E3 E6AP ...... 407

4. Constructing the Orthogonal Ubiquitin Transfer Cascades with U-Box E3 E4B and

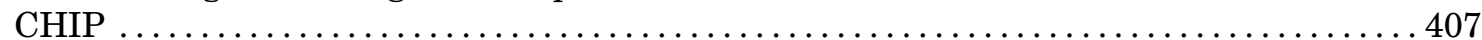

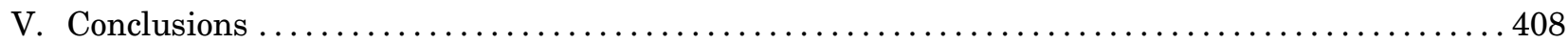

Acknowledgments ................................................... 408

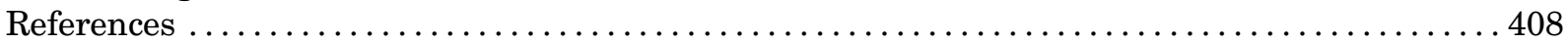

\begin{abstract}
Ubiquitin (UB) transfer cascades consisting of E1, E2, and E3 enzymes constitute a complex network that regulates a myriad of biologic processes by modifying protein substrates. Deubiquitinating enzymes (DUBs) reverse UB modifications or trim UB chains of diverse linkages. Additionally, many cellular proteins carry UB-binding domains (UBDs) that translate the signals encoded in UB chains to target proteins for degradation by proteasomes or in autophagosomes, as well as affect nonproteolytic outcomes such as kinase activation, DNA repair, and transcriptional regulation. Dysregulation of the UB transfer pathways and malfunctions of DUBs and
\end{abstract}

UBDs play causative roles in the development of many diseases. A greater understanding of the mechanism of UB chain assembly and the signals encoded in UB chains should aid in our understanding of disease pathogenesis and guide the development of novel therapeutics. The recent flourish of protein-engineering approaches such as unnatural amino acid incorporation, protein semisynthesis by expressed protein ligation, and high throughput selection by phage and yeast cell surface display has generated designer proteins as powerful tools to interrogate cell signaling mediated by protein ubiquitination. In this study, we highlight recent achievements of protein engineering

\footnotetext{
ABBREVIATIONS: aGFP, against GFP; Aha, azido-homoAla; AVSN, vinyl sulfonamide linkage; BocK, Boc-protected $\varepsilon$-amino group; BoNT/ A, type A botulinum neurotoxin; CHIP, carboxyl terminus of Hsc70-interacting protein; CRL, Cullin RING ligase; Dha, dehydroAla; DHFR, dihydrofolate reductase; diUB, di-ubiquitin; DUB, deubiquitinating enzyme; EPL, expressed protein ligation; ER, endoplasmic reticulum; FL, firefly luciferase; FRET, Förster resonance energy transfer; GOPAL, genetically encoded orthogonal protection and activated ligation; HECT, homologous to E6-AP C-terminus; IMiD, immunomodulatory drug; MAPK, mitogen-activated protein kinase; MESNa, sodium $\beta$-mercaptoethane sulfonate; MINDY, motif interacting with UB domain-containing novel DUB; NEMO, NFкB essential modulator; OUT, orthogonal UB transfer; PCNA, proliferating cell nuclear antigen; PROTAC, proteolysis-targeting chimera; PTM, post-translational modification; Pyl-RS, pyrro-Lys tRNA synthetase; RBR, RING-between-RING; RING, Really Interesting New Gene; RL, renilla luciferase; SCF, Skp1-Cullin-F box; SH2, Src homology 2; tRNA, transfer ribonucleic acid; TUBE, tandem UB-binding entity; UAA, unnatural amino acid; UB, ubiquitin; UB ${ }^{\mathrm{A}}$, acceptor UB; UBA, UB-associated domain; UBC, UB-conjugating domain; UB ${ }^{\mathrm{D}}$, donor UB; UBD, UB-binding domain; UBL, UB-like protein; Ubv, UB variant; UbxD8, ubiquitin-domain-containing protein 8; UFD, UB-fold domain; UIM, UB-interacting motif; USP, UB-specific protease; wt, wild-type.
} 
on mapping, probing, and manipulating UB transfer in the cell.

Significance Statement-The post-translational modification of proteins with ubiquitin alters the fate and function of proteins in diverse ways. Protein engineering is fundamentally transforming research in this area, providing new mechanistic insights and allowing for the exploration of concepts that can potentially be applied to therapeutic intervention.

\section{Introduction}

The 2018 Nobel Prize in Chemistry was awarded to Frances H. Arnold, George P. Smith, and Sir Gregory P. Winter for fundamental contributions to enzymedirected evolution and protein engineering. Frances Arnold engineered enzymes by directed evolution to gain tolerance to high temperature or high concentration of organic solvent (Chen and Arnold, 1993; Zhao et al., 1998). She also engineered cytochrome $P 450$ to catalyze challenging organic reactions (Kan et al., 2016, 2017; Hammer et al., 2017; Chen et al., 2018). Gregory Smith developed a phage display method for sorting through millions of peptides or proteins for desired molecular recognition with a target molecule through a process known as biopanning (Smith, 1985; Smith and Petrenko, 1997). Gregory Winter applied phage display to engineering humanized antibodies and optimizing their therapeutic efficacy (McCafferty et al., 1990; Clackson et al., 1991; Winter et al., 1994). The field of protein engineering pioneered by these scientists is constantly evolving and expanding. Designer proteins coming from the proteinengineering pipeline assume versatile roles not only as enzymes or antibodies with desired catalytic or binding capacities but also as powerful chemical tools to study cell biology. As examples, components of the protein translational machinery consisting of transfer ribonucleic acid (tRNA) synthetases and ribosomes were engineered for site-specific incorporation of unnatural amino acids (UAA) into proteins (Liu and Schultz, 2010; Lang and Chin, 2014). The UAAs expand the chemical functionalities on the protein scaffold and generate precise acetylation, methylation, or phosphorylation patterns to reveal the roles of post-translational modifications (PTM) in cell signaling (Wang et al., 2001; Neumann et al., 2010). In contrast, PTM enzymes, including acetyltransferases, methyltransferases, and kinases, were engineered to append chemical labels to their cellular targets to enable their identification from the proteome (Shah et al., 1997; Islam et al., 2013; Yang et al., 2013).

Ubiquitin (UB) is a 76-residue protein that modifies other proteins to mediate signal transduction in the cell and is particularly amenable to protein engineering due to its compact size and stable fold. We will review the technical platforms for engineering UB transfer and a sampling of approaches to the design of UB, enzymes of the UB system, and targets of UB transfer to deduce the cellular signals encoded in this ubiquitous posttranslational modification.

UB was first determined to be a post-translational protein modifier that targets eukaryotic proteins for proteolysis in the late 1970s (Ciechanover et al., 1978, 1980; Hershko et al., 1979; Wilkinson et al., 1980). This discovery was recognized by the awarding of the 2004 Nobel Prize in Chemistry to Aaron Ciechanover, Avram Hershko, and Irwin Rose. Until the mid-90s, ubiquitination was primarily studied as a signal that targets proteins for degradation in the $26 \mathrm{~S}$ proteasome. Indeed, UB-mediated proteasomal degradation controls myriad critical cellular processes. The importance of proteasomal degradation has recently been underscored by the awarding of the 2019 Nobel Prize in Physiology or Medicine, in part, for the discovery of regulated degradation of hypoxia-inducing factor $1 \alpha(\mathrm{HIF} 1 \alpha)$ as a means of sensing changes in cellular oxygen (Maxwell et al., 1999; Ivan et al., 2001; Jaakkola et al., 2001). However, we now understand UB to have a number of nonproteasomal functions in, for example, endocytosis and lysosomal targeting, subcellular localization of proteins, autophagy, DNA repair, and kinase activation. Malfunction of the UB system plays causal roles in diseases such as cancer, inflammatory diseases, and neurodevelopmental and degenerative disorders. The reader is recommended to the many comprehensive reviews on the topics of cell regulation and disease pathogenesis associated with protein ubiquitination (Nakayama and Nakayama, 2006; Frescas and Pagano, 2008; Hoeller and Dikic, 2009; Schwartz and Ciechanover, 2009; Lipkowitz and Weissman, 2011), including a review in this journal summarizing neuronal functions supported by protein ubiquitination (Yi and Ehlers, 2007).

UB is conjugated to proteins through a multienzyme cascade that entails the sequential involvement of enzyme classes known as E1s or UB-activating enzymes, E2s or UB-conjugating enzymes, and E3s or UB protein ligases (Fig 1A). The outcome of this is generally the formation of an isopeptide bond between the $\mathrm{C}$ terminus of UB and the $\varepsilon$-amino group of a Lys residue. As will be discussed below, UB can be added to proteins not only as a single moiety but also, and perhaps more commonly, in chains of various linkages involving any of its seven Lys residues or its $\mathrm{N}$-terminal amine on Met1. The nature of these chains is determined largely by specific E2s and E3s involved, which, together with E1, write the UB signal on proteins. Ubiquitination is a reversible process, and deubiquitinating enzymes (DUBs; deubiquitinases) can either completely reverse or alternatively edit substratebound chains by cleaving linkages with various degrees of specificity. The outcome of protein ubiquitination is largely a function of the UB chain linkage in the context of the substrate and its recognition by the many 
A

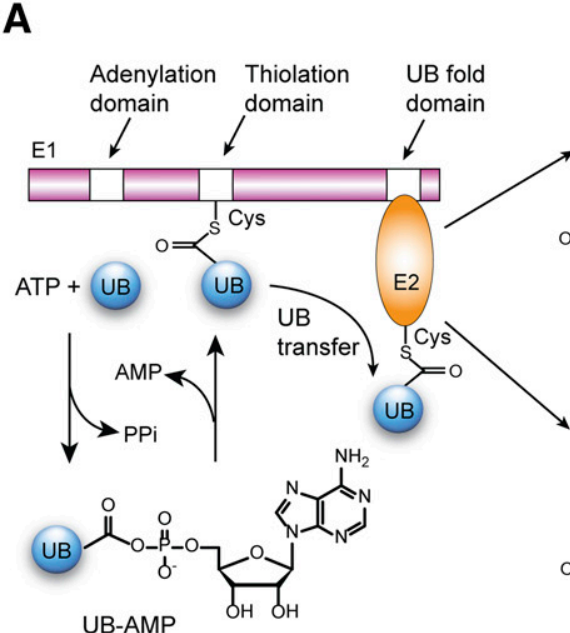

HECT/RBR E3
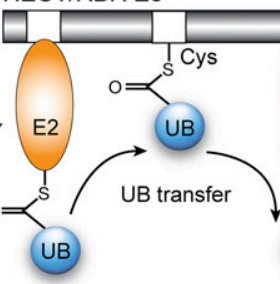

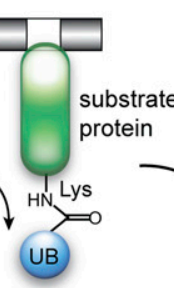

RING/U-box E3

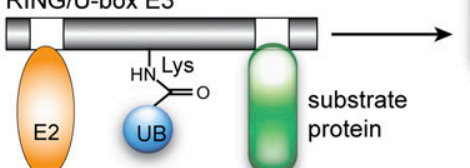

$={ }^{S}$

i auto-

' auto- HN Lys

nation $U B$

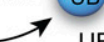

UB transfer
H

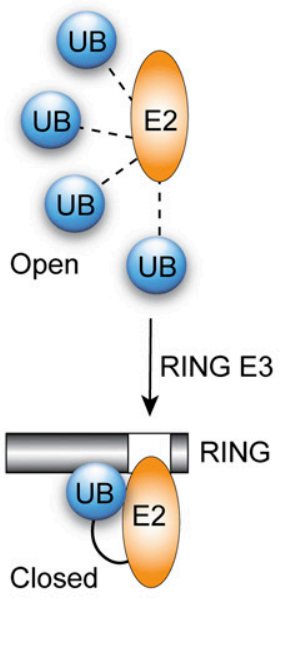

B

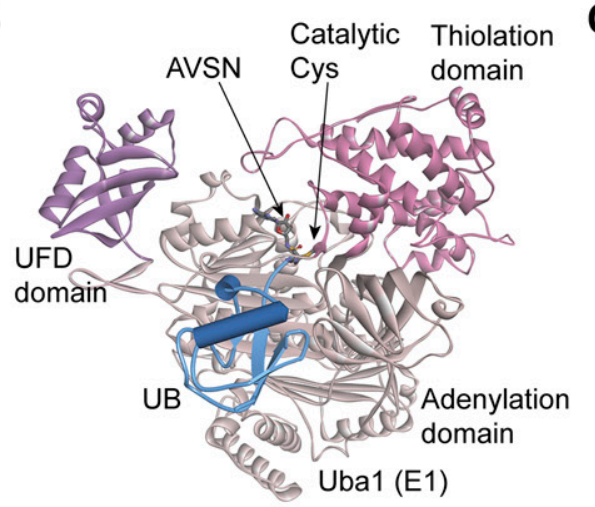

$\mathbf{E}$

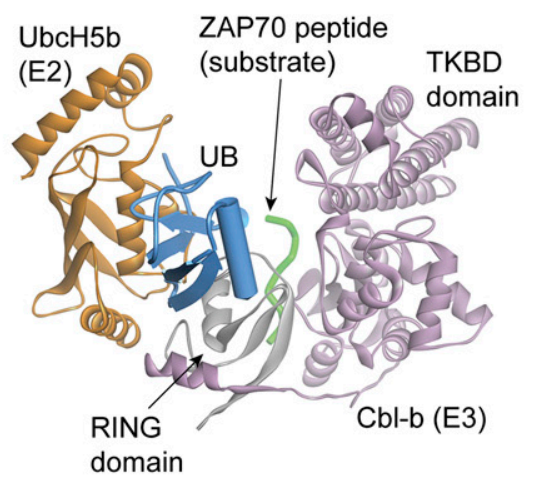

C

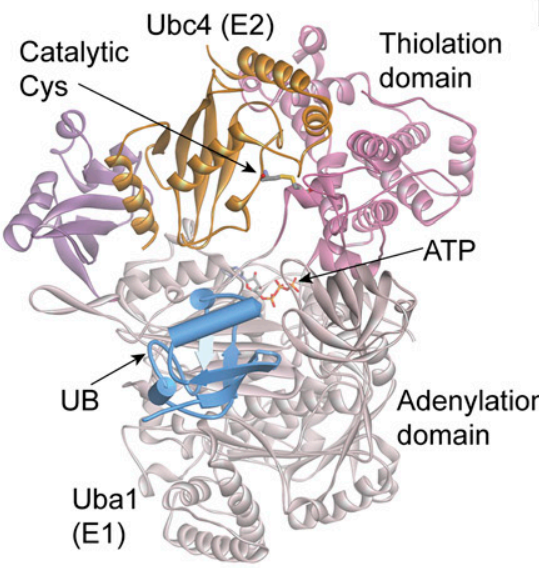

D

$\mathbf{F}$

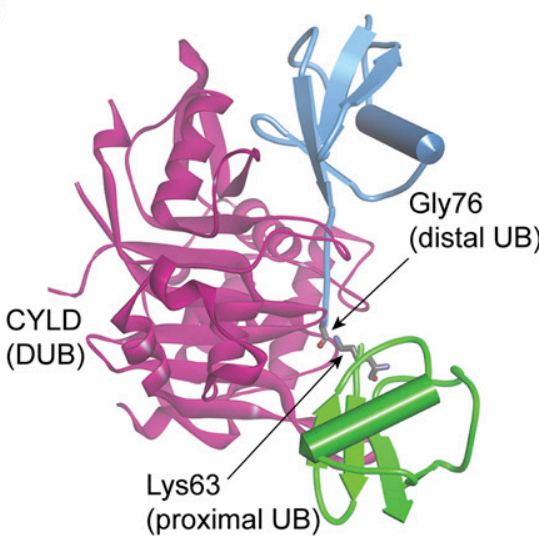

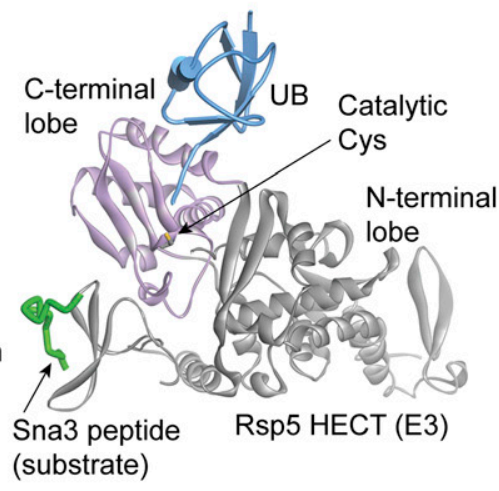

G

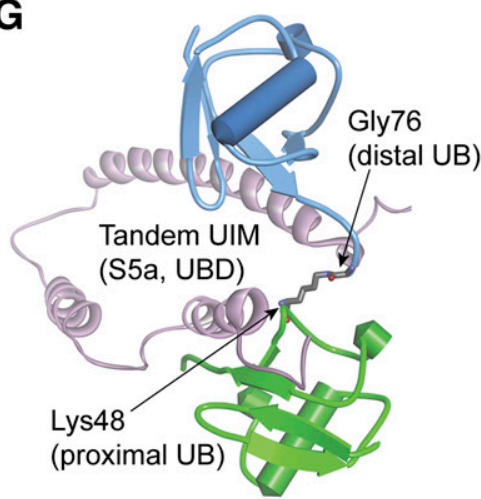

Fig. 1. Writers, editors, and readers of cellular signals encoded in protein ubiquitination. (A) The UB-activating enzymes E1s, UB-conjugating enzymes E2s, and UB ligases E3s constitute the UB transfer cascade. E3s are classified into HECT and RBR UB ligases, which have catalytic Cys residues that form thioester intermediates with UB, and RING-type ligases that include the families of RING finger and U-box-containing proteins. RING-type E3s activate E2 UB to directly transfer UB to substrate proteins. E3s can also undergo autoubiquitination (shown for RING-type E3s). UB chains installed on the substrate proteins are recognized by DUBs that cleave or edit the chain. Chains are also recognized by UBD-containing proteins that, in many cases, recruit other cellular partner proteins. (B) Crystal structure of yeast E1 Uba1 in complex with UB with a C-terminal AVSN functionality. AVSN is covalently conjugated to the catalytic Cys residue of Uba1 to freeze its conformation at the moment of UB E1 thioester formation [Protein Data Bank (PDB) ID 6O83] (Hann et al., 2019). (C) The E1-E2 complex linked by a disulfide bond between the catalytic Cys residues of yeast Uba1 and Ubc4. The conformation of E1 enables the catalytic Cys of E2 to attack the E1 UB thioester to form a E2 UB thioester linkage (PDB ID 4II2) (Olsen and Lima, 2013). (D) Tricomplex of the HECT domain of Rsp5 with UB and the Sna3 substrate peptide. Through a three-way linker, the catalytic Cys of the HECT domain is linked to the C terminus of UB and the substrate peptide to capture the conformation of the HECT domain at the moment of UB transfer to substrate (PDB ID 4LCD) (Kamadurai et al., 2013). (E) RING E3 Cbl-b in complex with UbcH5b UB conjugate and the substrate peptide from the ZAP70 protein. UB adopts a closed conformation when the E2 UB conjugate is bound to the RING domain to activate UB transfer (PDB ID 3ZNI) (Dou et al., 2013). (F) The catalytic domain of the DUB CYLD in complex with K63 diUB with the proximal UB in green and the distal UB in blue (PDB ID 3WXG) (Sato et al., 2015). (G) Tandem UIMs of the Rpn10/S5a protein in a complex with K48 diUB (PDB ID 2KDE) (Zhang et al., 2009). (H) Schematic view of open and closed conformation of UB in relative to E2 with and without the association with RING E3s. UB adopts a closed conformation upon the association of RING E3 to prime the transfer of UB to substrates. 
proteins containing UB-binding domains (UBD), which translate or read the UB code on a particular protein.

Despite the intense focus on identifying the signaling pathways mediated by UB transfer, there are many important outstanding questions about the mechanism of UB transfer through the E1-E2-E3 cascade and the roles of individual enzymes in cell regulation (Hochstrasser, 2006; Deshaies and Joazeiro, 2009; Harper and Tan, 2012). Due to the roles of the UB system and of altered protein levels in disease, there is great interest in specifically enhancing, inhibiting, or redirecting components of the UB system with the goal of therapeutic development. Recently, some exciting work on engineering UB, its multi-enzyme E1-E2-E3 transfer cascade (the writers), DUBs (the editors), and UBDs (the readers) has provided powerful chemical tools to decode the protein ubiquitination signal in the cell. In this study, we first introduce the basic components of UB transfer cascades and the techniques of protein engineering and enzyme-directed evolution. We then devote much of the review to laying out the technical platforms for engineering protein ubiquitination and provide illustrative examples. It is our hope that recent progress in engineering UB and its transfer inspires the development of new tools to probe, map, and manipulate the cellular pathways of protein ubiquitination.

\section{A. The E1-E2-E3 Cascade as the Writer, Deubiquitinating Enzyme as the Editor, and Ubiquitin-Binding Domain as Reader of Protein Ubiquitination Signals}

1. E1: The Ubiquitin-Activating Enzyme. E1 initiates UB transfer by activating the carboxylate of the C-terminal Gly residue of UB with ATP to form a UBAMP conjugate (Fig. 1A) (Hershko and Ciechanover, 1998; Pickart, 2001). A catalytic Cys residue of E1 reacts with UB-AMP to form a thioester linkage with UB. The $\mathrm{UB} \sim \mathrm{E} 1$ thioester (" " designates the labile thioester bond) is reactive with the catalytic Cys residue of the E2 enzymes to initiate UB transfer. The human genome encodes two E1s, Uba1 (also known as Ube1) and Uba6, which pair with distinct sets of E2s to direct UB transfer to different pools of substrate proteins, with Uba1 being the E1 responsible for the large majority of cellular ubiquitination (Jin et al., 2007; Liu et al., 2017b). Each E1 has unique functions in cell regulation. The crystal structures of yeast E1 (the ortholog of human Uba1) reveal that E1 uses different binding sites to sequentially engage UB. A UB molecule first associates with the adenylation domain of E1 as a UB-AMP conjugate and then is transferred to the active site Cys in the thiolation domain, resulting in a $\mathrm{UB} \sim \mathrm{E} 1$ conjugate (Fig. 1B) (Lee and Schindelin, 2008; Olsen and Lima, 2013; Hann et al., 2019). UB transfer from the adenylation to the thiolation domain would require a substantial rearrangement of the E1 enzyme to enable the reaction of the catalytic Cys residue of $\mathrm{E} 1$ with UB-AMP (Fig. 1C). The UB-binding site in the adenylation domain has been targeted by inhibitors to regulate protein ubiquitination in the cell (Hyer et al., 2018). A series of UB-like proteins (UBL) that are also protein modifiers have been identified. Included among these proteins are Nedd8, SUMO, and ISG15. These UBLs modify their downstream targets through a similar mechanism as UB and have specific E1s that activate transfer through unique enzymatic cascades (Schulman and Harper, 2009). Similar to the inhibitors of the UB E1, NEDD8 E1 inhibitors with promising anticancer activities have been developed (Soucy et al., 2009; Brownell et al., 2010; Bedford et al., 2011).

2. E2: The Ubiquitin-Conjugating Enzyme. E2s are central players in the ubiquitination cascade. Members of this $\sim 40$-member family have a conserved UB-conjugating domain (UBC) fold that is critical to interactions with both $\mathrm{E} 1$ and the various families of E3s (Ye and Rape, 2009; Wenzel et al., 2011). This fold includes a catalytic Cys through which UB is bound in a thioester linkage (E2 UB) after transesterification from E1. The N-terminal helix of UBC is a key element for interacting with the UB-fold domain (UFD) of the E1 enzyme (Lee and Schindelin, 2008; Olsen and Lima, 2013) (Fig. 1C). Besides the UBC, various E2s may have extended $\mathrm{N}$ or $\mathrm{C}$ termini that affect their pairing with various E1 and E3 enzymes. The function of these proteins is significantly more complex than initially appreciated. They can either serve as carriers of UB to substrate-specific E3s, in the case of homologous to E6-AP C-terminus (HECT) and RING-between-RING (RBR) E3s, or function as the final catalytic intermediates in substrate ubiquitination and chain elongations when employed by Really Interesting New Gene (RING) or U-box E3s (RING-type E3s), which constitute the large majority of known E3s (Fig. 1A and 1C).

Particularly when directly transferring UB to ubiquitin chains, E2s play important roles in defining the linkage types of UB chains generated. How specific Lys on substrates are targeted by the RING ligase:E2 UB complex is still poorly understood and clearly depends on the E3-substrate interaction. However, some general concepts in UB chain formation have emerged. Upon the covalent loading of donor $\mathrm{UB}\left(\mathrm{UB}^{\mathrm{D}}\right)$ to $\mathrm{E} 2$, which results in the formation of $\mathrm{UB}^{\mathrm{D}} \sim \mathrm{E} 2$ thioester conjugate, E2s orient a specific Lys (or the $\alpha$-amino group of Met1) of the acceptor $\mathrm{UB}\left(\mathrm{UB}^{\mathrm{A}}\right)$ to enable its approach and nucleophilic attack on the $\mathrm{UB}^{\mathrm{D}} \sim \mathrm{E} 2$ thioester, resulting in an isopeptide (or peptide) bond between the amino group of $\mathrm{UB}^{\mathrm{A}}$ and the C-terminal carboxylate of $\mathrm{UB}^{\mathrm{D}}$ and the formation of di-ubiquitin (diUB). Repeating such a process with a specific Lys residue on a $U^{A}$ at the growing end of a substrate-bound (or free) UB chain would lead to the assembly of UB chains of a specific linkage. Because each of the seven Lys residues and the $\mathrm{N}$-terminal amino group of $\mathrm{UB}^{\mathrm{A}}$ could be the site of 
isopeptide linkage with $\mathrm{UB}^{\mathrm{D}}$, it remains to be fully sorted out as to how various E2s specify the synthesis of different UB chains of defined linkages, which ultimately serve as the means of storing cellular signals in the context of the modified substrate. Various proteinengineering platforms have a great opportunity to tease out subtle differences among various E2s in programming UB chain synthesis. In addition to UB, most UBL proteins, such as SUMO and NEDD8, have their own E2s that mediate the transfer of UBLs to their substrates (Walden et al., 2003; Huang et al., 2004; Yunus and Lima, 2006).

3. E3: The Ubiquitin Ligase. E3 enzymes bridge UB transfer from E2 to substrate proteins. There are more than 600 E3s encoded in the human genome. These proteins are largely responsible for providing the exquisite substrate specificity that characterizes the UB system. As noted above, they can be classified into two major types based on whether they form catalytic thioester intermediates with the $\mathrm{C}$ terminus of $\mathrm{UB}$ (E3 UB) after transfer from E2 $\sim \mathrm{UB}$, or alternatively serve to allosterically activate $\mathrm{E} 2 \sim \mathrm{UB}$ for direct transfer to substrate. In humans, the former category includes the $\sim 28$ HECT E3s and 12 RBR E3s (Fig. 1, A and D) (Rotin and Kumar, 2009; Spratt et al., 2014). RING-type E3s include $>500$ RING E3s and $\sim 7$ structurally related U-box E3s (Hatakeyama and Nakayama, 2003; Deshaies and Joazeiro, 2009; Rotin and Kumar, 2009; Lipkowitz and Weissman, 2011; Spratt et al., 2014). They activate the direct transfer of UB from E2 to substrate proteins by orienting $\mathrm{UB}^{\mathrm{D}}$ bonded to $\mathrm{E} 2$ in a restricted closed conformation through interactions involving the RING or U-Box, E2, and UB and thereby facilitate nucleophilic attack from a Lys residue on substrate proteins or a substratebound UB chain (Fig. 1, E and H) (Dou et al., 2012, 2013; Pruneda et al., 2012; Metzger et al., 2014). The outcome of E3-catalyzed ubiquitination is most often the conjugation of UB to one or more Lys residues on the substrate protein and extension of existing UB chains. Besides domains engaging the UB $\sim$ E2 conjugates, E3s include diverse protein interaction domains that bind substrates. Although many E3s of all classes contain substrate-recognition domains on the same polypeptide as their canonical catalytic domains, many others rely on assembly of multisubunit complexes. The prime example of the latter is the Cullin RING ligase (CRL) superfamily. These E3s are characterized by interchangeable adaptor subunits that recruit distinct cellular targets (Deshaies and Joazeiro, 2009; Zheng and Shabek, 2017). As E3s carry out the final step in UB transfer to substrate, they regulate not only substrate specificity but also the timing and subcellular location of substrate modification. E3s are also subject to selfubiquitination (auto-ubiquitination), which can regulate their levels and function as well as be employed to assess ligase activity in vitro (Lorick et al., 1999;
Weissman et al., 2011). Importantly, E3s can also be targets of heterologous UB ligases; this serves as an important mechanism for regulating both E3 stability and function (Lorick et al., 1999; Weissman et al., 2011). Malfunction or dysregulation of E3s is a key factor in the development of many diseases (Nakayama and Nakayama, 2006; Frescas and Pagano, 2008; Hoeller and Dikic, 2009; Schwartz and Ciechanover, 2009; Lipkowitz and Weissman, 2011). A first step in understanding the regulatory roles of an E3 in cell biology and disease pathogenesis is to identify its substrates. E3s are major targets of drug discovery and represent a major area of protein engineering to map and rewire UB transfer in the cell.

4. Deubiquitinating Enzymes. Once UB is transferred to the substrate proteins, each of its seven Lys residues and the $\mathrm{N}$-terminal amine can be the site of the next round of UB conjugation. The outcome of the repeated conjugation could be a UB chain of linear linkage at Met1 of UB, a UB chain of a specific linkage at an exclusive Lys residue, a branched UB chain of mixed linkages, or even hybrid chains mixing with UBL proteins such as NEDD8 and SUMO (Behrends and Harper, 2011; Komander and Rape, 2012). UB chains are constantly edited or erased by DUBs, which account for more than 100 genes in the human genome (Fig. 1A). DUBs also have other critical functions, including generating the mature form of UB by cleaving newly translated UB precursors, which exist as either linear polyubiquitin fusions, or as the $\mathrm{N}$-terminal components of fusions with ribosomal subunits. Importantly, they also play a number of roles at the $26 \mathrm{~S}$ proteasome in, for example, the removal of UB from proteins as they are undergoing proteolysis (Komander et al., 2009; ReyesTurcu et al., 2009). The majority of DUBs are Cys proteases, including UB-specific proteases (USP), ovarian tumor proteases, UB C-terminal hydrolases, and the motif interacting with UB domain-containing novel DUB (MINDY). Others are Zn-dependent metalloproteases of the JAMM family (Nijman et al., 2005; Mevissen and Komander, 2017). DUBs have varying degrees of specificities in cleaving UB chains. For examples, JAMM DUBs are Lys63 specific, and motif interacting with UB domain-containing novel DUBs are Lys48 specific (Fig. 1F) (Sato et al., 2008; Abdul Rehman et al., 2016). DUBs have been the focus of drug discovery efforts due to their pivotal roles in editing the length and topology of UB chains on cellular proteins in response to alterations in cell physiology. They are also potentially attractive targets as, unlike RING-type E3s, they have defined catalytic centers (Daviet and Colland, 2008; Nicholson et al., 2014). Understanding the role of a DUB in cell biology demands a detailed understanding of its linkage specificity and the cellular substrates it recognizes. Protein engineering has provided UB probes with tailored functionalities to help reveal the 
molecular basis for recognition of ubiquitinated proteins by DUBs.

5. Ubiquitin-Binding Domains. The message encoded in UB chains attached to cellular proteins needs to be read to be translated into specific outcomes (Husnjak and Dikic, 2012; Sokratous et al., 2014). This is accomplished through binding to specific UBDs (Fig. 1A). Analogous to the diversity in UB chain topology, more than 20 families of UBDs have been identified; they are found throughout the cell in shuttle and adaptor molecules, within subunits of the 19S cap of the $26 \mathrm{~S}$ proteasome, and are embedded in E2s, E3s, and DUBs. Structures of UBDs vary widely and include, for example, UB-associated domains (UBA) and coupling of UB conjugation to ER degradation domains, which are triple-helical bundles; UB-interacting motifs (UIM), which have a single long $\alpha$-helix; and zinc finger domains. These readers of signals can recognize various structural features on UB such as the classic hydrophobic patch surrounding Ile44, the TEK box (Thr9-Glu10-Lys11), the loop region of Glu51-Lys63, or the C-terminal Gly of UB (Husnjak and Dikic, 2012). UBD proteins are natural affinity reagents for UBmodified proteins. UBDs recognize one or more UB moieties, and many demonstrate linkage specificity. For example, a single $\mathrm{PH}$ receptor for UB domain of the proteasome receptor Rpn13 is specific for Lys48-linked UB chains (Husnjak et al., 2008). This is similarly the case for the tandem UIMs of the proteasome subunit Rpn10 (S5a) (Fig. 1G) (Zhang et al., 2009). Taking advantage of characterized UBDs, tandem UB-binding entities (TUBEs) have been developed with up to five UBD repeats that can capture UB chains either nonselectively or with a high degree of linkage specificity (Scott et al., 2015; Mattern et al., 2019). TUBEs and other UB chain affinity reagents are powerful tools to follow the dynamics of protein ubiquitination in the cell and interpret the signals encoded in UB chains.

\section{B. Platforms of Protein Engineering}

1. Divergent Versus Directed Evolution. Protein engineering in the laboratory aligns well with divergent evolution in nature. Gene duplication is the first step of divergent evolution (Gilbert, 1978; Eigen, 1992). Through this process, an organism acquires more than one copy of a gene. By retaining a copy to carry out its original functions, there is the flexibility for other copies to diversify through mutagenesis or gene recombination. Natural selection favors the survival of the organism with a duplicated copy of the gene that provides a beneficial trait. Divergent evolution could allow the gene pool of an organism to expand when it confers adaptive advantages for the organism in the environment. Similarly, directed evolution starts with a gene that encodes a protein that is likely to acquire certain binding or catalytic properties by protein engineering (Arnold and Volkov, 1999). The target gene is diversified in the laboratory by error-prone polymerase chain reactions or saturated mutagenesis at key positions. A screen or selection procedure directs the gene pool under a selection pressure to enrich the gene with mutations that give rise to desired traits in binding or catalysis. The choice of the gene as the starting point and the design of screens or selection systems to apply evolutionary pressure is the key to the successful outcome of protein engineering by directed evolution.

2. Screen Versus Selection. Once a protein library is generated by expression from a diversified gene pool, it is assayed to reveal clones with desired features. In a screening experiment, each clone within the library is expressed by itself and is retained spatially separated from other clones (Zeymer and Hilvert, 2018). Each is then assayed to identify positive clones. For screening of individual clones to be efficient and cost-effective, migration from a low-throughput bench approach to medium- or high-throughput approaches employing, for example, 96- or 384-well formats and application of robotics is desirable and increasingly used. The availability of genetic systems based on yeast two-hybrid or luciferase reporter genes also makes it possible to screen libraries with $10^{5}-10^{6}$ distinct clones. An alternative approach is a selection experiment in which all clones are combined in one pot to compete for the catalytic turnover of a substrate or binding to a target. Clones showing desired catalytic or binding properties are retained on a solid support and affinity-purified, whereas negative clones are eliminated by washing. Because selection combines all the clones in a library, it can have significantly higher throughput than a screen, as $10^{7}-10^{9}$ clones can be assessed in one round of selection. It is relatively easy to design a selection scheme based on binding affinity. It is more challenging to design a selection experiment to enrich clones with desired catalytic activities. Typically, this is done by coupling catalysis with the labeling of the mutant enzymes with an affinity probe such as biotin (Yin et al., 2004; Zhang et al., 2013b). Proteins showing desired catalytic features can then be selected by binding. In this example, the biotin-conjugated proteins would bind to streptavidin. Another challenge for selection reactions is the deconvolution of the selection results. It is often technically challenging or even unfeasible to identify the mutations on the selected protein itself. A coupling of the phenotype (the protein with the desired catalytic or binding properties), with the genotype (the gene encoding the protein), would enable the identification of the selected protein mutants by sequencing the DNA encoding the mutant. Phage display and yeast cell surface display provide highthroughput selection platforms to enrich clones by catalysis or binding, and enable the deconvolution of selected library clones by DNA sequencing (Kay et al., 1996; Barbas et al., 2000; Chao et al., 2006). 
A

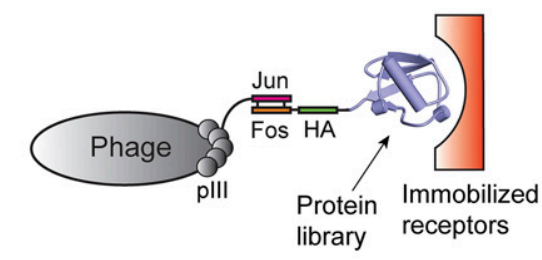

B

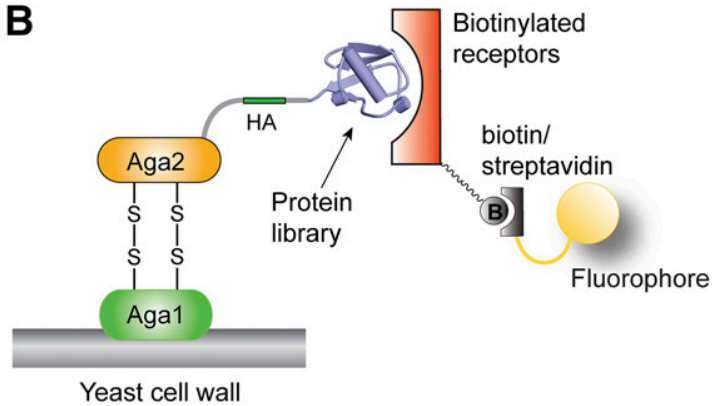

C Chitin-binding

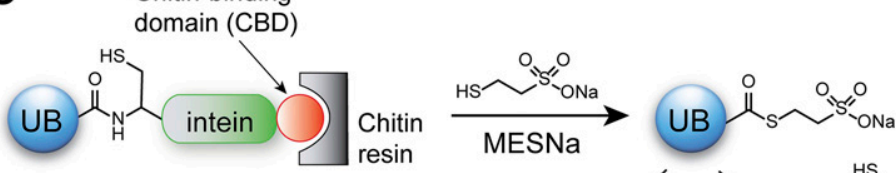

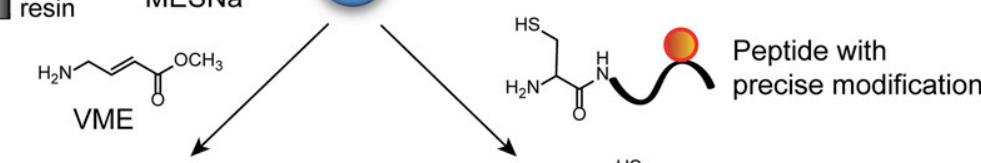<smiles>COC(=O)/C=C/CNC(=O)c1ccccc1</smiles><smiles>CCOCCNC(=O)C(CS)NC(=O)c1ccccc1</smiles>

UB-VME

D<smiles>CC1CC=NC1C(=O)NCCCCC(N)C(=O)O</smiles>

Pyrro-Lys<smiles>C#CCOC(=O)NCCCCC(N)C(=O)O</smiles>

Propargyl-Lys (PrK)<smiles>CC(C)(C)OC(=O)NCCCCC(N)C(=O)O</smiles><smiles>C=CCOC(=O)NCCCCC(N)C(=O)O</smiles>

Alloc-Lys (BocK)<smiles>NCC(S)CCC(N)C(=O)O</smiles>

$\delta$-Thiol-Lys<smiles>NC(CS)CCCCNC(=O)C(N)CS</smiles>

Cys-Lys (CysK)

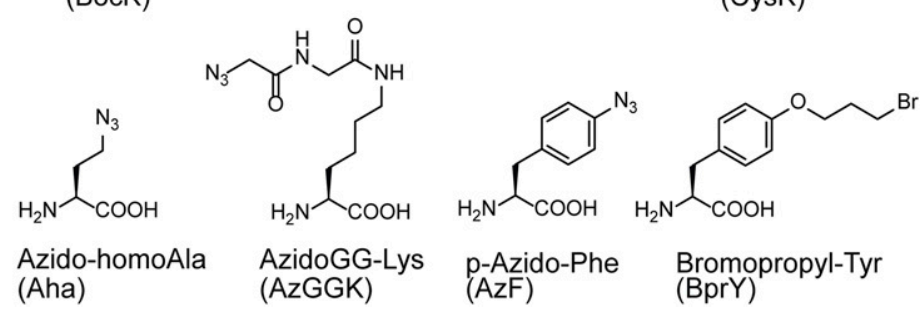

Fig. 2. Protein-engineering platforms for manipulating the activities of UB and its transferring cascade. (A) Phage display of a protein library and selection (biopanning) based on affinity binding with a receptor immobilized on a solid support. (B) Yeast cell surface display with a protein library expressed as a fusion with the yeast cell surface protein Aga2 and binding-based selection with a biotinylated receptor. Yeast cells with biotin labeling are labeled with a streptavidin-fluorophore conjugate and selected by fluorescence-activated cell sorting. (C) EPL for adding functional groups to the UB C terminus. UB is expressed as a fusion to the intein and chitin-binding domain (CBD). The fusion protein is purified by binding to chitin resin and cleaved from the resin with a thiol regent such as sodium $\beta$-mercaptoethane sulfonate (MESNa). The UB thioester is released from the chitin resin and reacts with an amine-functionalized probe to add electrophiles such as vinylmethylester (VME) to the UB C terminus. Or the UB thioester can ligate with a synthetic peptide to generate precise modifications at the $\mathrm{C}$ terminus. (D) UAA can be incorporated into UB to facilitate the synthesis of UB chains of defined linkages or add specific functionalities to the UB molecule. UAA shown are Lys or Tyr derivatives that can be loaded on Amber suppressor tRNA with engineered Pyrro-Lys or Tyr tRNA synthetases. In the genetically encoded orthogonal protection (GOPAL) and activated ligation method for diUB synthesis, Lys residues in UB are post-translationally protected in the form of either Boc-Lys or Alloc-Lys.

3. Phage and Yeast Cell Surface Display. George Smith first demonstrated the expression of peptides or proteins as a fusion to the pIII protein on the filamentous phage (Parmley and Smith, 1988; Smith and Petrenko, 1997). Later a display system using $\mathrm{pCom} 3 \mathrm{H}$ phagemid gained popularity as it allowed the monovalent display of protein library fused to pIII on the surface of M13 phage (Barbas et al., 1991). For affinity-based selection, the phage library can be biopanned against a target immobilized on solid support (Fig. 2A). Catalysis-based selection often takes advantage of a mechanism-based inhibitor that can form a covalent adduct with the enzyme upon its turnover at the enzyme active site and that is also conjugated to an affinity probe such as biotin. Mutant enzymes with higher catalytic activities would have a faster turnover of the inhibitor and would therefore be more readily covalently conjugated to the biotin-linked inhibitor. The corresponding phage particles could then be 
preferentially selected by binding to streptavidin (Yin et al., 2004). For either approach, once the phage particles are selected, they can be amplified for subsequent rounds of selection or for sequencing to reveal the amino acid sequence of the selected clones. Yeast cell surface display is another platform that enables the coupling of phenotype and genotype for high-throughput selection (Colby et al., 2004; Chao et al., 2006). Protein libraries are, for example, expressed as fusions with the yeast cell surface protein Aga2p. Selection is based on the binding of the yeastdisplayed library to a fluorescently-labeled probe followed by selecting yeast cells displaying high-affinity binders by fluorescence-activated cell sorting (Fig. 2B) (Zhang et al., 2013a,b). Catalysis-based selection may be achieved by reacting the protein library with affinity probes in the presence of enzymes to couple enzyme catalysis with labeling of proteins by affinity probes on the yeast cell surface.

4. Protein Semisynthesis by Expressed Protein Ligation. It has been a challenge to generate precise PTM patterns on a cellular protein to elucidate the effect of a specific modification on the cellular function of the protein. Expressed protein ligation (EPL) fills this gap as it allows for the appending of synthetic peptides with defined modifications to truncated proteins expressed from bacterial cells. EPL can generate proteins with precise PTMs, and, most importantly for this review, it allows modification of the $\mathrm{C}$ termini of proteins with amine functionalities to install reactive warheads (Fig. 2C) (Flavell and Muir, 2009). To do this, the protein fragment for the EPL reaction is expressed as a fusion with the intein protein and the chitinbinding domain so the fusion can be purified by binding to the chitin column. Rearrangement of the intein generates a thioester intermediate between the $\mathrm{C}$ terminus of the expressed protein fragment and the $\mathrm{N}$-terminal Cys of the intein. A thioester exchange reaction between the protein-intein thioester and a small-molecule thiol compound such as sodium 2-mercaptoethanesulfonate (MESNa) generates a reactive protein thioester. Synthetic peptides with an N-terminal Cys and a defined PTM pattern can then be ligated with the protein thioester to generate full-length proteins with the desired C termini. Alternatively, the protein thioester can be conjugated to small-molecule probes with an amine functionality to install reactive warheads at the C terminus (Fig. 2C).

5. Site-Specific Incorporation of Unnatural Amino Acids. The development of UAA incorporation with engineered tRNA synthetase has enabled a broad scope of functionalities to be introduced in any position in a protein (Fig. 2D) (Wang and Schultz, 2004). The engineered tRNA synthetase would load an UAA to an Amber suppressor tRNA that would carry the UAA to the ribosome and insert the UAA at the site specified by the Amber stop codon (UAG) in the expressed transcript. The UAA incorporation method circumvents tedious synthesis of peptides for the incorporation of unnatural functionalities into the target protein by EPL. It also offers the freedom of incorporating an UAA at any position of the target protein, not restricted to the $\mathrm{C}$ terminus as in the EPL reaction. A variety of UAAs bearing PTM functionalities has been incorporated, such as phospho-Ser, Thr, and Tyr (Park et al., 2011; Lee et al., 2013; George et al., 2016; Hoppmann et al., 2017; Luo et al., 2017; Zhang et al., 2017a); acetylated Lys (Neumann et al., 2008); and methylated Lys (Nguyen et al., 2009, 2010; Ai et al., 2010; Groff et al., 2010; Wang et al., 2017b). Furthermore, a Lys analog with a $\delta$-thiol entity is also available for incorporation as an UAA, opening the possibility of synthesizing UB chains of various linkages with the combined use of UAA incorporation and EPL (Fig. 2D) (Virdee et al., 2011).

\section{Probing the Mechanism of Ubiquitin Transfer by Protein Engineering}

A relay of enzymatic transfers of the carboxy terminus of UB involving a cascade of E1, E2, and E3 delivers UB to cellular targets. Protein engineering has been used to capture crucial intermediates in this cascade to reveal, in some cases, dramatic conformational changes in component enzymes that would not be evident from assessment of static structures. The activity of ubiquitinating enzymes, particularly E3 activity toward substrates, is tightly regulated and coupled to dynamic changes of cell physiology. This is also found with DUBs, as exemplified by the regulated expression and phosphorylation of A20, and the phosphorylation of VCIP135 (Dixit et al., 1990; Zhang et al., 2014; Wertz et al., 2015). To probe the activity of both specific UB transfer enzymes and DUBs, protein-engineering tools have been developed to generate UB or UB conjugates equipped with reactive functionalities. These are being employed as activity-based probes to report the writing, editing, and reading of UB chains. As cellular signals are encoded in the diverse linkages of UB chains, fragments of UB chains or UB-substrate conjugates of defined linkages are being made available by protein engineering based on EPL and UAA incorporation. These represent critical tools to interpret the signals encoded in UB chains.

\section{A. Designer Ubiquitin Conjugates To Probe the Catalytic Mechanism of Ubiquitin Transfer Cascade}

1. Ubiquitin-E1 and E1-E2 Conjugates To Capture the Conformational Change of E1. The crystal structure of the yeast E1 Uba1 in complex with UB shows UB binding to the adenylation domain of the enzyme with the C-terminal carboxylate of UB approaching ATP to form UB-AMP conjugate (Lee and Schindelin, 2008). It also reveals a large distance between the catalytic Cys residue in the thiolation domain E1 with UB-AMP. 
To enable UB transfer, a conformational change of the thiolation domain is expected to close the gap between the catalytic Cys of E1 and the C-terminal carboxylate of UB engaged in the UB-AMP conjugate bound to the adenylation domain of E1. Furthermore, after the formation of $\mathrm{UB} \sim \mathrm{E} 1$ thioester conjugate, the $\mathrm{E} 2$ enzyme bound to the UFD domain of E1 needs to position its catalytic Cys residue in the vicinity of $\mathrm{UB} \sim \mathrm{E} 1$ thioester bond to enable the transthioesterification reaction. This would require another conformational change of the E1-E2 complex. To capture the conformation of $\mathrm{E} 1$ at the moment of thioester formation with UB, EPL was used to conjugate the adenosine nucleoside to the UB C-terminal carboxylate through a vinyl sulfonamide linkage (UB-AVSN) (Fig. 3A) (Lu et al., 2010; Hann et al., 2019). The sulfonamide group is an isostere of the phosphate group in the native UBAMP conjugate that enables the neighboring vinyl group to function as an electrophile to react with the catalytic Cys residue of $\mathrm{E} 1$ when the thiolation domain of $\mathrm{E} 1$ is approaching UB-AMP. The crystal structure of UB-AVSN bound to yeast Uba1 was solved, revealing the conformation of the $\mathrm{E} 1$ enzyme during the handover of UB from the adenylation domain of $\mathrm{E} 1$ to its thiolation domain to form the E1 UB thioester (Hann et al., 2019) (Fig. 1B). The SUMO-AVSN conjugate was also synthesized and coupled with the SUMO E1. The analogous crystal structure of the conjugate similarly captured the conformation of the catalytic Cys residue of E1 approaching SUMO-AMP for thioester bond formation (Olsen et al., 2010). In another study, the catalytic Cys residues of an E1-E2 pair (Uba1-Ubc4) was conjugated through a disulfide linkage to stabilize the complex and force E1 to adopt a conformation simulating its conformation at the moment of UB transfer from E1 to E2 (Olsen and Lima, 2013). The crystal structure of the E1-E2 conjugate reveals that the $\mathrm{E} 2$ bends toward the thiolation domain of $\mathrm{E} 1$ to enable the catalytic Cys residue of $\mathrm{E} 2$ to approach the $\mathrm{UB} \sim \mathrm{E} 1$ thioester (Fig. 1C). The engineering of UB-E1 and E1-E2 conjugates has enabled the capture of key moments of UB transfer through the E1 enzyme. It also provides a molecular explanation for the known requirement for dissociation of E2 from canonical binding sites on E3s to be loaded with UB by E1 (Eletr et al., 2005).

2. Ubiquitin-E2 Conjugates To Elucidate the Conformation of Ubiquitin Passing through E2. To stabilize the E2 UB conjugates for structural studies by NMR or $\mathrm{X}$-ray crystallography, researchers have mutated the catalytic Cys residues of E2s to Ser or Lys, which can function in nucleophilic attack on the E1 UB thioester, but would form stable oxyester or amide conjugates with UB, respectively (Eddins et al., 2006; Pruneda et al., 2011; Middleton et al., 2014). Alternatively, Gly76 of UB can be mutated to Cys to allow for nonenzymatic formation of a disulfide linkage with the E2 enzyme and also stabilize the conjugate (Serniwka and Shaw, 2009).
Structural and biophysical studies of these engineered E2-UB conjugates reveal that UB has an unrestrained open conformation that adopts a restricted closed conformation with respect to the E2 enzyme when the E2-UB is docked to RING-type E3s for direct UB transfer to the substrate (Pruneda et al., 2012; Metzger et al., 2014) (Fig. 1, E and H). In contrast, when E2-UB conjugates are bound to HECT or RBR E3s, an open conformation of UB is observed (Kamadurai et al., 2009; Lechtenberg et al., 2016), suggesting UB transfer to a Cys residue of a HECT or RBR or to a Lys residue of a substrate would rely on different positioning and/or reactivities of the $\mathrm{E} 2 \sim \mathrm{UB}$ conjugate, which results from distinctive positioning of UB in relation to E2s.

3. Ubiquitin-E3 Conjugates To Elucidate the Conformation of Ubiquitin Passing from E3 to Substrates. To structurally characterize the activated form of the HECT domain, UB has been linked to the catalytic Cys residue of the mammalian HECT E3 NEDD4 through a disulfide bond to generate a relatively stable mimic of a HECT UB thioester (Maspero et al., 2013). To capture the catalytically-active conformation of the related yeast HECT E3 Rsp5 at the moment of UB transfer to its substrate Sna3, the C-terminal Gly of UB was mutated to Cys and linked to the catalytic Cys of Rsp5 HECT domain through a three-way cross-linker functionalized with two maleimide groups and one alkyne group (Fig. 3B) (Kamadurai et al., 2013). To accomplish this, a peptide corresponding to the C-terminal portion of substrate protein Sna3 was synthesized with the Lys residue at the ubiquitination site replaced by an azidefunctionalized sidechain. A click reaction between alkyne and azide (Kolb et al., 2001) generated a three-way complex mimicking the moment of UB handover from the catalytic Cys residue of HECT to the acceptor Lys of Sna3. Although the structure of the HECT-UBsubstrate complex did not show the structure of the cross-linker at the core of the complex due to missing electronic densities, it reveals the potential for reorientation of the C-lobe of the HECT domain to facilitate UB transfer to the substrates (Fig. 1D).

\section{B. Activity-Based Probes for Ubiquitin-Transferring Enzymes and Deubiquitinating Enzymes in the Cell}

1. Ubiquitin with C-Terminal Electrophiles as Probes of Deubiquitinating Enzyme. The C terminus of UB can be conveniently derivatized by EPL with new functionalities such as electrophiles acting as DUB traps (Hemelaar et al., 2004; Love et al., 2009). Several examples are described below, all of which involve generation of an activated C-terminal carboxylate by EPL with intein (Flavell and Muir, 2009). To prime for EPL, UB is expressed with a C-terminal intein tag fused with a chitin-binding domain. The fusion is purified by affinity chromatography with chitin agarose. Intein-mediated self-cleavage is then triggered by the addition of a thiol reagent such as 
A

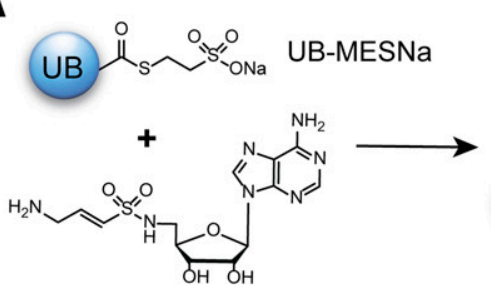

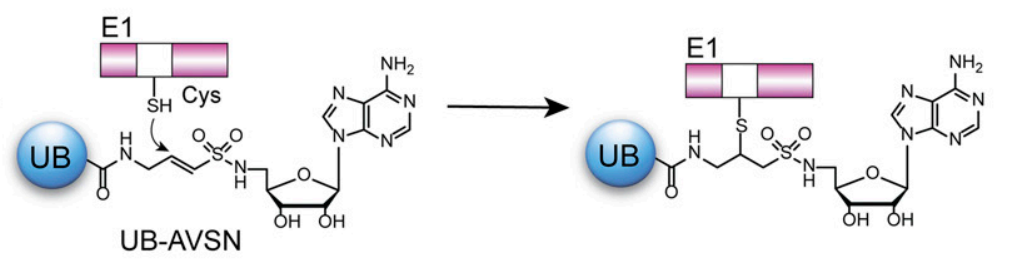

B

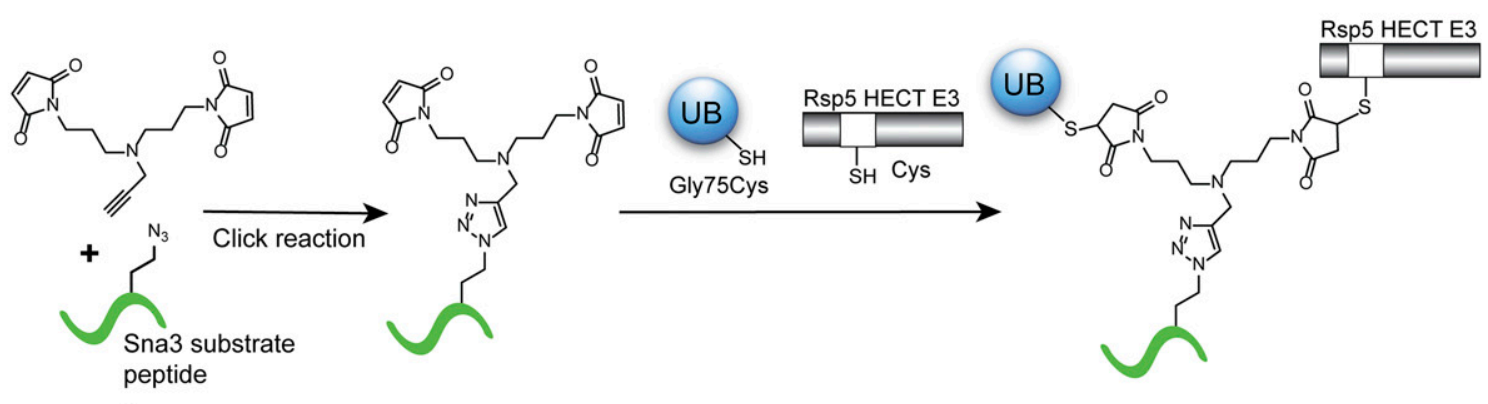

C

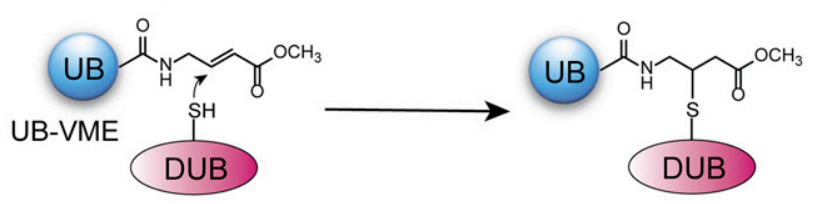

D

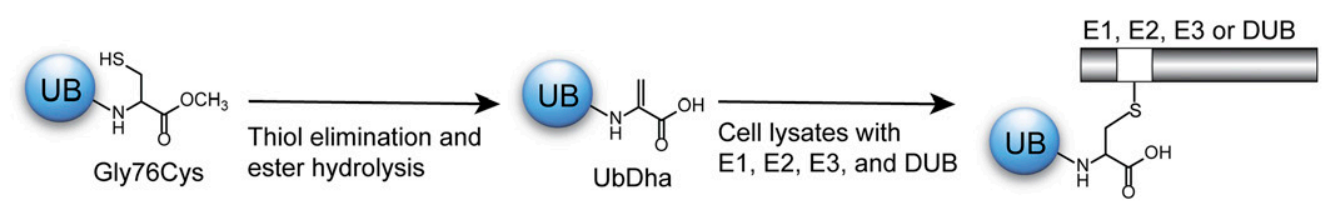

E

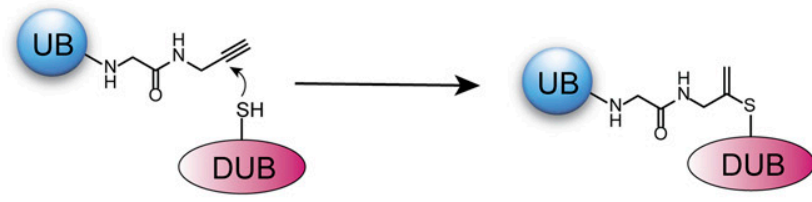

$\mathbf{F}$

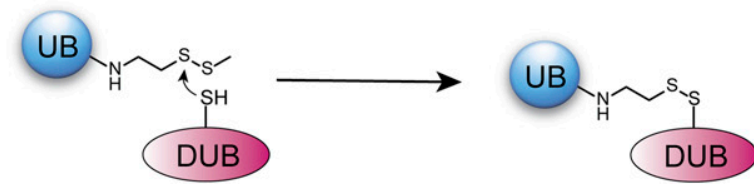

G

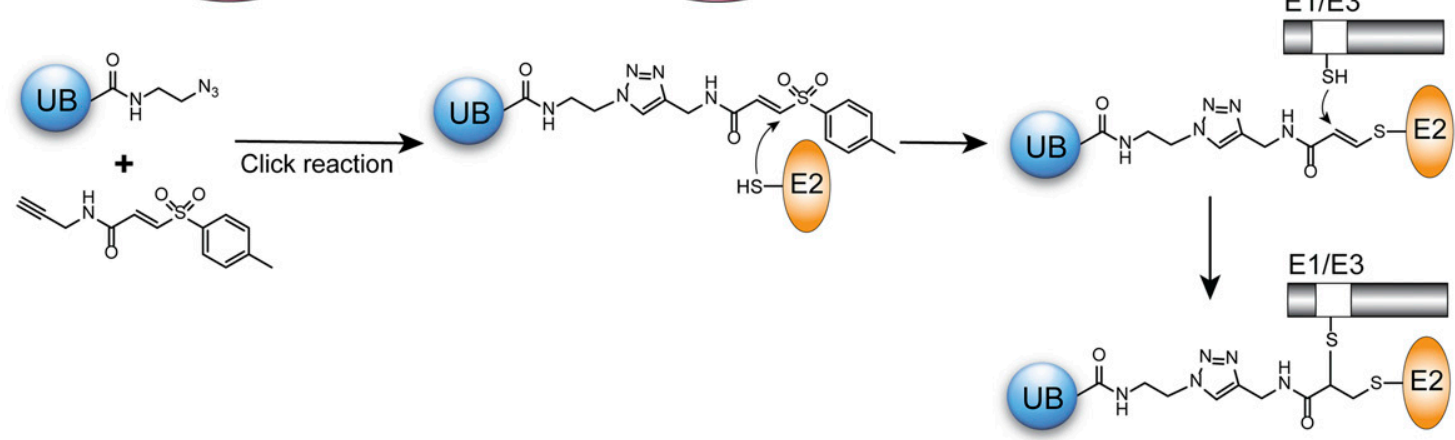

Fig. 3. Enzyme-UB conjugates as probes to study the structure and function of UB transfer cascades and DUB. (A) UB-AVSN conjugate for reacting with the catalytic Cys residue of the E1 enzyme to capture the conformational change in E1 during E1 UB thioester formation. (B) Three-way conjugate of UB, Rsp5 HECT, and Sna3 substrate peptide synthesized by click chemistry and thiol-maleimide coupling. (C) UB-vinylmethylester probe for reacting with the catalytic Cys residues of DUBs. (D) UB with a C-terminal Dha residue that can be conjugated to the catalytic Cys residues of E1, E2, E3, and DUB enzymes. (E) UB with a C-terminal alkyne for conjugation with the catalytic Cys residue of DUB. (F) UB with a C-terminal disulfide for disulfide exchange with the catalytic Cys residue of DUB. (G) E2-UB conjugates containing a vinylsulfide linker, which is reactive with catalytic Cys residues of E1 and E3 enzymes. 
MESNa, leading to elution of UB as a UB MESNa thioester (Fig. 2B, C). The activated C-terminal carboxylate of UB can then form an amide linkage with one of several described electrophilic functionalities for thiol addition to serve as warheads to conjugate UB to the catalytic Cys residues of DUBs (Fig. 3C). C-terminal UB-vinylmethylester has been used as an activity-based probe to identify DUBs that are upregulated in tumor cells and in virally-infected cells (Borodovsky et al., 2001; Ovaa et al., 2004). UB probes having dehydroAla (Dha) as the electrophile have been reported to have the potential to covalently capture catalytic Cys residues of DUBs, but can also migrate through the E1-E2-E3 cascade and be covalently linked to the catalytic Cys residues at each step of UB transfer (Mulder et al., 2016). This functionality is installed at the $\mathrm{C}$ terminus of UB by eliminating the thiol from the Gly76Cys mutant of UB (Fig. 3D) (Chalker et al., 2012). A nonconventional electrophile such as a terminal alkyne can also be appended to the $\mathrm{UB} \mathrm{C}$ terminus to react with the catalytic Cys residue of DUBs (Fig. 3E) (Ekkebus et al., 2013). Using a similar approach, the $\mathrm{C}$ terminus of the SUMO protein has been functionalized with an alkyne probe to covalently capture SUMO-specific proteases (Sommer et al., 2013). A disulfide was also used to functionalize the UB C terminus so it could react with the catalytic Cys residues of DUBs by disulfide exchange (de Jong et al., 2017) (Fig. 3F). UB with $\mathrm{C}$-terminal electrophiles generated by protein engineering provide versatile activities to probe DUB and UB transferring enzymes in the cell lysates. Besides installing Cys traps on UB, a thioester-linked fluorophore has been added to the UB C-terminal carboxylate (Park et al., 2017). This probe, known as UbFluor, can directly load UB onto the catalytic Cys residues of HECT or RBR E3s accompanied by the release of the fluorophore to report the activity of the E3 enzymes. Although these reagents have great potential for use in cell-free systems, the in vitro intein ligation and functionalization make their use in cells problematic.

2. Ubiquitin-E2 Conjugates as Probes of E1 and E3 Enzymes. To generate probes targeting specific stages of UB transfer, E2-UB conjugates were designed with an embedded vinylsulfide functionality to trap Cys nucleophiles of E1 or E3 (Pao et al., 2016). The synthesis of the UB-E2 conjugate began with UB derivatized with a C-terminal azide generated by EPL. Click reaction between the UB-azide and alkyne-functionalized acrylate with a tosyl substitution installs the linker on the UB C terminus with an electron-deficient alkyne moiety. The tosyl group in the linker is then replaced with the catalytic Cys of $\mathrm{E} 2$ through an addition-elimination mechanism to generate the UB-E2 probe (Fig. 3G). The probe generated can react with the catalytic Cys residues of E1 and E3 enzymes (Stanley et al., 2015). The UbcH7 (UBE2L3) version of the probe could be conjugated to Parkin, a RBR E3, and was used to detect Parkin activities in cell lysates of neuronal cells or fibroblasts from Parkinson's disease patients (Pao et al., 2016). Besides identifying known HECT and RBR E3s that formed covalent conjugates with the probe, MYCBP2 was strongly labeled by the probe. This protein is an E3 with an annotated RING domain. However, unlike conventional RING E3s that directly mediate UB transfer to substrates or RBR E3s, evidence suggests MYCBP2 transfers UB through a double Cys relay, leading to UB conjugation to the hydroxyl groups on substrates with a preference for transfer to Thr (Pao et al., 2018). Thus, the E3 was named a RING-Cys-relay E3, and it is the first E3 shown to have a preference for Thr ubiquitination. Similar design of E2-UB conjugates with an acrylamide linker as a Cys trap has been used to probe HECT E3 activity in cell lysates (Byrne et al., 2017). E2-UB probes demonstrate the power of protein engineering to generate customized tools to discover new cellular protein ubiquitination activities.

3. diUB Probes with Cys Traps To Target Deubiquitinating Enzyme and E3s. To probe the linkage specificity of DUBs, diUB conjugates with Lys-specific isopeptide linkages between the C-terminal carboxylate of one UB (distal UB or donor UB, $\mathrm{UB}^{\mathrm{D}}$ ) and the Lys sidechain of other UB (proximal UB or acceptor UB, $\mathrm{UB}^{\mathrm{A}}$ ) have been synthesized with built-in thiol-reactive linkers to trap Cys residues on DUBs (Ekkebus et al., 2014; Hewings et al., 2017). Linkage-specific diUB was prepared by total peptide synthesis with a Gly76Cys mutation at the isopeptide linkage of the diUB. The thiol elimination reaction generated a Dha functionality at the linkage that could trap the catalytic Cys residues of DUBs (Fig. 4A) (Kumar et al., 2010; Haj-Yahya et al., 2014). Following a similar strategy, linear diUB with Dha at the linkage was generated by total peptide synthesis with Gly76Cys mutation at the Met1 linkage. Thiol elimination at the Cys residue generated the linear diUB probe with the Dha functionality. The probe was shown to capture OTULIN, a DUB specific for linear UB chains (Weber et al., 2017). diUB probes were also generated by incorporating azido-homoAla (Aha) in place of a Lys in the proximal UB to enable the linkage of the distal UB through click reaction (Fig. 2D). In such a design, Aha was used to replace a specific Lys residue on the proximal UB through site-specific UAA incorporation. Correspondingly, the $\mathrm{C}$ terminus of the distal UB was functionalized with an acrylamide-alkyne linker by EPL. Click reaction between the two parts generated a linkage-specific diUB as a DUB trap, although it is not obvious if the triazole ring at the linkage would affect DUB recognition of the diUB probe (Fig. 4B) (McGouran et al., 2013). Other linkers that have been generated include an acrylamide trap that more closely mimics the native isopeptide linkage of a diUB (Li et al., 2014; Mulder et al., 2014). Linkage-specific tri-ubiquitin probes can be assembled by coupling a distal UB functionalized with 
a C-terminal $\alpha, \beta$-unsaturated ketone linker with a Cys residue replacing a specific Lys on the diUB (Fig. 4C). The tri-ubiquitin probe has been used to investigate the recognition of UB chains by the DUB USP9X (Li et al., 2014; Paudel et al., 2019). Similar to the synthesis of diUB probes, UB-substrate conjugates were prepared with a Dha group at the isopeptide linkage to trap DUBs that are specific for cleaving UB from the substrate proteins (Whedon et al., 2016; Meledin et al., 2018). Through the Dha functionality, a photocross-linking group has also been installed at the junction of the two UB molecules to trap DUB by photoactivation (Tan et al., 2017).

\section{Linkage-Specific Ubiquitin Chains Enabled by} Solid-Phase Peptide Synthesis and Unnatural Amino Acid Incorporation

\section{Total Peptide Synthesis of Ubiquitin Chains.} UB chains of defined linkages are critical tools for assaying and differentiating the chain specificities of DUBs and UBDs. Peptides with a partial sequence of the proximal UB including its ubiquitination sites were prepared by peptide synthesis, and their conjugates with the distal UB at a specific Lys were used to mimic diUB conjugates and assay DUB activities (Faesen et al., 2011; Weller et al., 2014). Total synthesis of diUB of defined linkages was achieved by a series of ligation reactions of peptide fragments to generate diUBs with native isopeptide linkages (El Oualid et al., 2010; Kumar et al., 2010). Tetra UB chains having K48 isopeptide linkages have also been assembled by total peptide synthesis (Kumar et al., 2011). This synthesis sets the stage for synthesis of tetra UB chains having other native linkages (Spasser and Brik, 2012). DiUB probes have also been prepared with fluorophores of a Förster resonance energy transfer (FRET) pair specifically labeling the two ends of a diUB conjugate to screen chain specificities of DUB enzymes (Geurink et al., 2016). diUB from total synthesis were further derivatized at the isopeptide linkages with amide alkylation, $\alpha$-carbon modification, and linker modifications to probe the conformation of diUB recognized by UBDs (Haj-Yahya et al., 2013).

A

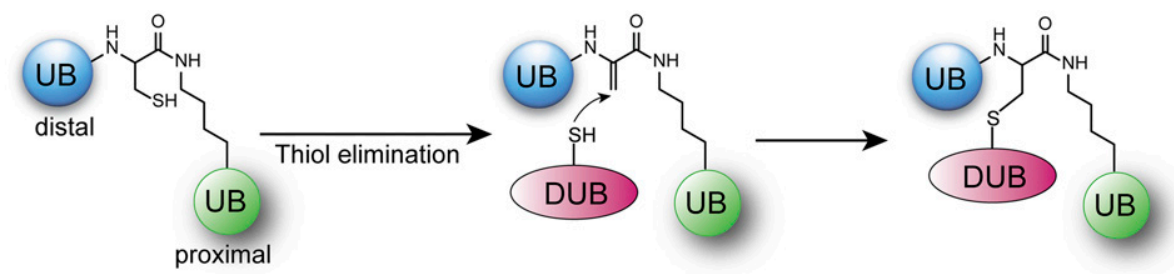

B
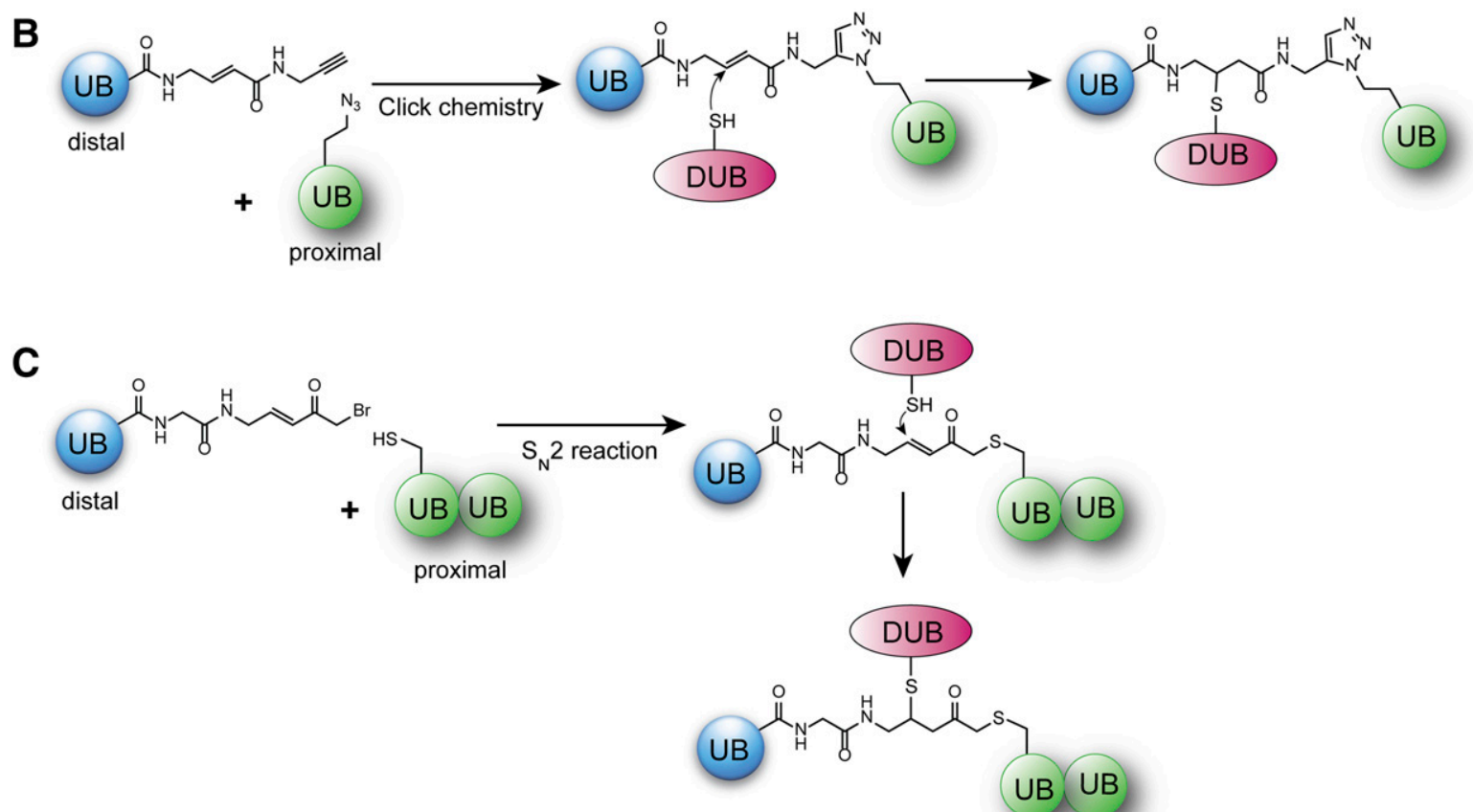

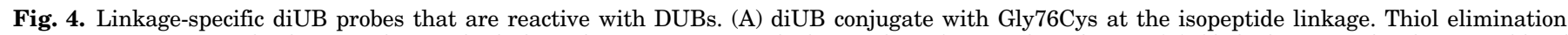

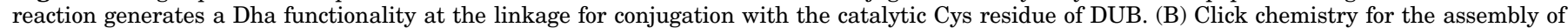

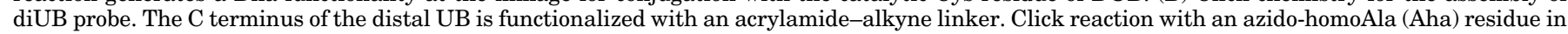

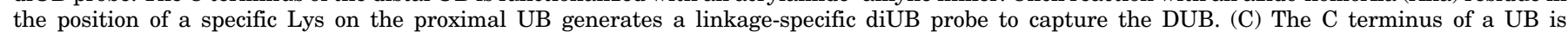

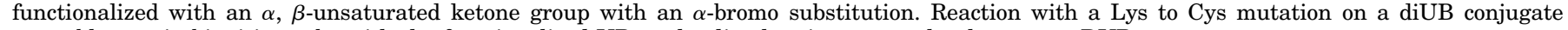
assembles a tri ubiquitin probe with the functionalized UB as the distal moiety to covalently capture DUB. 
2. Ubiquitin Chain Synthesis Enabled by Unnatural Amino Acid Incorporation. Total peptide synthesis can elegantly generate UB chains with defined Lys linkages. There are downsides, however, that include the equipment and expertise necessary for these syntheses and the limited quantity of products. E2s with strict linkage specificities have been shown to have the capacity to generate specific UB linkages in an E3independent manner. This has been established for K48 and K63 linkages using E2-25K or Ubc13-Mms2, respectively (Piotrowski et al., 1997; Hofmann and Pickart, 2001), and more recently for K11 linkages using Ube2S (Castañeda et al., 2013). These enzymes represent powerful tools for generating defined diUB conjugates. To produce a homogenous K48 or K63 diUB chain, the proximal UB is blocked at the $\mathrm{C}$ terminus with an Asn77 extension, which can later be cleaved off by a DUB after diUB synthesis is complete. On the distal UB, the Lys residue recognized by E2 for further chain elongation is blocked by mutation to a Cys or Arg. These variations force E2-catalyzed coupling to occur only once between the designated proximal and distal UB molecules (Fig. 5A). For K11 diUB chains, Ube2S has been fused to a zinc finger UBD to enhance recruitment of the UB monomer and accelerate K11 chain formation (Bremm and Komander, 2012). Although UB mutants with various combination of Lys to Arg mutations may force the assembly of specific linkages by E2s and E3s, the use of linkage-specific E2s enables the synthesis of native K11, K48, and K63 diUB linkages with nonparticipating Lys residues left intact (Castañeda et al., 2016). For other diUB linkages (i.e., K6, K27, K29, and K33), the incorporation of UAAs at positions corresponding to the site of linkage formation provides a generally applicable route to generate UB chains of various linkages. Recently, a chemosynthetic method known as genetically encoded orthogonal protection and activated ligation (GOPAL) has been developed and shown to be useful for diUB synthesis (Fig. 5B) (Virdee et al., 2010; Castañeda et al., 2011). GOPAL takes advantage of the pyrro-Lys tRNA synthetase (Pyl-RS) that incorporates a Lys analog with a Boc-protected $\varepsilon$-amino group (BocK) (Fig. 2D). After BocK incorporation in the place of a specific Lys in what will become the acceptor UB, the remaining amino functionalities (the N-terminal amine and six Lys residues) are globally protected with $\mathrm{Cbz}$ or Alloc groups (Fig. 2D). Acid treatment selectively removes the Boc group to unmask the reactivity of the designated Lys. The deprotected Lys is then used to couple with the intein-derived thioester of the distal UB that is also globally protected on the amines. After coupling, the protecting groups are removed to afford diUB of a native linkage. Such an approach generates native isopeptide linkages between the two recombinant UBs produced in Esherichia coli. Other strategies for UB chain synthesis have been developed to incorporate derivatized Lys as a UAA that would facilitate EPL at the site of UB conjugation. For example, a pyrro-Lys tRNA synthetase was engineered that could incorporate $\delta$-thiol-Lys into proteins (Fig. 2D) (Virdee et al., 2011). The $\delta$-thiol group attached to a Lys sidechain in what will become the proximal UB undergoes transesterification with the UB thioester, and subsequent S-N acyl transfer would form the precursor for the isopeptide linkage for UB chain synthesis. To complete the synthesis, after ligation, the $\delta$-thiol group is desulfurized to leave a native isopeptide bond between the two UB. UB chain synthesis enabled by UAA incorporation is an extremely valuable approach to generating linkage-defined diUB for decoding chain-encoded UB signals. As an example, diUB probes assembled by UAA-assisted semisynthesis, as well as by total peptide synthesis, have been functionalized by photocross-linking groups to identify UBD proteins as readers of the UB linkage (Liang et al., 2017; Braxton et al., 2019).

3. Engineered Ubiquitin Chains of Non-native Linkages. UB chains of native linkages are ideal choices of reagents when studying the specificity of DUBs for various chain types. However, depending on the purpose of the study, UB chains of non-native linkages are a close mimic of native chains that can be employed to reveal chain topology and identify reader proteins of UB chains. Often UB chains of non-native linkages are relatively easy to assemble, and there is a wider choice of coupling chemistry available. Linkagespecific E2s provide a facile way to assemble tetra UB chains or even longer conjugates with a periodic thioether linkage (Varadan et al., 2002; Pickart and Raasi, 2005; Raasi and Pickart, 2005). In such a method, E2 is initially used for diUB formation with the Lys residue for further chain extension on the distal UB mutated to Cys (Fig. 5A). The diUB product is divided into two portions with one portion reacting with ethyleneimine to transform the Cys residue on the distal UB to a Lys analog with a thioether functionality. The other portion is treated with a DUB Yuh1 to cleave Asn77 and expose the C-terminal Gly for conjugation. The two parts are combined for E2-catalyzed UB chain assembly to generate tetra UB chains with a thioether linkage. Such a process can be repeated to generate higher order of UB chains. With the linkage-specific E2s E2-25K and Ubc13-Mms2, tetra UB chains of K48 and K63 linkages have been made (Piotrowski et al., 1997; Hofmann and Pickart, 2001). These chains have been used to obtain insights into chain structure and function, including the initial determination that K48-linked tetra UB chains are specifically recognized by the proteasome, and to study interactions with UBDs (Thrower et al., 2000; Raasi and Pickart, 2005; Varadan et al., 2005; Eddins et al., 2007). Nonenzymatic reactions such as thiol-ene coupling have also been used to assemble diUB and UB chains (Fig. 5C). To enable the coupling reaction, the $\mathrm{C}$ terminus of the distal UB is functionalized with an allyl 
A

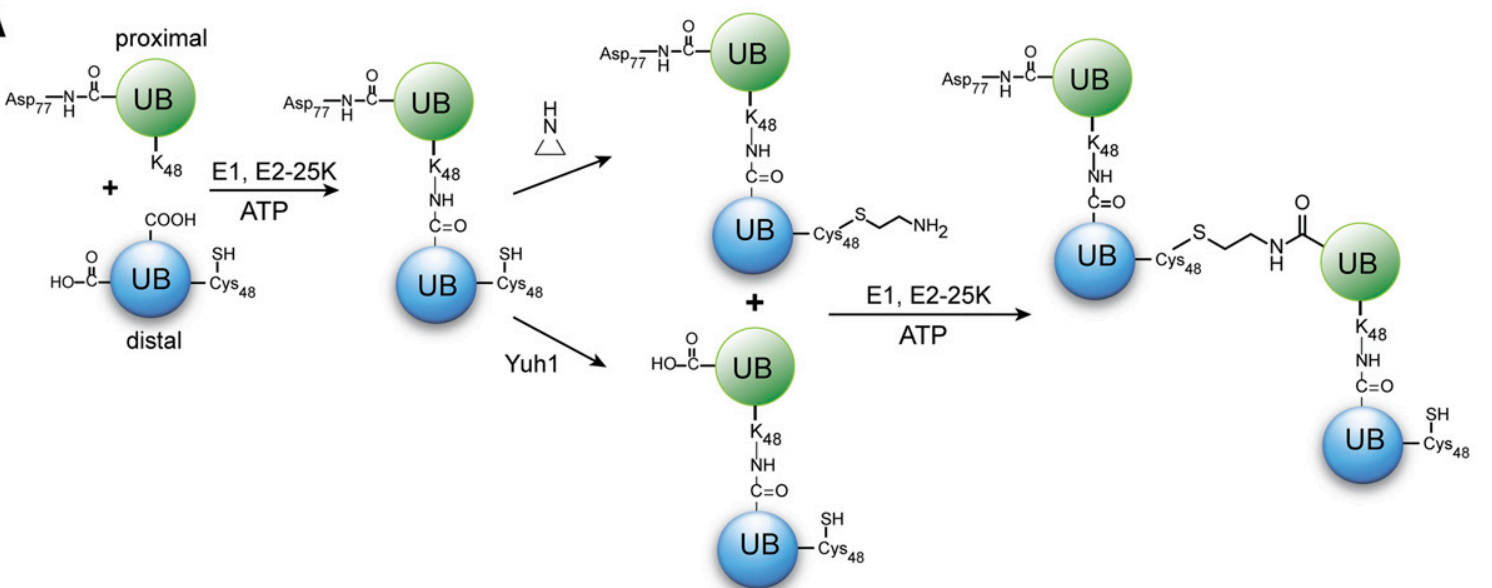

B

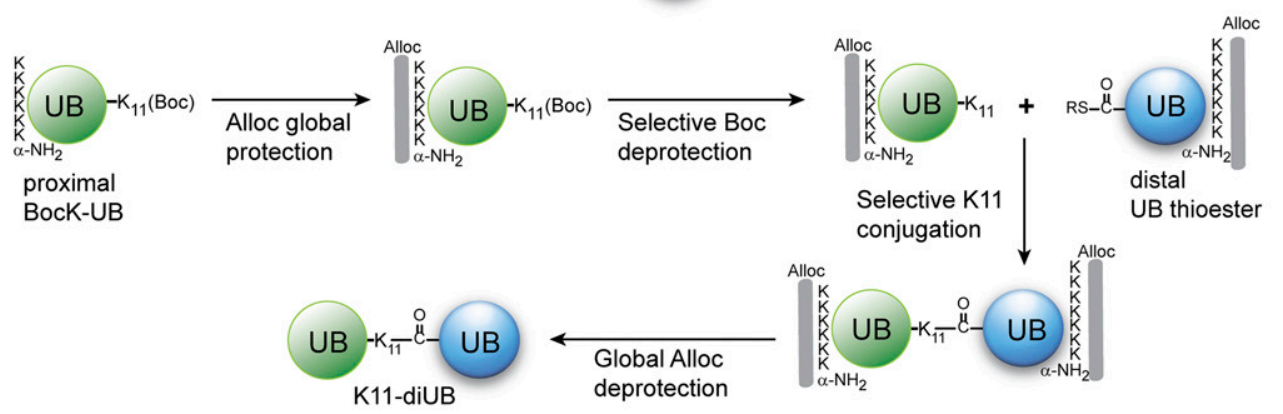

C
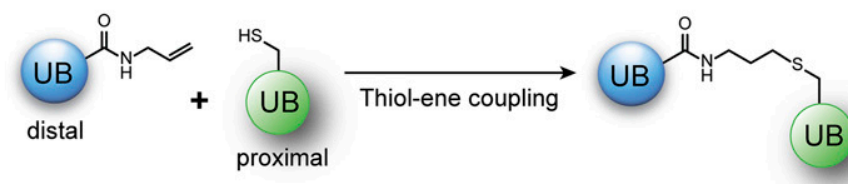

D

E

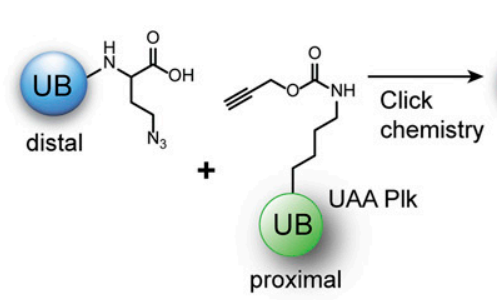

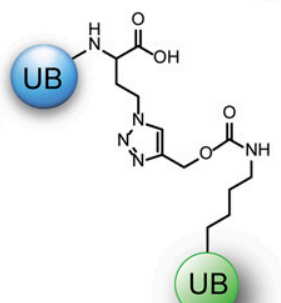
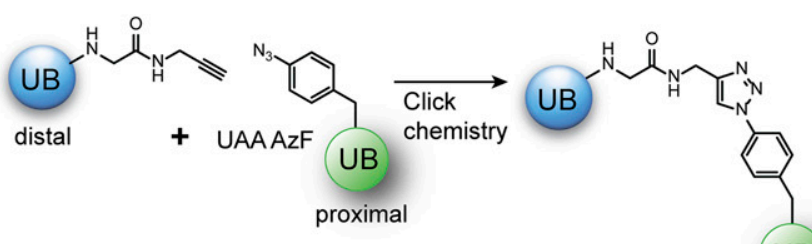

UB

F

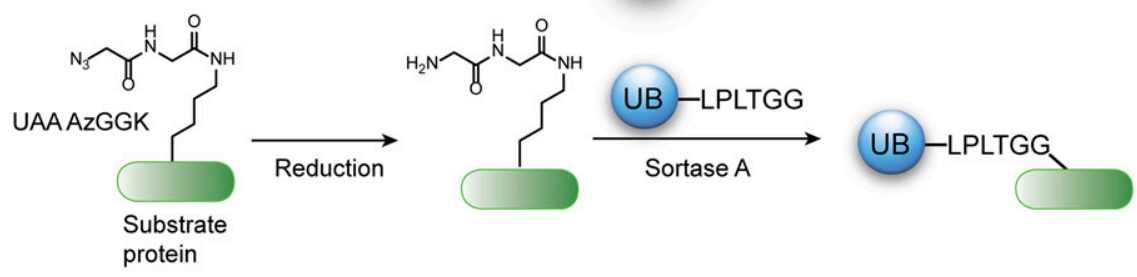

G
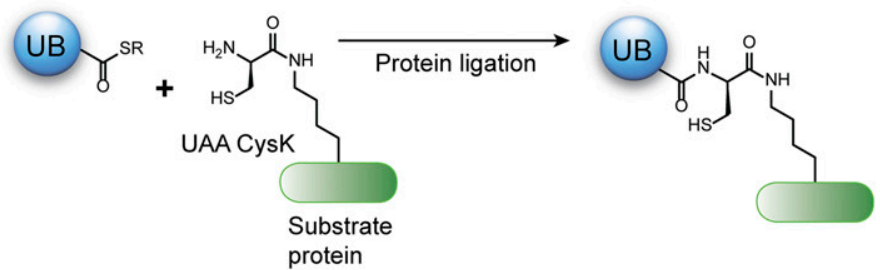

Fig. 5. Synthesis of diUB and tetraUB conjugates of specific linkages. (A) Synthesis of tetraUB of K48 linkages using a K48-specific E2, E2-25K. In the first step, diUB is assembled using UB with an Asp77 extension as the proximal UB and UB with a Lys48Cys mutation as the distal UB. E225-catalyzed UB conjugation generates a diUB with a K48 isopeptide linkage. Next, the diUB conjugate is divided into two parts, with one part reacting with ethylenimine to derivatize the Cys48 residue on diUB with an amine functionality so it can be recognized by E2-25K as a Lys residue. 
group. On the side of the proximal UB, the Lys residue for UB conjugation is replaced with a Cys by mutagenesis. Taking advantage of the fact that UB has no native Cys residues, a photoinitiator was used to induce radical formation on the thiol group of the Cys side chain (Trang et al., 2012). Thiol-ene coupling between the two UB generates a diUB with a thioether linkage that was one carbon longer than the native isopeptide bond. The coupling strategy can be further expanded to generate linear or branched UB chains. UB chains can also be synthesized by copper-catalyzed click chemistry between alkyne and azide functionalities yielding a triazole linkage that is resistant to DUB cleavage (Valkevich et al., 2012). In one example, the $\mathrm{C}$ terminus of the distal UB was functionalized with alkyne and the proximal UB was produced by solid-phase peptide synthesis with the incorporation of azido-ornithine at the site of Lys for UB conjugation. Click reaction generated diUB of specific linkages to identify chainspecific UBDs (Flierman et al., 2016; Zhang et al., $2017 \mathrm{c}$ ). The click ligand can also be installed by UAA incorporation. For example, alkyne-functionalized propargyl-Lys (PrK) can be used to replace a specific Lys in UB at the site of UB chain formation through UAA incorporation by Pyl-RS (Fig. 2D; Fig. 5D). In the same UB molecule, azido-homoAla (Aha) was used to replace Gly76 at the $\mathrm{C}$ terminus of UB by changing the Gly codon to a Met codon, so Aha was added to the UB C terminus as a Met analog. Click reactions with the double mutant of UB generated UB chains of defined linkages through a triazole linker (Eger et al., 2010; Schneider et al., 2014; Rösner et al., 2015). These chains have been used as affinity reagents to identify UBD binding to various chain types (Zhao et al., 2017). UAA p-azidophenylalanine ( $\mathrm{AzF})$ has also been used to replace specific Lys sidechains on UB to generate diUB of defined linkages by click chemistry (Fig. 5E) (Weikart et al., 2012). Besides click chemistry, an $\varepsilon$-aminooxy Lys analog can be introduced by UAA incorporation for coupling with UB C terminus functionalized with an aldehyde moiety (Stanley and Virdee, 2016).

4. Ubiquitin-Substrate Conjugates. Similar to diUB synthesis in which the $\mathrm{C}$ terminus of the distal UB is site-specifically coupled to a Lys or its analog on the proximal UB, the synthesis of UB-substrate conjugate would require the coupling of the UB $\mathrm{C}$ terminus to a specific Lys on the substrate protein to generate a defined modification pattern. All tools developed for diUB synthesis could be applied to the synthesis of UBsubstrate conjugates. For examples, UB was linked to histone or proliferating cell nuclear antigen (PCNA) through a disulfide to mimic isopeptide bond linkages (Chen et al., 2010; Yang et al., 2014; Zhou et al., 2016; Debelouchina et al., 2017). The global protection strategy was applied to the synthesis of human Dishevelled protein with two mono-UB modifications (Madrzak et al., 2015). The UB chains from total synthesis were coupled to substrate proteins via a maleimide linkage with a Cys residue on the substrate proteins replacing a specific Lys at the ubiquitination site or via an oxim linkage with an aldehyde group attached to the Cys residue in the substrate (Hemantha et al., 2014; Singh et al., 2016). UB was linked to a substrate peptide by total synthesis through oxime coupling between an aldehyde-functionalized UB C terminus and a substrate peptide presenting an aminoxy-derivatized Lys residue (Shanmugham et al., 2010). Click chemistry has been used to generate monoubiquitinated PCNA with UAA incorporation to introduce Aha at the UB C terminus and PrK at the ubiquitination site in PCNA (Fig. 2D) (Eger et al., 2011). Recently, Pyl-RS has been engineered to incorporate a Lys derivative with azido-diGly peptide at a specific position of substrate proteins. Reduction of the azido group would generate diGlyconjugated Lys with a free amino end as the substrate of sortase-mediated peptide ligation that would conjugate UB to the specific Lys residue on the substrate (Fig. 5F). The ligation product would have C-terminal mutations in UB to match the specificity of the sortase (Fottner et al., 2019). In another report, wild-type (wt) Pyl-RS was used to incorporate Cys-conjugated Lys into calmodulin (Fig. 2D). EPL reaction between UB thioester with the Cys-conjugated Lys residue on calmodulin generated a UB-CaM conjugate that has a Cys residue replacing the C-terminal Gly of the distal UB at the isopeptide connection (Fig. 5G) (Li et al., 2009).

\section{Manipulating Ubiquitin Transfer by Protein Engineering}

UB rivals the phosphate in the scope of cellular targets modified and the cellular outcomes of the modification.

\footnotetext{
The other part is treated with DUB Yuh1 to cleave the Asn77 tail and expose Gly76. Finally, E2-25K-catalyzed UB chain formation assembles tetraUB with a thioether connection linking two dimers. (B) The genetically encoded orthogonal protection and activated ligation (GOPAL) strategy for preparation of diUB of defined linkages. UB with Boc-protected $\varepsilon$-amino group at the site of the isopeptide linkage is prepared by UAA incorporation. The amine groups on UB, including Lys side chains and the $\alpha$-amino group, are globally protected with Alloc. Selective removal of Boc then exposes a specific Lys for conjugation with the proximal UB, on which all primary amines (Lys and Met1) are protected. After coupling, the Alloc protecting groups are removed to generate diUB of specific linkages. (C) diUB formation through thiol-ene coupling. The $\mathrm{C}$ terminus of the distal UB is functionalized with an alkene group for coupling with a Cys residue in place of a specific Lys on the proximal UB. (D and E) diUB formation through click chemistry. In (D), the distal UB is derivatized with a C-terminal azido-homoAla (Aha) for coupling with the propargyl-Lys (PrK) UAA in place of a specific Lys on the proximal UB. In (E), the $\mathrm{C}$ terminus of distal UB is functionalized with propargyl amine for coupling with p-azidophenylalanine (AzF) UAA on the proximal UB. (F) Formation of UB-substrate conjugates by sortase A. Azido diGly-conjugated Lys (AzGGK) is used as an UAA for incorporation into the substrate protein replacing a specific Lys. The azido group is reduced to generate the diGly peptide with a free $\alpha$-amino group that is recognized by sortase A for ligation with the mutated $\mathrm{C}$ terminus of a UB molecule (LPLTGG). Note that the $\mathrm{C}$ terminus of UB is mutated from its native LRLRGG sequence to match the specificity of sortase. (G) UAA Cys-Lys (CysK) is introduced to a specific site in the substrate protein for EPL with the UB thioester.
} 
Being a protein itself, UB can be further modified by phosphorylation, acetylation, or glycosylation, which adds another layer of complexity to the signals encoded in protein ubiquitination (Swatek and Komander, 2016). Because UB is genetically encoded, it can be plugged into all protein-engineering platforms such as site-directed mutagenesis, phage display, and yeast cell surface display to engineer how it is transferred through the E1-E2-E3 cascade, processed by DUBs, and bound by UBDs. By manipulating the reactivity of UB with these writers, editors, and readers, we can potentially control the ubiquitination status of specific proteins in the cell and regulate their degradation, interactions, trafficking, and enzymatic activities.

\section{A. Engineering Ubiquitin To Manipulate Ubiquitin Transfer}

\section{Ubiquitin and Ubiquitin-Like Protein-Mimicking} Peptides. UB C-terminal peptide bearing the LRLRGG sequence (amino acids 71-76) was found to be a surrogate substrate of the UB transfer cascade, although the activity of peptide transfer is orders of magnitude lower than that of the full-length UB (Jonnalagadda et al., 1988; Madden et al., 2008). To define the sequence space of the UB C terminus that could be accommodated by E1 to activate UB transfer, we (Yin and colleagues) randomized UB C-terminal residues covering LRLRG in the context of full-length UB and developed a phage selection scheme to identify UB variants that could be activated by E1 (Zhao et al., 2012a). The UB library was displayed on phage with exposed randomized $\mathrm{C}$ termini, and selection was carried out based on thioester bond formation between the UB variants and $\mathrm{E} 1$ immobilized on a streptavidin plate. The selection yielded UB variants with alternative C-terminal sequences that could be recognized by E1 for transfer through the cascade. Furthermore, the C-terminal peptides derived from the UB variants from phage selection have hundreds-fold higher activity with E1 compared with the native LRLRGG sequence, presumably due to the optimized interaction between the $\mathrm{E} 1$ and the peptides from phage selection. The peptides known as UB-mimicking peptides could be transferred through the ubiquitination cascade, where they blocked the transfer of the full-length UB from passing through the cascade by forming thioester conjugates with E1, E2, and HECT E3s (Zhao et al., 2012c; Jin et al., 2018). In this way, these peptides serve as inhibitors of UB transfer through the cascades, although they would not target a specific protein ubiquitination pathway. Using a similar phage selection platform, short C-terminal peptides have been identified that mimic the transfer of UBL proteins NEDD8 and SUMO through their respective enzymatic cascades. In vitro assays showed the inhibition of UBL transfer through their cascades by the NEDD8- and SUMO-mimicking peptides (Zhao et al., 2013a,b, 2014).

2. Ubiquitin Variants That Regulate the Activity of Deubiquitinating Enzyme and E3 in the Cell. DUB and E3 enzymes frequently harbor UB-binding sites for substrate recognition or allosteric control of activity (Komander et al., 2009; Maspero et al., 2011). The association of these UB-binding sites with UB would have rapid on and off rates to accommodate the processivity of UB chain formation and the editing capacity of DUBs. By enhancing the binding affinity of UB with these sites on DUB and E3, Zhang and Sidhu (2014) and Gorelik and Sidhu (2017) found that engineered UB variants (Ubv) could function as specific DUB or E3 inhibitors. To do this, they identified a binding interface for the DUB USP21 on UB that comprised $\sim 30$ residues. These amino acids were randomized in a UB phage display library and panned against USP21 as well as USP8 and USP2a (Ernst et al., 2013). Ubvs were identified that specifically interact with their cognate DUB in cells and similarly show evidence of selective modulation of function. Thus, Ubvs from phage selection can function as genetically encoded DUB inhibitors. The crystal structures of USP2a and USP21 with Ubvs bound showed the Ubvs adopted the same binding mode as the wt UB at the distal UB-binding site of the DUBs. Interestingly, the crystal structure of USP8-Ubv complex shows a significantly different mode of binding than USP8-UB, suggesting phage selection using the Ubv library could find alternative binding modes with DUBs that maximize binding affinity. Zhang and Sidhu (2014) and Gorelik and Sidhu (2017) also generated Ubvs for binding to DUBs of various families as well as viral DUBs. The E2 enzyme Cdc34, and HECT, RING, and U-box E3s have also been assessed, and Ubvs for these that inhibited UB transfer have been identified. In some cases, this has been found to occur through previously unappreciated E3UB interactions (Brown et al., 2016; Gorelik et al., 2016, 2018; Leung et al., 2016; Gabrielsen et al., 2017; Zhang et al., 2017b; Ordureau et al., 2018). In another report, the computation-assisted design was used as a guide to generate Ubv libraries, resulting in Ubvs that inhibit the DUB USP7 (Zhang et al., 2013c). Besides their roles as inhibitors of E3s and DUBs, engineered Ubv can also activate E3s (Zhang et al., 2016; Gabrielsen et al., 2017). In the case of the HECT E3, NEDD4L, an Ubv showed enhanced affinity for a UB-binding site in the N-lobe of the HECT domain and thereby allosterically released the selfinhibited state of the HECT domain-activating UB transfer. Ubvs also have revealed novel sites of proteinprotein interaction on an E3. The structural characterization of Ubv binding with the Fbw7-Skp1 subcomplex of the E3 SCF ${ }^{\mathrm{Fbw} 7}$ [Skp1-Cullin-F box (SCF) E3 complex with Fbw7 as the F-box component (also known as $\mathrm{CRL1}^{\mathrm{Fbw} 7}$ )] showed the Ubv to be bound to a site normally occupied by Cul1, and, as a result, the Ubv inhibits the association of 


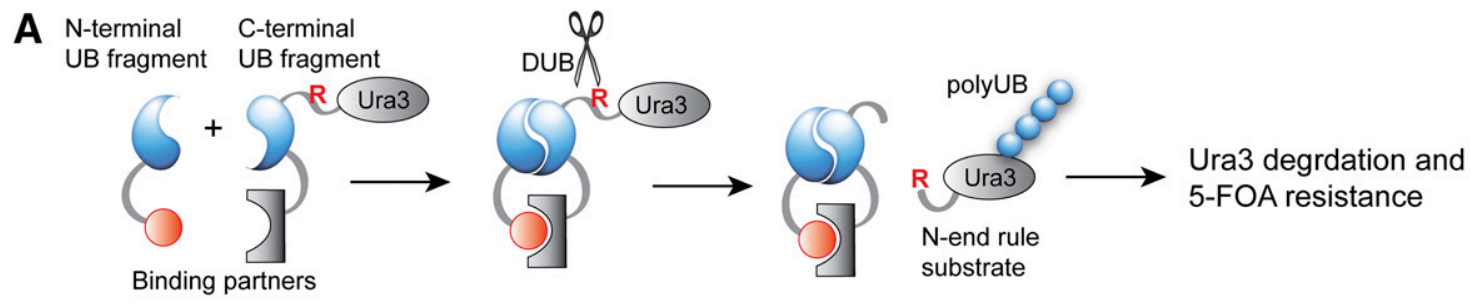

B

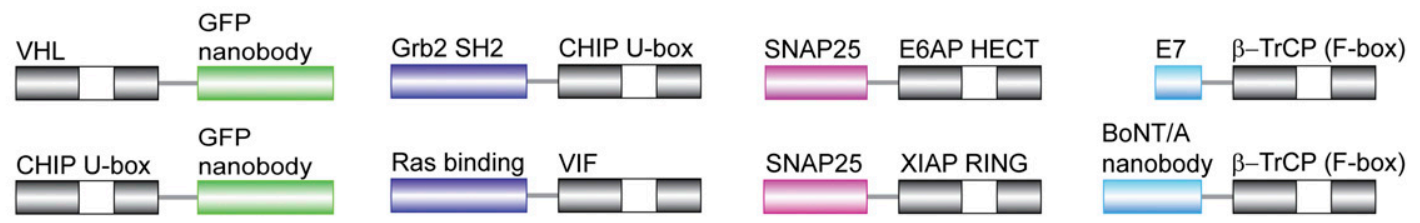

C
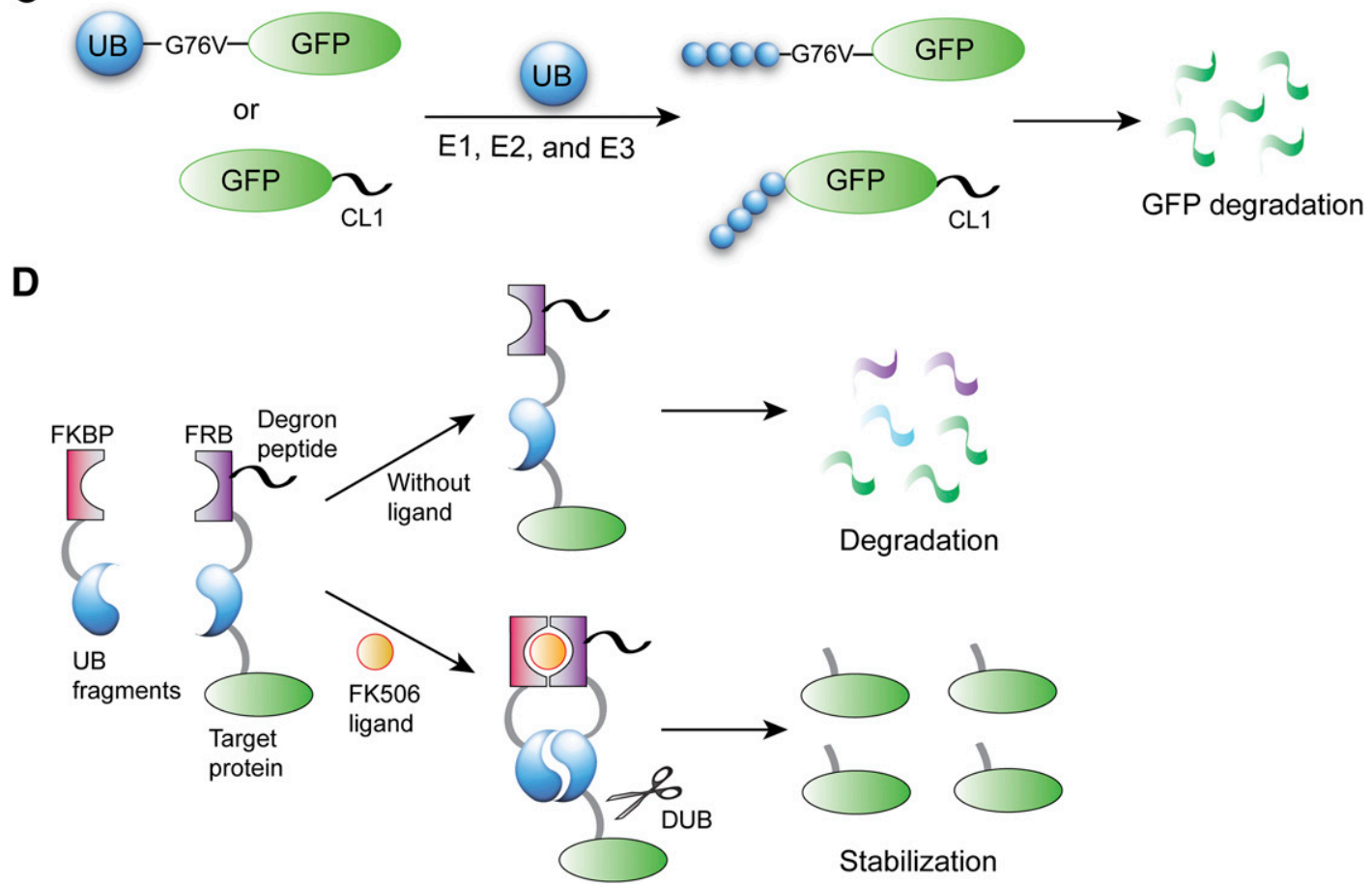

Fig. 6. Fusion proteins with UB and E3. (A) The split UB assay. N- and C-terminal fragments of UB, containing a mutation to limit spontaneous assembly, are reconstituted into a UB fold with the binding of two partner proteins that are fused to the UB fragments. The reassembled UB is recognized by a DUB that cleaves after the $\mathrm{C}$ terminus of UB, resulting in an N-terminal Arg, which destabilizes Ura3. This triggers Ura3 to be ubiquitinated by the $\mathrm{N}$-end rule pathway and degraded, resulting in yeast that are resistant to 5-fluoroorotic acid (5-FOA). (B) Fusions between E3s and the substrate-recruiting domains to enable the E3 to recognize new cellular targets, as described in the text. (C) UB-GFP fusion or GFP fusion with degron peptide CL1 as reporters of the activity of UB transfer cascades in the cell. (D) Ligand-induced substrate degradation. The small-molecule ligand rapamycin induces the dimerization of FKBP and FKBP12-rapamycin-binding protein (FRB) and triggers the assembly of the split UB. DUB cleavage at the $\mathrm{C}$ terminus of the reassembled UB releases the substrate protein and prevents it from degradation induced by the degron peptide fused to FRB.

Cul1 with Skp1-Fbw7. This led to the structure-based design of a Ubv that functions similarly with Skp1-Fbw11 (Gorelik et al., 2016) and to the selection of Ubv inhibitors of SCF assembly for 17 additional F-box proteins complexed with Skp1 (Gorelik et al., 2018). Thus, phage selection using a Ubv library has led to the identification of an interface that could be targeted by designer protein ligands to interfere with the assembly of SCF complexes. As there are other Cullins that have a similar interaction interface as Cul1, there is the potential for other CRL E3 families to be similarly targeted (Gorelik et al., 2018). Overall, Ubvs have potentially broad applications in probing the catalytic mechanisms of E3s and DUBs by forming high-affinity complexes with enzymes and allowing their structural characterization by X-ray crystallography and electron microscopy. Ubvs could also be used as genetically encoded inhibitors of E3 and DUBs to validate the therapeutic potentials of specific E3 or DUB targets for drug development. Ubvs are recombinant engineered proteins. As potential protein therapeutics, they present challenges related to issues such as stability, cell penetration, and potential immune responses due to introduction of foreign antigenic epitopes on the Ubv. However, with the development of gene and protein 
delivery platforms, Ubvs may have the potential to be further developed to target DUBs and E3s in vivo.

3. Split Ubiquitin. Aside from engineering UB to directly probe components and substrates of the UB system, the stable UB fold has been employed as the basis for sensors to detect protein-protein interactions. Varshavsky's laboratory demonstrated the capacity of an $\mathrm{N}$-terminal fragment and a C-terminal fragment of UB to self-assemble in yeast. When a mutation was introduced, self-assembly occurred only when two binding partners that were fused to the separate UB fragments interacted. As the system was originally engineered, this assembly resulted in DUBmediated cleavage of a protein linked to the $\mathrm{C}$ terminus of UB. This cleavage therefore served as a proximity sensor (Johnsson and Varshavsky, 1994) (Fig. 6A). This propensity for self-assembly has been adapted for use as sensors in the discovery of novel protein-protein interactions by screening of expression libraries in yeast. This complements yeast two-hybrid systems in that it can be used to screen for transcription factors and is not dependent on the ability of the assembled complex to localize to the nucleus (Laser et al., 2000). In the original iteration of this screening assay, the prey (library to be screened) and N-terminal UB fragment are expressed from a yeast plasmid library as $\mathrm{N}$ to $\mathrm{C}$ fusions. This was similarly done for the bait (protein for which partners are being screened for) and the C-terminal UB fragment. Critical to the assay is the fusion of a selection marker (initially Ura3) to the other (C-terminal) end of the bait-containing fusion protein. When bait and prey interact, the two halves of UB associate and the C-terminal Ura3 fusion is cleaved by a DUB. Once cleaved, the $\mathrm{N}$-terminal Arg of the engineered Ura3 is exposed. N-terminal Arg is a primary destabilizing amino acid - a degron recognized by the yeast $\mathrm{N}$-end rule E3 (Varshavsky, 1996). Thus, in the yeast cells in which such interaction occurs, Ura3 is ubiquitinated and degraded, allowing for selection by growth in media containing 5fluoroorotic acid-expression of Ura3 in yeast cells converts 5-fluoroorotic acid to 5-fluorouracil, which is toxic to the cell. Plasmid can be recovered from transformed yeast and sequenced, and the identity of the interaction protein(s) determined. The split UB can be fused to other reporters to induce their DUB-mediated cleavage and can be used for screen interactions between specific membrane proteins (Stagljar et al., 1998), for detecting conformational changes in proteins, as well as for other purposes (Müller and Johnsson, 2008). This concept is now being adapted and used in mammalian cells as are other, more recently developed, protein biosensors such as split GFP, $\beta$-lactamase, luciferase, and dihydrofolate reductase (DHFR) (Wehr and Rossner, 2016).

\section{B. Engineering E3s To Regulate New Cellular Targets}

1. Engineering E3 Adaptors. CRLs are multisubunit complexes that recruit their substrates through adaptor proteins, recognizing specific degron sequences on substrates. The degron sequences on key signaling proteins are frequently mutated, which results in decoupling their regulation by E3s (Hayes and McMahon, 2009). It would be useful to engineer E3s to recognize the mutant degrons and restore substrate regulation through ubiquitination. In CRL3 ${ }^{\text {Keap1 }}$, the adaptor protein Kelch-like enoyl-CoA hydratase-associated protein (Keap1) binds to the substrate Nrf2. Mutations in the degron sequence allow mutant Nrf2 to evade proteasomal degradation by $\mathrm{CRL} 3^{\text {Keap1 }}$ and promote cancer development (Zhang et al., 2013a). To engineer a Keap1 that recognizes mutant Nrf2, we (Yin and colleagues) generated a library of the Kelch repeat domain of Keap1 displayed on the yeast cell surface with randomized residues at the degron-binding site. The yeast library was allowed to bind biotin-labeled degron peptidebearing cancer-related mutations (Fig. 2B). Next, yeast cells were incubated with streptavidin-fluorophore conjugates to label cells displaying Kelch domain mutants that show high affinities for the biotinylated degron peptide. Sorting of yeast has identified Kelch-repeat domains with altered specificity for the Nrf2 mutant. It remains to be tested whether the engineered Keap1 could induce degradation of Nrf2 with a mutated degron in cells, but this work suggested that the yeast selection platform is amenable for engineering E3-substrate recognition (Zhang et al., 2013a).

2. E3 Fusions To Redirect the Ubiquitination Targets. E3s determine the specificity of substrate ubiquitination. Conceptually, E3s consist of at least two modular domains: a substrate-binding domain and a UB transfer domain (e.g., HECT, RBR, RING, U-box) (Fig. 1A). An E3 can therefore be targeted to a different substrate by mutating its substrate-binding region. For example, the UB ligase Cbl regulates epidermal growth factor signaling by targeting phosphorylated epidermal growth factor receptor for degradation. When the Src homology 2 (SH2) domain of $\mathrm{Cbl}$ is replaced with the $\mathrm{SH} 2$ domain from growth factor receptor-binding domain 2, the resulting chimeric E3 is also able to target HER2 for degradation ( $\mathrm{Li}$ et al., 2007). Based on this idea, designer E3s can be constructed by fusing a substratebinding domain with a UB transfer domain to target any undesirable cellular protein (Fig. 6B). Indeed, the $\mathrm{SH} 2$ domain of growth factor receptor-binding domain 2 fused to either the RING domain of Cbl or U-box domain from carboxyl terminus of Hsc70-interacting protein (CHIP) is sufficient to downregulate EGFR in lung cancer cells (Lee et al., 2014; Zhong et al., 2015). Similarly, a SH2 domain fused to the U-box domain of CHIP downregulates breakpoint cluster region proteinAbelson murine leukemia viral oncogene homolog 1 kinase and inhibits tumor growth of chronic myeloid leukemia cells in mouse xenografts (Ru et al., 2016).

When the protein targeted for degradation is an enzyme, its substrate may be engineered to serve as 
the targeting domain for the designer E3. Type A botulinum neurotoxin (BoNT/A) prevents neurotransmission by cleaving soluble NSF attachment protein 25 , a SNAP receptor protein in the presynaptic terminal, thereby preventing synaptic vesicle fusion. A designer E3 consisting of a mutant soluble NSF attachment protein 25 resistant to BoNT/A cleavage fused with the HECT domain from E6-AP successfully targets the toxin for proteasomal degradation (Fig. 6B). Besides the HECT domain from E6-AP, the RING domain from $\mathrm{X}$-linked inhibitor of apoptosis protein (XIAP) also functions to target BoNT/A toxin for degradation (Tsai et al., 2010). The choice of the UB ligase domain does not appear to be critical, although the optimal length of the linker region connecting the substrate-binding region to the ligase domain may differ for the ligase domains.

Designer E3s can also be constructed from multisubunit E3 complexes such as members of the modular SCF E3 family of E3s. Among the SCF E3 subunits, the F-box protein serves to recruit the substrate for ubiquitination. A hybrid F-box protein was constructed by fusing $\beta$-transducin repeat containing protein with the $\mathrm{N}$-terminal 35-amino-acid region of the human papilloma virus E7 protein to target the retinoblastoma protein for degradation (Fig. 6B) (Zhou et al., 2000). Recently, nanobodies-single-chain antibodies from camelid species-have been used as substrate adaptors due to their specificity and small size. A chimeric protein consisting of a nanobody against BoNT/A light chain fused to the minimal F-box domain of $\beta$-transducin repeat containing protein was demonstrated to target BoNT/A toxin for degradation. More importantly, it has been shown to accelerate neuronal recovery following intoxication, supporting the idea that the stability of the toxin accounts for its long-lasting effect (Kuo et al., 2011). In addition to F-box proteins, the von-Hippel-Lindau protein, the substrate adaptor of Cul $2 \mathrm{E} 3$, has been fused to a nanobody directed against GFP (aGFP) to induce the degradation of GFP-tagged proteins (Fulcher et al., 2016). The U-box E3 CHIP has also been fused to aGFP to induce the degradation of subunits of $\mathrm{K}^{+}$ion channels bearing a GFP tag (Kanner et al., 2017). Because GFP fusions are commonly used for investigating the subcellular localization of proteins, designer E3s based on aGFP nanobodies will become versatile reagents for regulating the levels of these fusion proteins.

Instead of directly fusing to an E3 or E3 subunit, molecules that bridge the substrate and E3 can be used to target specific substrates for degradation. These proteolysis-targeting chimera (PROTAC) molecules contain a binding domain for the substrate joined by a variable linker to a binding domain for the E3. The first reported PROTAC used ovalicin linked to the phospho-degron peptide of $\mathrm{I} \kappa \mathrm{B}-\kappa$ to target MetAP-2 to $\mathrm{SCF}^{\beta-\mathrm{TRCP}}$ (Sakamoto et al., 2001; Lai and Crews, 2017). Subsequent PROTACs have been developed to recruit substrates to the von-Hippel-Lindau E3 complex using a degron derived from HIF1 $\alpha$ (Schneekloth et al., 2004). Similarly, thalidomide-like immunomodulatory drugs (IMiDs), have been found to be efficacious in multiple myeloma by binding to Cereblon $\left(\mathrm{CRL} 4^{\text {Cereblon }}\right.$ ) and targeting bound lymphoid-specific transcription factors (IKZF1 and IKZF3) for ubiquitination and proteasomal degradation (Krönke et al., 2014; Lu et al., 2014). These are now being adapted to target Cereblon to other proteins (Lu et al., 2015; Winter et al., 2015; Koduri et al., 2019).

Engineered E3 variants are not suitable for general therapeutic development without parallel development of specialized delivery systems. Nevertheless, they can be useful for studying the effects of degrading specific cellular targets. The recent development of smallmolecule PROTACs and the discovery and development of IMiDs and molecular glues with better cell permeability will help realize the therapeutic use of these molecules. Readers are referred to recent reviews such as Lai and Crews (2017), Asatsuma-Okumura et al. (2019), and Pettersson and Crews (2019).

3. Engineered E3 Substrates. A simple way to target a specific protein for degradation is to attach a degron to the protein. For example, a protein can be targeted for degradation by the $\mathrm{N}$-end rule pathway by fusion with UB at its $\mathrm{N}$ terminus (Varshavsky, 1996). When the UB is cleaved by cellular DUBs, the first amino acid following the UB determines the half-life on the protein according to the N-end rule. This approach can be used to bypass the normal degradative process in the cell and study the effects of protein degradation in cellular function. Fzo1 is the mitofusin that regulates outer mitochondrial membrane fusion in Saccharomyces cerevisiae (Hermann et al., 1998; Rapaport et al., 1998). Cells lacking Fzo1 have fragmented mitochondria and fail to respire when grown in nonfermentable carbon source (Cohen et al., 2008). Fzo1 is normally degraded by $\mathrm{SCF}^{\mathrm{Mdm} 30}$. Surprisingly, cells lacking Mdm30 also have fragmented mitochondria even though Fzo1 accumulates in these cells. Expression of a Ub-Fzo1 fusion, which can be degraded by the $\mathrm{N}$-end rule pathway independently of Mdm30, bypassed the requirement of Mdm30 for mitochondrial reparation and demonstrated that degradation of Fzo1 is required for outer mitochondrial membrane fusion (Cohen et al., 2011).

Fluorescence proteins fused to UB or a degron peptide could function as reporters of the activity of UB transfer cascades or in cells (Salomons et al., 2005). $\mathrm{UB}^{\mathrm{G} 76 \mathrm{~V}}$ GFP, in which the N-terminal UB has its C-terminal Gly76 mutated to Val, making it resistant to cleavage by DUBs, is rapidly degraded by the proteasome and can be used to monitor proteasome activity in cells and in vivo (Dantuma et al., 2000). To this end, an unstable GFP $\left(\mathrm{GFP}^{\mathrm{U}}\right)$ was generated by fusing GFP with the CL1 degron peptide on its $\mathrm{C}$ terminus (Bence et al., 2005) (Fig. 6C). CL1 was isolated from a screen in yeast of C-terminal extensions that produced 
unstable $\beta$-galactosidase and Ura3 fusions that were stabilized in E2 mutant strains (Gilon et al., 1998). In $S$. cerevisiae, CL1 fusion degradation occurs at the cytosolic face of endoplasmic reticulum (ER) membranes (Gilon et al., 2000; Ravid et al., 2006; Metzger et al., 2008). The means by which the CL1 fusion is targeted for degradation in human cells had not been known until recent studies suggested that it is degraded at the ER membrane through a UB-mediated ER-associated degradation pathway requiring the RING E3 TRC8, UBE2G2, and an ER-associated degradation accessory protein AUP1 (Stefanovic-Barrett et al., 2018; Leto et al., 2019).

In another approach to monitor degradation, a fusion protein was constructed in the order of following components: Renilla luciferase (RL), K48R mutant of UB, firefly luciferase (FL), and RhoB, a substrate of HECT E3 Smurf1. Both Renilla and firefly luciferase are tagged with multiple FLAG epitopes for affinity purification. When the construct is expressed in cells, DUB cleavage of the fusion generates an equal concentration of RL-UB and FL-RhoB in the cell. Because UB bears the K48R mutation, the RL-UB fusion is less likely to be ubiquitinated and therefore should be relatively stable. FL-RhoB would be readily ubiquitinated by SMURF1 that has been coexpressed in the cell and degraded. The ratio of the activity of RL and FL was measured to report the activity of SMURF1 in the cell (Tian et al., 2019). Such an engineered reporter system was used to screen SMURF1 inhibitors. Substrate proteins of an E3 could also be engineered to couple its stability with the presence of a small-molecule ligand. The split UB system (discussed above) was adapted to regulate substrate stability using the small-molecule rapamycin (Fig. 6D). In the system, the substrate was expressed as a fusion in the following order from amino to carboxyl terminus: degron peptide, FKBP12rapamycin-binding protein (FRB), C-terminal fragment of UB, and substrate. Upon treatment with rapamycin, the FRB domain in the fusion protein would bind to FK506-binding protein (FKBP) that was fused with the N-terminal fragment of UB. This would bring the two UB fragments together to assemble a UB fold and trigger DUB cleavage to release the substrate protein from the degron-containing fusion. In this way, assembly of a UB fold upon addition of rapamycin serves to stabilize the substrates from ongoing degradation (Pratt et al., 2007).

\section{Engineering Deubiquitinating Enzymes}

DUBs have been expressed as fusions with either substrates or E3 enzymes to control the ubiquitination status of substrates in the cell (Stringer and Piper, 2011; MacDonald et al., 2017). To probe the role of ubiquitination in endosomal trafficking, fusions between endosomal membrane proteins and the catalytic domains of both viral and yeast DUBs were generated.
It was found that the fusion proteins were blocked from sorting into multivesicular bodies and accumulated on the cell surface. This suggests the DUB fused to the target protein can remove UB from the fusion and affect its trafficking in the endocytic pathway (Stringer and Piper, 2011). The same group also generated fusions between all annotated yeast $\mathrm{E} 3$ open reading frames (ORFs) and the catalytic domain of the UL36, a DUB derived from Herpes virus. The E3-DUB fusions reversed ubiquitination of substrates of the fused E3s and thereby functioned as dominant-negative mutants of these E3s (Fig. 7A). These "antiligases" serve as specific inhibitors of the fused E3 and can be used to probe the function of these E3s in cells (MacDonald et al., 2017).

DUB can be engineered to transfer UB to a Lys. The native function of the yeast DUB Yuh1 is to cleave C-terminal extensions beyond Gly76 of UB. During the normal catalytic cycle of the DUB, Yuh1 would form an acyl-enzyme intermediate with the UB through a catalytic Cys residue, and, subsequently, the intermediate would hydrolyze to release UB and complete the catalytic cycle. Yeast cell surface display was used to screen a Yuh1 library to enhance its transamination activity so that, instead of hydrolysis, the acyl-enzyme intermediate would react with an active site Lys on the DUB so that UB forms an isopeptide conjugate with the mutant DUB. Such identity switch converts a DUB to an enzyme capable of transferring UB to itself independent of E1 and E2 (Chang and Strieter, 2018).

Recently, a protease targeting UBLs has been repurposed for cleaving UB chains to dissect chain topology. It was noted that leader protease $\left(\mathrm{Lb}^{\text {pro }}\right)$ from the footand-mouth disease virus cleaves the UBL protein ISG15 before the C-terminal diGly motif to prevent its conjugation with viral proteins. This serves to disarm host antiviral responses (Swatek et al., 2018). Based on the modeled structure of $\mathrm{Lb}^{\text {pro }}$-UB complex, a L102W mutation was introduced to the enzyme-binding site of ISG15 so the engineered enzyme ( $\mathrm{Lb}^{\text {pro*}} *$ ) could recognize and cleave UB before its C-terminal diGly motif. When $\mathrm{Lb}^{\text {pro } *}$ is used to process UB chains conjugated to a substrate protein, it would remove UB chains from the substrate, leaving the diGly motifs on Lys residues that served as sites of UB conjugation (Fig. 7B). This is in contrast to cleavage by DUBs, which cleave the isopeptide linkage of a UB chain after the diGly motif to regenerate unmodified Lys residues on UB. After $\mathrm{Lb}^{\text {pro }}$ cleavage, UB units derived from a chain in which there were no branch sites (i.e., involving a linkage from one Lys) would bear one diGly motif at the site of Lys linkage, whereas UB units derived from branch points to which distal UBs had been covalently linked to more than one Lys would bear two or more diGly motifs. Trypsin, the protease most commonly used to cleave proteins after positively charged Lys and Arg residues to generate peptide fragments for mapping ubiquitination sites, also cleaves UB chains into peptides with 
A

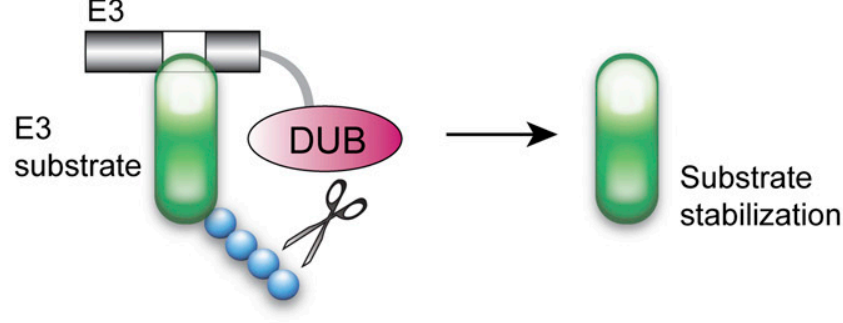

B

B UB

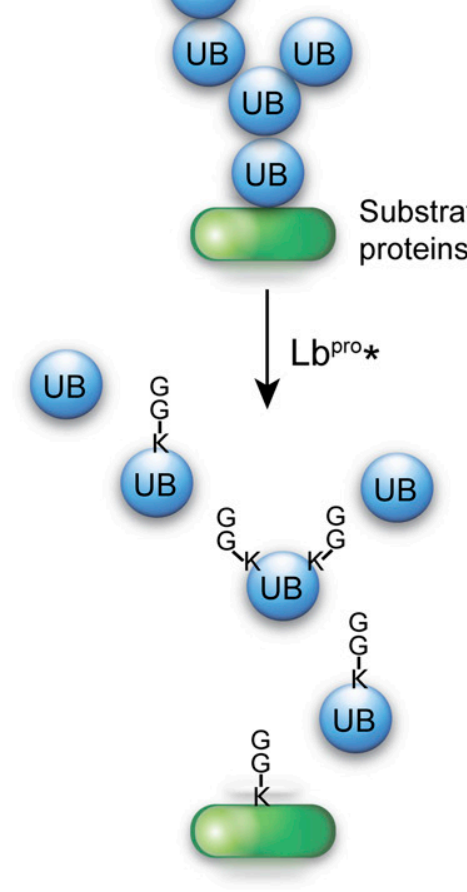

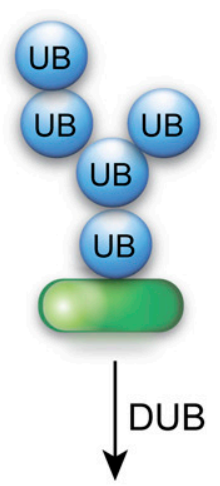

$5 X \underset{\substack{G \\ G}}{1}$

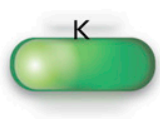

C

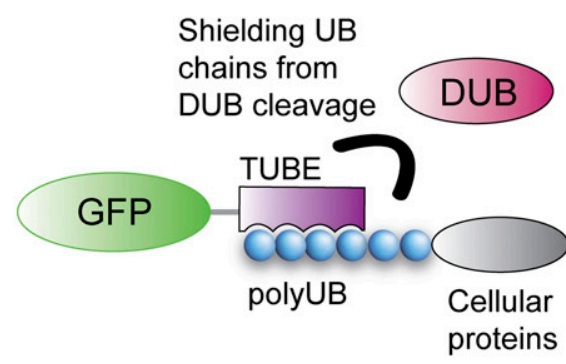

D

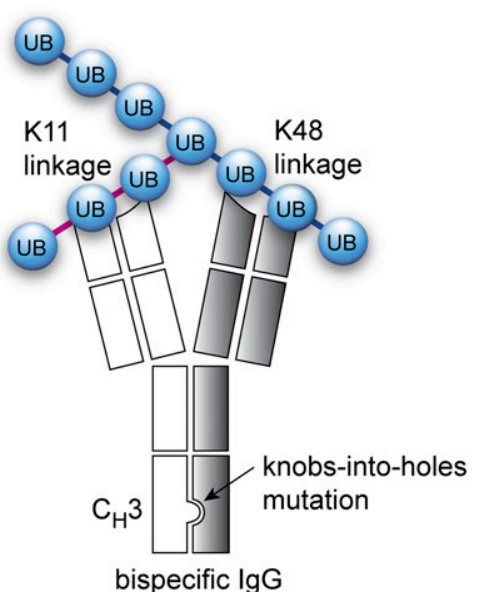

Fig. 7. Engineering of DUBs and UBDs. (A) DUB fusion as antiligase to inhibit the ubiquitination of the E3 substrates. (B) Viral protease for ISG15 cleavage ( $\mathrm{Lb}^{\text {pro*}}$ ) is engineered to recognize UB chains and cleave UB before the C-terminal diGly motif on each UB unit. After cleavage, the diGly peptide remained covalently linked to Lys residues of substrate proteins or of linked UB, providing a footprint of the UB modification. In contrast, native DUBs would disassemble UB chains into UB units with unmodified Lys, and trypsin would digest UB chains into peptides with diGly motifs attached to Lys at the ubiquitination sites. (C) GFP-TUBE fusion to image the polyubiquitinated proteins in the cell. Trypsin-resistant TUBE can protect UB chains from cleavage by proteasome or DUB to facilitate the purification of UB-modified proteins. (D) Bispecific antibody recognizing K11 and K48 linkages is assembled by knobs-into-holes mutations to bind to branched UB chains.

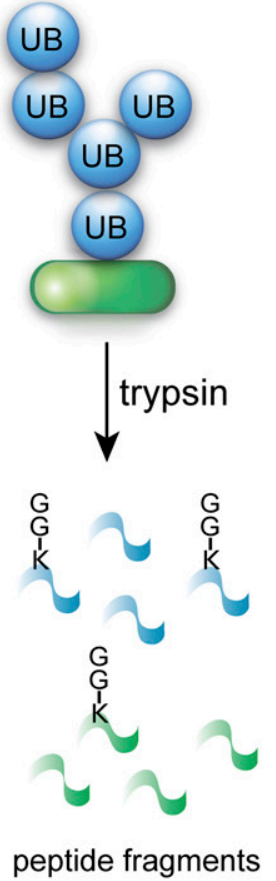


diGly motif conjugated to Lys at the linkage sites; however, the branching pattern of the UB chain is often lost because all UB units are fragmented into peptides (Fig. 7B). A UB-clipping method has been developed using $\mathrm{Lb}^{\text {pro* } *}$ to cleave UB chains and deduce the chain topology based on the ratio of UB units bearing various numbers of diGly and the sites of diGly modifications. Analysis of mitochondrial ubiquitination reveals a complex topology of UB chains on depolarized mitochondria orchestrated by the dual action of Pink1 and Parkin during initiation of mitophagy (Swatek et al., 2019).

\section{Engineering Ubiquitin-Binding Domains}

UBDs can be employed in the laboratory as affinity reagents for purifying ubiquitinated proteins. For such purposes, glutathione $S$-transferase fusions to $\mathrm{S} 5 \mathrm{a} /$ Rpn10, Rad23, and Dsk4 UBDs have been used to isolate UB conjugates from cell and tissue lysates (Layfield et al., 2001; Mayor and Deshaies, 2005). Multiple repeats of UBD motifs have been fused to generate affinity reagents for polyubiquitinated proteins (Hjerpe et al., 2009). These TUBEs would typically have four repeats of a UBD. Their polyvalency results in high-avidity reagents. Depending on the UBD, TUBEs can either recognize a variety of UB linkages or be linkage specific (Scott et al., 2015; Gao et al., 2016; Mattern et al., 2019). To facilitate the isolation of polyubiquitinated substrates of an overexpressed E3, constructs encoding FLAG epitope-tagged TUBEs that are resistant to trypsin have been developed for coexpression in cells with E3s. The TUBEs protect UB chains from both DUBs and proteasome activity (Yoshida et al., 2015) (Fig. 7C). After affinity purification from cell lysates, the immunoprecipitated material can then be subject to trypsin digestion and reimmunoprecipitation with an antibody directed against the UB isopeptide linkage (anti-GG- $\varepsilon-\mathrm{K}$ ) (Kim et al., 2011; Xu and Jaffrey, 2011). This results in a highly enriched population of peptides corresponding specifically to substrate-UB linkages, which enhances the ability to detect these linkages by mass spectrometry. Sensors tracking the formation and the location of polyUB chains have also been developed by engineering UBD motifs (Fig. 7C). Triple repeats of the UIM from the UB-binding protein Vps27 (Vx3) were designed and shown to have a high degree of specificity for K63 UB chains. Vx3 was expressed in cells as a fusion with enhanced green fluorescent protein and used to image the location of newly-formed K63 UB chains during nuclear factor $\kappa \mathrm{B}$ pathway activation (Sims et al., 2012). In another report, fusions of the UBD domains of both $\mathrm{NF}_{\kappa} \mathrm{B}$ essential modulator (NEMO) and A20 binding and inhibitor of $\mathrm{NF} \kappa \mathrm{B}(\mathrm{ABIN})$ with GFP were generated to detect linear UB chains. In the same study, GFP was fused with the UIM of Rap80 to detect K63 chains in cells (van Wijk et al., 2012). The engineered UBD affinity reagents along with linkage-specific antibodies and GG- $\varepsilon-K$ antibodies together constitute a powerful suite of tools for characterizing UB chain topology, reading the signals encoded in substrate-linked UB chains, and determining substrates linked to specific UB chains (Newton et al., 2008; Kim et al., 2011; Xu and Jaffrey, 2011).

Antibodies have also been generated as artificial UBDs to differentiate the linkage types of UB chains. To generate linkage-specific antibodies, fragment antigenbinding libraries with randomized complementaritydetermining regions were displayed on phage and panned against linear, K11, K48, and K63 UB chains. Fragment antigen binding recognizing various linkages of UB chains were selected and expressed in an IgG format for the identification of cellular proteins modified with various types of UB chains (Newton et al., 2008; Matsumoto et al., 2010, 2012). Recently, K11 and K48 linkagespecific antibodies were assembled into a heterodimer with a knobs-into-holes strategy to generate a bispecific antibody to recognize K11/K48 chains of mixed linkages (Merchant et al., 1998; Yau et al., 2017) (Fig. 7D). To suppress homodimer formation between antibody heavy chains, a sterically bulky Thr to Trp mutation was introduced as a knob into the $\mathrm{C}_{\mathrm{H}} 3$ region of the heavy chain specific for the K11 UB chain. In contrast, multiple mutations were installed on the $\mathrm{C}_{\mathrm{H}} 3$ of the heavy chain specific for the K48 UB chain to create a hole and structurally complement the knob mutation. Half antibodies for K11 and K48 UB chains are expressed separately and assembled into bispecific antibodies as an affinity reagent to purify cellular proteins modified with branched UB chains. Enrichment of UB conjugates using the bispecific antibody found mixed K11/K48 chains present on substrates of E3 enzymes critical to cell cycle regulation by anaphase-promoting complex/cyclosome and recognition of misfolded proteins by UB protein ligase E3 component n-recognin 5 (Yau et al., 2017).

\section{Identifying E3 Substrates by Protein Engineering}

Dysfunction of specific UB ligases can have profound consequences that contribute to a host of disorders from cancer to neurodegeneration to autoimmune diseases (Rougeulle et al., 1997; Shimura et al., 2000; Nakayama and Nakayama, 2006; Kobashigawa et al., 2011; Lipkowitz and Weissman, 2011). Identifying the range of substrates for specific E3s is therefore of critical importance to understanding the regulation of cell physiology. The large number of E3s and their often transient interactions with substrates presents a significant challenge to the identification of target proteins. Although an oversimplification, methods for E3 substrate identification can be grouped into three categories-affinity binding to the native E3 or fragment of an E3; monitoring changes in protein stability 
A

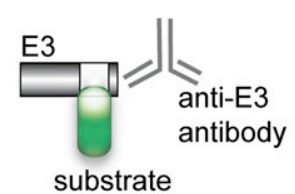

B
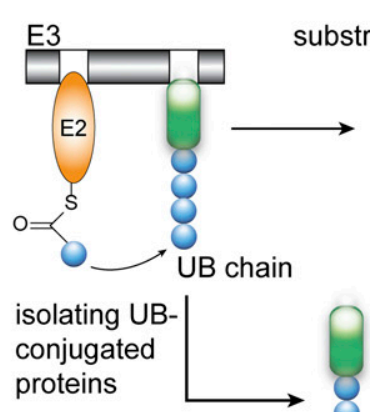

G

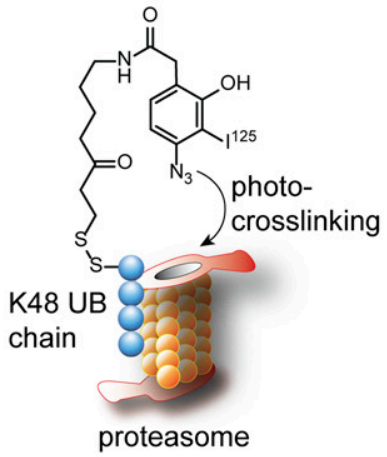

monitoring changes

in protein stability

proteasome

degradation

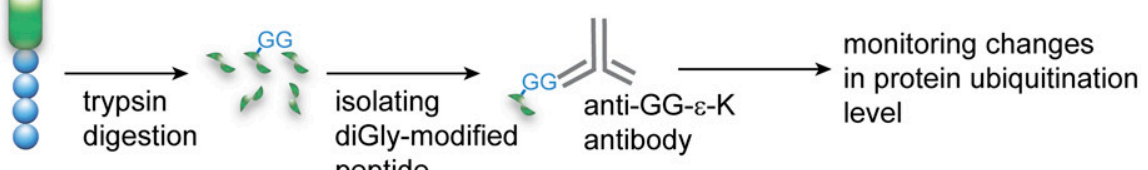
peptide

C

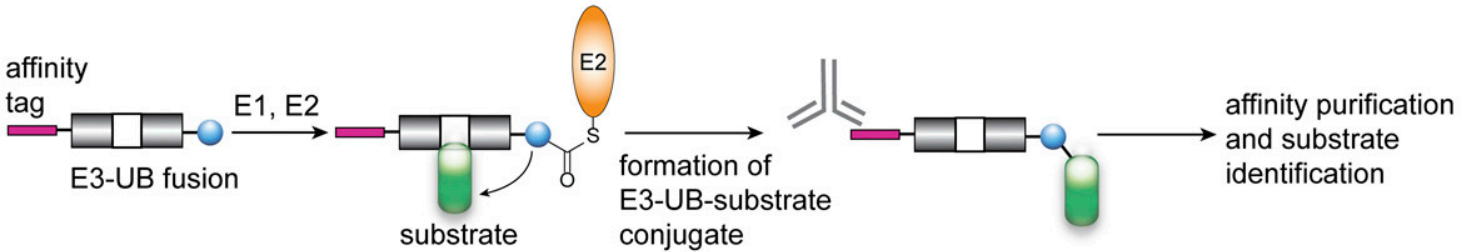

D

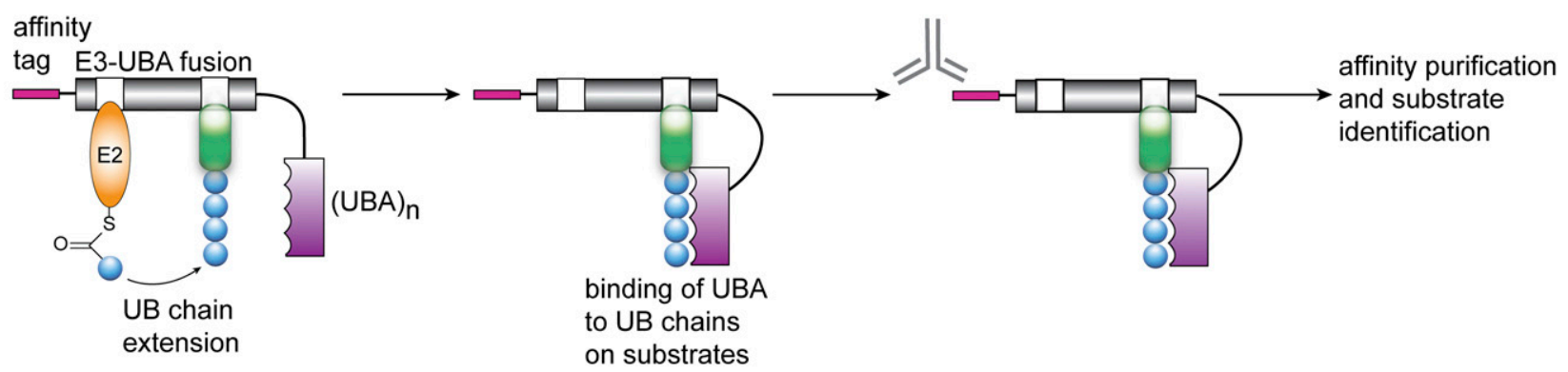

E

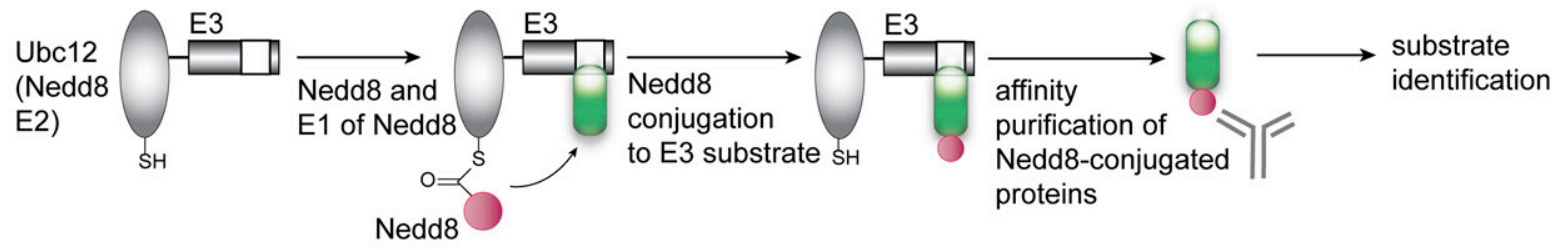

F

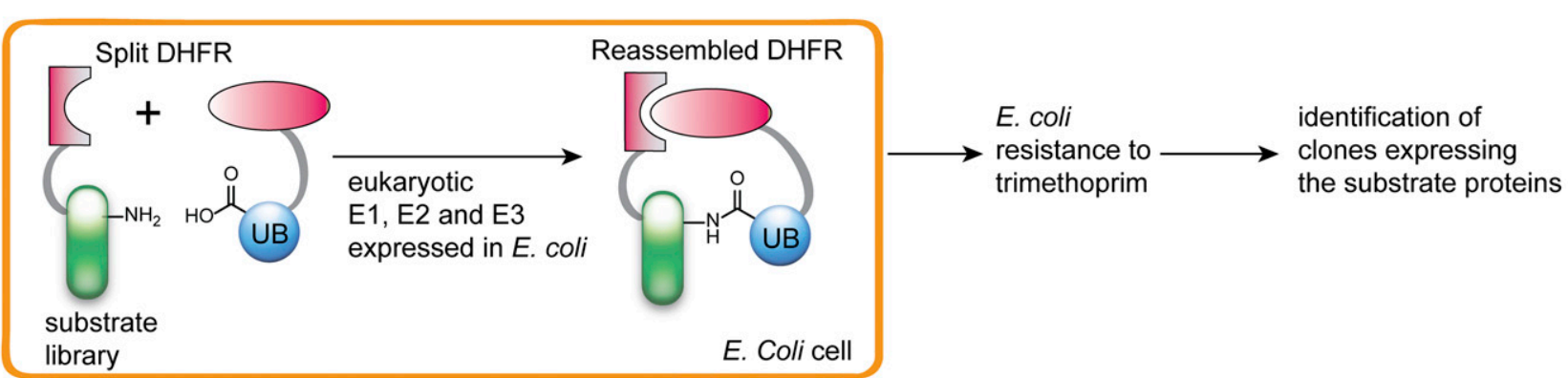

Fig. 8. Methods for identifying E3 substrates. (A) Identifying E3 substrates based on affinity binding between E3 and substrate proteins. (B) Identifying E3 substrates by monitoring changes in protein stability upon perturbation of E3 activity with a small-molecule inhibitor, short hairpin RNA, or by overexpression of an E3. Alternatively, ubiquitinated proteins are isolated from the cell; trypsin digestion generates peptides with diGly modifications at Lys residues. These branched peptides can be isolated by an anti-GG- $\varepsilon-\mathrm{K}$ antibody, and their levels monitored by mass spectrometry (MS) to correlate with changes in protein ubiquitination upon modulation of E3 activity. (C) For UBAIT, an E3-UB fusion is used to form conjugates with E3 substrates due to the in cis transfer of UB to substrates bound to E3. (D) An E3-UBA fusion was used to bind to polyubiquitinated proteins synthesized by the same E3 enzymes. (E) To generate a NEDDylator for E3 substrate identification, Ubc12, which is the E2 for the NEDD8 UBL, is 
or ubiquitination upon perturbation of E3 activity; and covalently or noncovalently trapping substrates using engineered E3 fusions (Fig. 8). Affinity-based approaches such as coimmunoprecipitation, yeast twohybrid screening, and protein microarrays have been used to directly assess E3-substrate interactions (Fig. 8A). These methods have been central to identifying E3-substrate interactions, but are naturally limited by affinities and unrecognized adaptors. Activity-based screening approaches experimentally manipulate E3 activity and correlate this with changes in the stability or ubiquitination of specific proteins. One example is a method known as global protein stability (GPS) profiling, which tracks the stability of thousands of cellular proteins fused to a fluorescence protein (Yen and Elledge, 2008; Yen et al., 2008; Emanuele et al., 2011). The use of TUBEs and anti-GG- $\varepsilon-\mathrm{K}$ antibodies, or both together, has also been employed to determine alterations in ubiquitination in response to E3 manipulation (see III. D. Engineering Ubiquitin-Binding Domains above) (Fig. 8B) (Kim et al., 2011; Xu and Jaffrey, 2011; Sarraf et al., 2013). These often highly data-intensive, proteomic approaches can be extremely powerful. Like all approaches, there are pitfalls, both physiologic and technical. One physiologic consideration is that perturbing the activity of one E3 may have downstream direct or indirect effects on the activity of other E3s (Weissman et al., 2011). Readers are referred to recent reviews on various proteomics methods (Kim et al., 2011; Harper and Tan, 2012; Ordureau et al., 2015; Beaudette et al., 2016; Iconomou and Saunders, 2016; Rayner et al., 2019). Protein engineering has added powerful tools for E3-substrate identification by engineering UB transfer enzymes with tailor-made activities to identify the cellular substrates of a specific E3.

\section{A. E3 Fusions To Identify E3 Substrates}

1. E3-Ubiquitin Fusions. UB-activated interaction traps (UBAIT) is a protein-engineering technique developed to identify substrates of specific E3s (Fig. 8C) (O'Connor et al., 2015). In UB-activated interaction traps, UB is fused to the $\mathrm{C}$ terminus of affinity-tagged E3s. After activation, the fused UB will preferentially interact with the linked E3 and be covalently attached to substrates of the E3-UB fusion. The E3-UB fusion therefore functions as a trap for substrates and can be purified through the affinity tag, followed by proteomic analysis. Using multiple E3s in both yeast and mammalian cells, proof of principle has been provided for this approach utilizing both HECT and RING E3s.
2. E3-Ubiquitin-Associated Domain Fusions. The UB ligase substrate-trapping method was developed to identify SCF E3 substrates (Fig. 8D) (Mark et al., 2014, 2016). In this method, F-box proteins, which are the substratespecific recruiting subunits of the SCF E3s, are fused to UBA domains that bind to polyUB chains of K48 and K63 linkages. When a substrate that is recruited to a specific F-box undergoes ubiquitination, the proximity of the fused UBA will result in stable association of the substrate and copurification with the F-box fusion. This method has been used to profile the substrate specificities of eight F-box proteins and identified several new SCF substrates.

3. E2-E3 Fusions. The "NEDDylator" method has been developed to redirect a UB E3 to transfer NEDD8, a UBL protein to the E3 substrates (Fig. 8E) (Zhuang et al., 2013). Because the number of NEDDylated proteins is markedly less than the number of ubiquitinated proteins in the cell, NEDDylators would considerably narrow down potential substrates of a specific E3 to those with NEDD8 modifications. The NEDDylator approach was validated by a C-terminal fusion of the NEDD8-specific E2, UbcH12, with a mutant XIAP that has been inactivated by deletion of its RING domain. The $\mathrm{N}$-terminal substrate-binding domain of XIAP in the fusion protein recognizes XIAP substrates and allows for their UbcH12-mediated NEDDylation. Using this approach, NEDDylated proteins could be affinity-purified from the cell lysates and assessed by proteomics. This technique has allowed the identification of PGAM5, a mitochondrial-localized protein phosphatase, as a validated XIAP substrate (Zhuang et al., 2013).

\section{B. Identifying E3 Substrates by a Reporter Gene or Chemical Cross-Linking}

1. Split Dihydrofolate Reductase Assays To Screen E3 Substrates in E. coli. The bacterium E. coli lacks an endogenous UB-conjugating system. This has now been taken advantage of to reconstitute highly specific E1E2-E3 cascades. Such a system can be used to isolate ubiquitination substrates in a high-throughput screening platform. This is carried out by constructing fusions of the N-terminal fragment of DHFR with UB and fusions of the C-terminal fragment of DHFR with a library of potential substrates and expressing these along with ubiquitinating enzymes (Levin-Kravets et al., 2016) (Fig. 8F). Recognition of a substrate by its cognate E3 in E. coli leads to the transfer of UB to the substrate, juxtaposing the $\mathrm{N}$ - and $\mathrm{C}$-terminal fragments of DHFR fused to UB and substrate, respectively. The reassembly of DHFR renders the cell resistant to

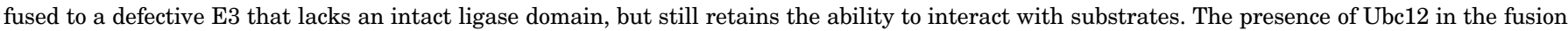

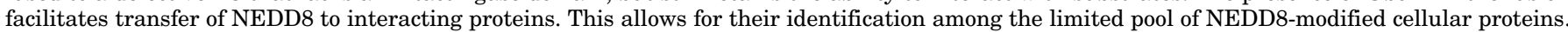

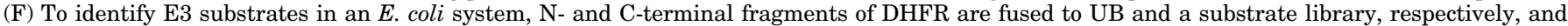

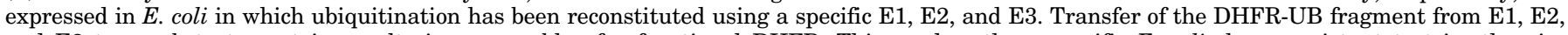

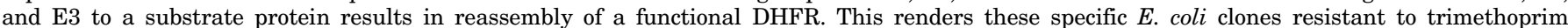

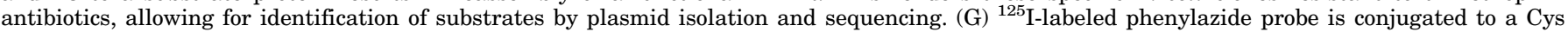

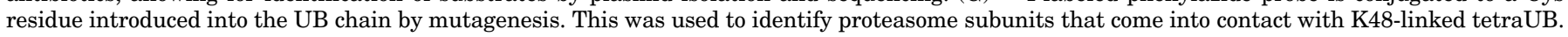


A

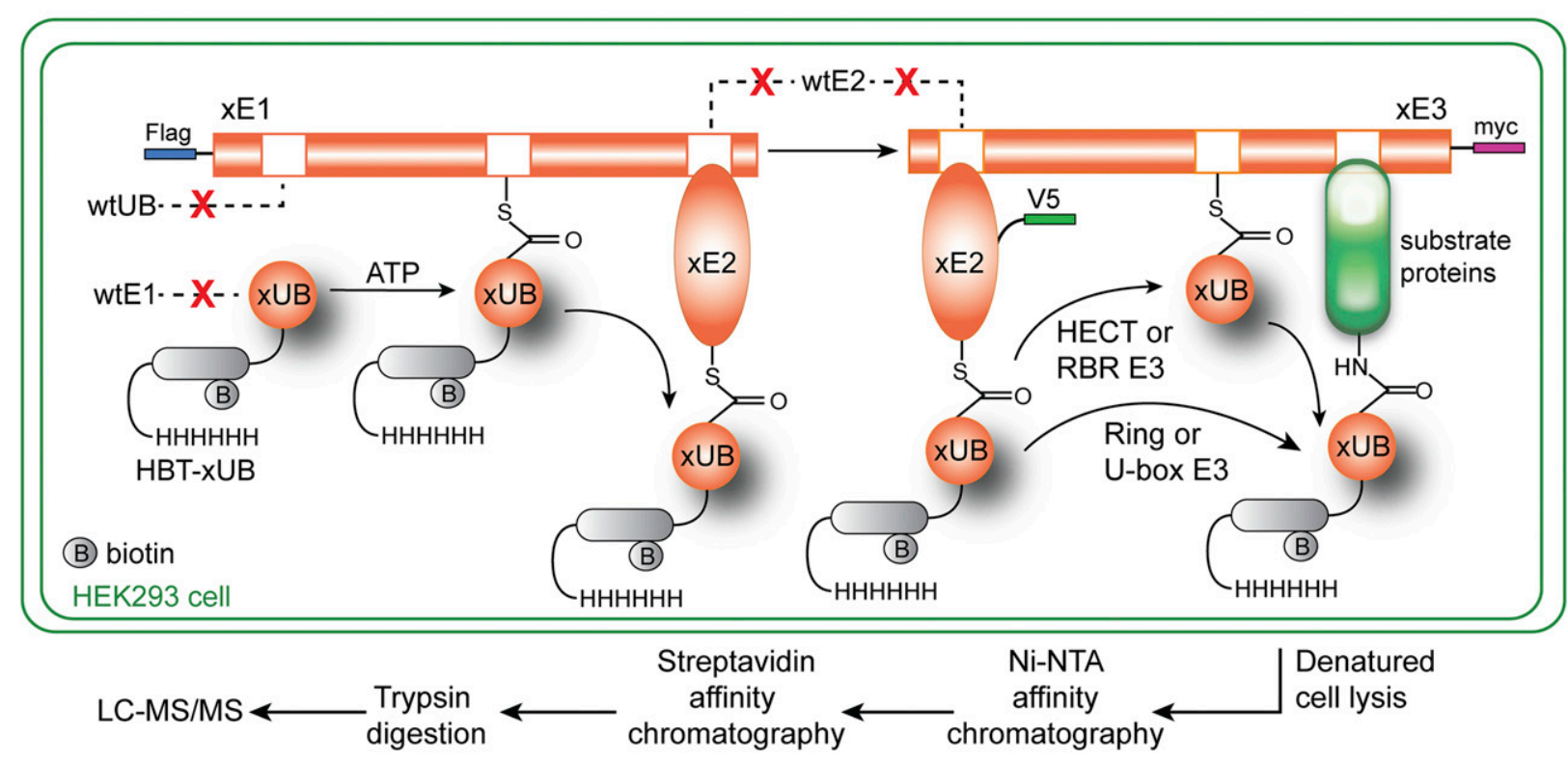

B

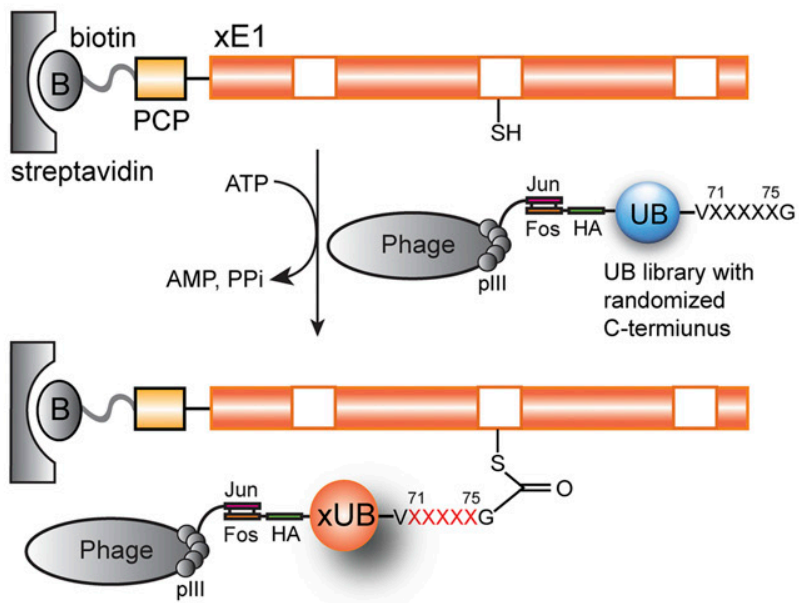

C
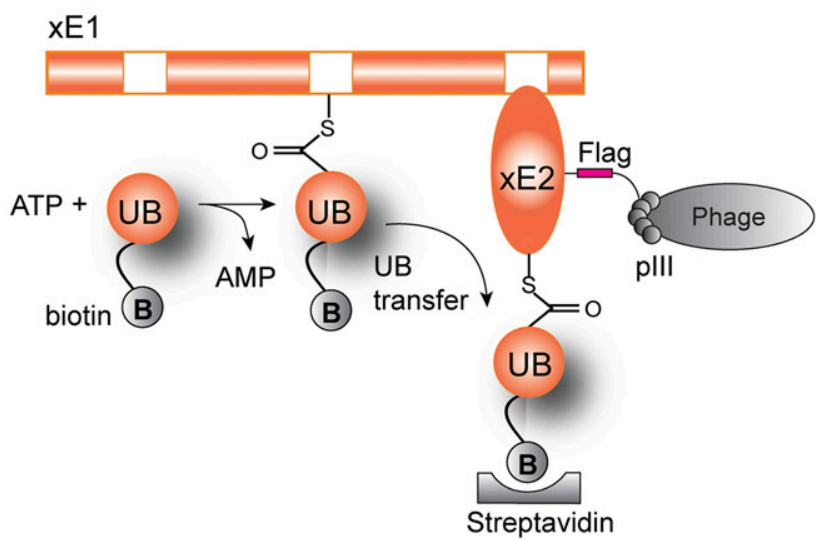

D

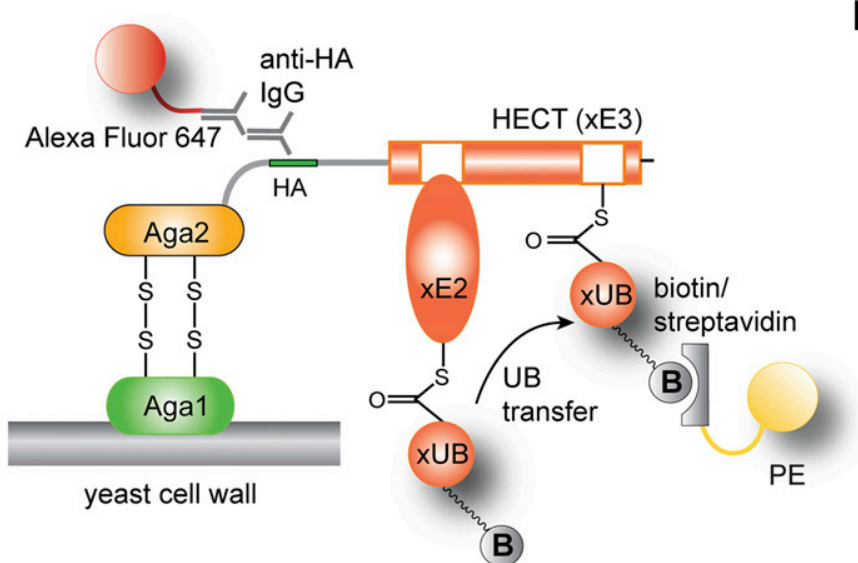

E

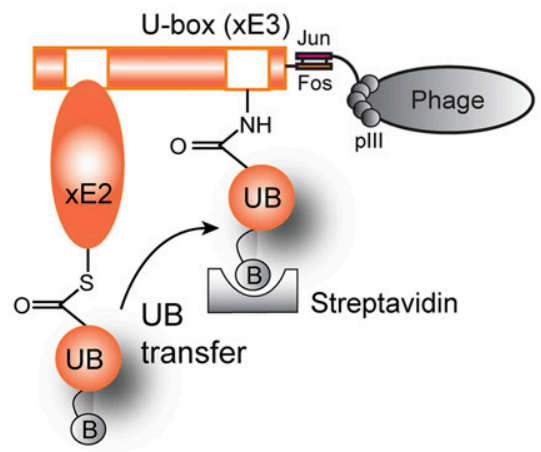

Fig. 9. OUT cascade. (A) Identifying E3 substrates by OUT. xUB is transferred through the engineered $x E 1$-xE2-xE3 cascade to the substrates of a specific E3 in the cell. xUB-conjugated proteins are purified by tandem affinity purification under denaturing conditions with the $6 \times$ His-biotin tag (HBT) fused to xUB and identified by liquid chromatography with tandem mass spectrometry (LC-MS/MS). (B) Engineering xUB-xE1 pair by phage display. xE1 with mutations in the adenylation domain was labeled with biotin and immobilized on the streptavidin plate. UB library with randomized $\mathrm{C}$ terminus was displayed on M13 phage and selected based on the formation of thioester conjugate with $\mathrm{xE} 1$ on the plate. (C) Engineering $\mathrm{xE} 1$ - $\mathrm{xE2}$ pair by phage display. E2 library with randomized N-terminal helix was displayed on the M13 phage and selected based on biotin-UB transfer from the 
trimethoprim antibiotics. As a result, clones expressing the substrates of a specific E3 can grow on agar plates supplemented with trimethoprim and be identified. Using this method, new substrates of the yeast HECT E3 Rsp5 have been identified (Levin-Kravets et al., 2016).

2. Chemical Cross-Linking. Chemical cross-linking methods represent promising approaches to identify interactions in the UB system. Early work using chemical cross-linking in the UB system assessed the interaction of tetra-UB with the 19S cap of the mammalian proteasome. In this work, a tetrameric UB chain with K48 linkage was generated by a combination of enzymatic and chemical conjugation with a P37C mutation introduced in the distal UB of the tetramer chain. Using disulfide exchange, an ${ }^{125}$ I-labeled photoreactive reducible cross-linker was added to the Cys (Fig. 8G). The mixture of proteasome and ${ }^{125}$ I tetra UB was then subject to UV cross-linking. A specifically iodinated species was characterized by twodimensional isoelectric focusing electrophoresis and peptide sequencing and identified as a 19S ATPase, Rpt5 (S6') (Lam et al., 2002). Another approach, based on chemical cross-linking, has also been employed to capture transient interactions of UB with proteasomes (Archer et al., 2008). In this case, a single UB is tagged with a short peptide that binds to a biarsenical fluorescent probe FlAsH, which is linked to biotin and a dihydroxyphenylalanine moiety. The tagged UB and proteasomes are coincubated and treated with $\mathrm{NaIO}_{4}$, which oxidizes the catechol ring of dihydroxyphenylalanine to ortho-quinone. This can then crosslink to nucleophilic residues on the proteasome. Using this method and employing yeast proteasomes, a different ATPase subunit of the proteasome was identified. It should be noted that, unlike other $19 \mathrm{~S}$ subunits, neither of the ATPase subunits identified have known UBDs.

In another study, chemical cross-linkers were introduced into a substrate by UAA incorporation to provide proof of principle to capture transient interaction between a substrate and an E2. The UAA BprY, which is a Tyr analog with an alkylbromide group attached to the phenylhydroxyl residue of Tyr, was introduced into the substrate PCNA (Yang et al., 2017) (Fig. 2D). When PCNA and the E2 were reacted in the test tube or coexpressed in E. coli, PCNA was specifically conjugated to the E2 UBE2D3/UbcH5c, but not to other proteins/peptides. This conjugation occurs through $\mathrm{S}_{\mathrm{N}} 2$ substitution of the bromo group of $\mathrm{BprY}$ by the catalytic Cys residue of $\mathrm{E} 2$.

\section{Orthogonal Ubiquitin Transfer}

1. The Concept of Orthogonal Ubiquitin Transfer. We (Yin and colleagues) have developed a method known as orthogonal UB transfer (OUT) to identify the direct substrates of E3s. In OUT, an affinity-tagged UB variant (xUB) is exclusively transferred through an engineered $\mathrm{xE} 1-\mathrm{xE} 2-\mathrm{xE} 3$ cascade to the substrates of a specific E3 (" $x$ " designates the engineered forms of the enzymes or UB) (Fig. 9A) (Zhao et al., 2012b). By expressing affinity-tagged $\mathrm{xUB}$ and the engineered $\mathrm{xE} 1-\mathrm{xE} 2-\mathrm{xE} 3$ cascade in the cell, we are able to purify xUB-modified proteins and identify them by proteomics. In this way, we can profile ubiquitination targets of a specific E3 and elucidate the associated cell signaling pathways. We have engineered OUT cascades for the HECT E3 E6AP and the U-box E3s E4B and CHIP. Using this approach, we have identified and confirmed their substrate proteins in HEK293 cells. We have established OUT as an efficient platform to identify the direct substrates of an E3. To enable OUT, we need to engineer specific $x U B-x E 1, x E 1-x E 2$, and $\mathrm{xE} 2$-xE3 pairs that have no cross-reactivities (orthogonal) with wt UB and wt E1, E2, and E3 enzymes (Fig. 9A). This will guarantee that $\mathrm{xUB}$ is confined on the single track of the OUT cascade on its way to the substrates of the $\mathrm{xE} 3$. $\mathrm{xUB}$ is expressed with the $\mathrm{xE} 1-$ $\mathrm{xE} 2-\mathrm{xE} 3$ cascade in the cell with the $\mathrm{N}$ terminus of xUB tagged with $6 \times$ His and biotin tags (HBT-xUB) (Tagwerker et al., 2006). xUB-conjugated proteins are then purified by tandem affinity chromatography by Ni-NTA and streptavidin columns. Proteins bound to the streptavidin resin are digested by trypsin, and their identities revealed by liquid chromatography with tandem mass spectrometry. xUB-conjugated proteins identified in this way are potential direct substrates of $\mathrm{xE} 3$. Because we are only changing the E2-binding site but not the substrate-binding site to generate $\mathrm{xE} 3$, it is proper to assume that the $\mathrm{xE} 3$ targets identified by the OUT screen are the substrates of wt E3.

We took a bump-and-hole approach to generate the orthogonal enzymatic pairs (Hwang and Miller, 1987; Alaimo et al., 2001). The general protocol is to introduce mutations at the binding interface of the enzymes so that the mutated enzymes would reject the binding of their native partners. We then use phage or yeast cell display to select for complementary mutations that would restore enzyme binding and enable the transfer of xUB. The mutated enzyme pair and the wt pair would have the same binding modes, but they have mutually

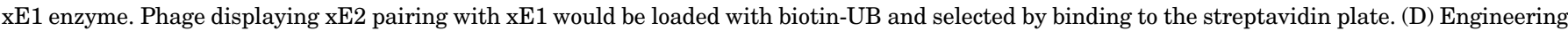

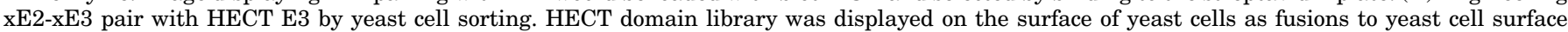

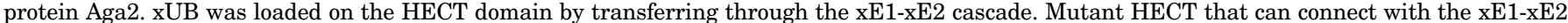

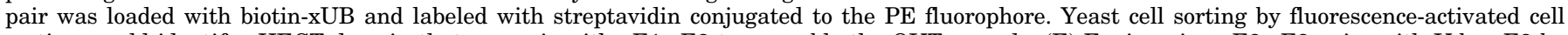

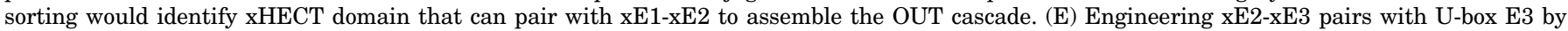

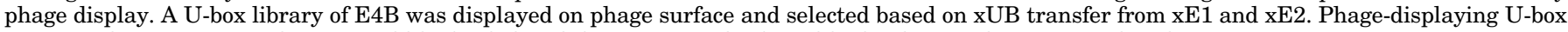
mutants that can pair with xE2 would be loaded with biotin-UB and selected by binding to the streptavidin plate.
} 
rejecting binding interfaces. As a result, the wt UB could not be transferred through the engineered OUT cascade, and xUB would not cross over to the native E1E2-E3 cascade. The advantage of such orthogonality is that 1) $\mathrm{xUB}$ is guaranteed to be transferred to the target proteins of $\mathrm{xE} 3$ in the OUT cascade for unambiguous identification of E3 substrates; 2) xUB would not compete with wt UB in the cell so the engineered system would assume minimal disturbance on various biologic processes in the cell.

2. Engineering the $x U B-x E 1$ and $x E 1-x E 2$ Pairs for the Orthogonal Ubiquitin Transfer Cascade. The first two stages of OUT are mediated by $\mathrm{xUB}-\mathrm{xE} 1$ and $\mathrm{xE} 1-$ $\mathrm{xE} 2$ pairs that deliver $\mathrm{xUB}$ to a designated $\mathrm{xE2}$ (Fig. 9A). We first generated a xUB-xE1 pair with yeast UB and yeast E1 (Uba1) (Zhao et al., 2012b). We generated xUba1 by introducing two sets of mutations to yeast $\mathrm{E} 1$, one to the adenylation domain to block binding of wt UB, and one to the UFD to block binding of wt E2s. Using phage selection, we identified xUB with mutations R42E and R72E, and $\mathrm{xUbc} 1$, the yeast $\mathrm{E} 2$, with mutations in the $\mathrm{N}$-terminal helix that allows it to interact with $\mathrm{xUba} 1$, but not the wt $\mathrm{E} 1$, and also enables xUB transfer from xUba1 to xUbc1 (Fig. 9, B and C) (Zhao et al., 2012b). To implement OUT in human cells, we transplanted mutations from yeast xUba1 and $\mathrm{xUbc} 1$ to human E1 (Uba1) and E2s (UbcH5b and

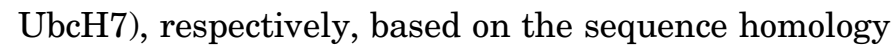
of the E1 and E2 enzymes. We expressed human xUB, xUba1, and xUbcH5b or xUbcH7 in HEK293 cells and tested their orthogonality with wt E1 and E2 enzymes. We confirmed that xUB was exclusively loaded on $\mathrm{xE} 1$ or $\mathrm{xE} 2$ enzymes and it would not cross over to the wt cascade during the transfer (Wang et al., 2017a; Bhuripanyo et al., 2018). These studies established that we could use mutant transplantation to extend the OUT cascade across species and reach different E2 enzymes.

We were also able to use mutant transplantation to build OUT cascades with two human E1 enzymes, Uba1 and Uba6, to differentiate their functions. We transplanted mutations in the adenylation domain of yeast xUba1 to human Uba1 and Uba6. The E1 mutants, $\mathrm{xUba1}(\mathrm{A})$ and $\mathrm{xUba6}(\mathrm{A})$, could exclusively activate $\mathrm{xUB}$ and transfer it to wt E2 and E3 partners and their downstream targets. We separately expressed xUBxUba1(A) or xUB-xUba6(A) pairs in the HEK293 cells and found that the two E1s have nonredundant roles in cell regulation because they had a distinct profile of UB transfer targets (Liu et al., 2017a,b). This study added the proof that the two E1s launch UB transfer through distinctive E1-E2-E3 cascades for cell signaling (Jin et al., 2007).

3. Constructing the Orthogonal Ubiquitin Transfer Cascade with HECT E3 E6AP. The R5E and K9E mutations in the $\mathrm{N}$-terminal helix of $\mathrm{xUbcH} 7$ interfered with the transfer of xUB to wt HECT E3s (Huang et al., 1999). We used yeast cell surface display to identify a mutant of E6AP HECT domain that can uptake xUB from xUbcH7 (Fig. 9D). We then incorporated the mutant HECT into full-length E6AP and confirmed that it could transfer xUB from the xUba1-xUbcH7 pair to p53 in the presence of E6. We could thus use E6AP mutant as XE6AP to generate the OUT cascade. We expressed the OUT cascade of E6AP in HEK293 and compared the profiles of xUBconjugated proteins with control cells expressing the xUba1-xUbcH7 pair without xE6AP. Three repeats of the proteomic screen revealed 144 proteins that we found to be consistently dependent on $\mathrm{xE} 6 \mathrm{AP}$ for conjugation to xUB. Among these, we confirmed that E6AP ubiquitinated mitogen-activated protein kinase 1 (MAPK1), $\beta$-catenin, cyclin-dependent kinase 1 , cyclin-dependent kinase 4, protein arginine methyltransferase 5 (PRMT5), and ubiquitin-like-domain-containing protein $8(\mathrm{UbxD} 8)$ in cells and induced their degradation. $\beta$-catenin was confirmed to be an E6AP substrate by two reports published at the same time as ours (Kuslansky et al., 2016; Yi et al., 2017).

4. Constructing the Orthogonal Ubiquitin Transfer Cascades with U-Box E3 E4B and CHIP. xUbcH5b will not pair with either wt E4B or CHIP to mediate xUB transfer due to the mutations in the $\mathrm{N}$-terminal helix of $\mathrm{xUbcH} 5 \mathrm{~b}$ that interferes with its binding to the U-box domain of the E3s (Benirschke et al., 2010). To identify U-box mutants complementary with $\mathrm{xUbcH} 5 \mathrm{~b}$, we randomized residues in loop1 of E4B U-box that interact with $\mathrm{K} 4 \mathrm{E}$ and $\mathrm{K} 8 \mathrm{E}$ mutations in $\mathrm{xUbcH} 5 \mathrm{~b}$ (Bhuripanyo et al., 2018). We used phage selection to identify catalytic active mutants of E4B U-box based on xUB transfer (Fig. 9E). One U-box mutant (R1233K, L1236I, D1238H) from the selection restores $\mathrm{xUB}$ transfer from $\mathrm{xUbcH} 5 \mathrm{~b}$. We also found the mutations from the E4B U-box can be transplanted to the CHIP U-box to activate CHIP for xUB transfer. We incorporated the mutations from phage selection into the full-length $\mathrm{E} 3 \mathrm{~s}$ to generate $\mathrm{xE} 4 \mathrm{~B}$ and xCHIP to assemble the OUT cascade. Profiling of their substrates with the OUT platform in HEK293 cells identified 185 and 225 potential substrates of E4B and CHIP, respectively. Among them we have confirmed that PRMT1, MAPK3, protein phosphatase 3 catalytic subunit $\alpha$, PGAM5, and ovarian tumor protease B1 are ubiquitinated by E4B and that PRMT1, MAPK3, protein phosphatase 3 catalytic subunit $\alpha$, and $\beta$-catenin were ubiquitinated by CHIP in HEK293 cells based on in vitro ubiquitination, E3 silencing by short hairpin RNA, and cycloheximide chase assays.

The OUT platform is not automatically adaptable to all E3s, and this is a limit to its general application. To guarantee the exclusive delivery of xUB to designated E3s and its substrates, we need to engineer an OUT cascade unique for each E3. We see potential for transplantation of mutations to expand the OUT cascade within a class of E3s. The E2-binding regions in HECT, U-box, RBR, and RING E3s are homologous 
within each class, and, as proof of principle, we have succeeded in extending the OUT cascade by transplanting mutations from the U-box domain of E4B to CHIP (Bhuripanyo et al., 2018). If transplantation is not efficacious for an E3 of interest, the phage and yeast display methods could be used to engineer individual xE2-xE3 pairs (Wang et al., 2017a; Bhuripanyo et al., 2018). Another limitation of OUT is that coexpression of HBT-xUB and the $x E 1-x E 2-x E 3$ cascade, although successful in HEK293 cells, could be a challenge to other cell types. The recently developed clustered regularly interspaced short palindromic repeats (CRISPR/Cas9) genome-editing method may provide an opportunity to introduce the OUT cascade into the native genetic background to identify E3 substrates (Cong et al., 2013).

\section{Conclusions}

In the years since the original characterization of the UB system as a means of targeting proteins for proteasomal degradation, the field has undergone explosive growth. This has been fueled by the development of proteasome inhibitors, the recognition of the various distinct classes of UB ligases and deubiquitinating enzymes, and the realization that ubiquitination can, through UB-binding domains, alter the fate and function of proteins in ways other than targeting to proteasomes. We now understand that the UB system touches on essentially all cellular processes, and its dysfunction is linked to an ever-expanding list of human diseases. It is therefore critical that we achieve an indepth mechanistic understanding of this system.

In this review, we have surveyed the rapidly increasing number of approaches to dissecting and manipulating the UB system through protein engineering. Depending on one's perspective, protein engineering can be conceived of as synthetic chemistry on the scale of protein molecules or, alternatively, synthetic biology enabled by laboratory-directed evolution in generating designer proteins. It is particularly fitting that, for a system first discovered by biochemists and initially characterized in vivo through yeast genetics, advances in our understanding would now be guided by this toolbox of approaches.

The use of powerful mutation-based protein screening and selection platforms is being complemented by genetically-expressed fusion proteins and structurebased mutations to explore sequence space, interrogate and affect interactions, and dissect and alter catalytic activities. This genetic approach is naturally integrated with advances in chemical biology, allowing for sitespecific conjugation, protein ligations, and the introduction of reactive chemical functionalities through unnatural amino acids.

The UB system is a rich source of molecular targets in disease. In the context of emerging genetic and protein delivery technologies, there is great potential for the development of UB system therapeutics, derived from protein engineering, in personalized medicine. Thus, as we look optimistically ahead and consider the trajectory of advances, it is reasonable to posit that, in the next decades, protein-based reagents will enter the clinic joining proteasome inhibitors, IMiDs, E1 inhibitors, and other UB system-based small molecules in the treatment of human disease.

\section{Acknowledgments}

We thank our creative and interactive colleagues who continue to make both protein engineering and the study of ubiquitin and ubiquitin-like modifiers stimulating areas of investigation. Because of the flourishing of research at the intersection of these areas, we could, unfortunately, only cite a sampling of the exciting work being carried out.

\section{Authorship Contributions}

Wrote or contributed to the writing of the manuscript: Zhao, Tsai, Jin, B. Wang, Y. Wang, Zhou, Carpenter, Weissman, Yin.

\section{References}

Abdul Rehman SA, Kristariyanto YA, Choi SY, Nkosi PJ, Weidlich S, Labib K, Hofmann K, and Kulathu Y(2016) MINDY-1 is a member of an evolutionarily conserved and structurally distinct new family of deubiquitinating enzymes. Mol Cell 63:146-155.

Ai HW, Lee JW, and Schultz PG(2010) A method to site-specifically introduce methyllysine into proteins in E. coli. Chem Commun (Camb) 46:5506-5508.

Alaimo PJ, Shogren-Knaak MA, and Shokat KM(2001) Chemical genetic approaches for the elucidation of signaling pathways. Curr Opin Chem Biol 5:360-367.

Archer CT, Burdine L, Liu B, Ferdous A, Johnston SA, and Kodadek T(2008) Physical and functional interactions of monoubiquitylated transactivators with the proteasome. J Biol Chem 283:21789-21798.

Arnold FH and Volkov AA(1999) Directed evolution of biocatalysts. Curr Opin Chem Biol 3:54-59.

Asatsuma-Okumura T, Ito T, and Handa H(2019) Molecular mechanisms of cereblonbased drugs. Pharmacol Ther 202:132-139.

Barbas CF III, Burton DR, Scott JK, and Silverman GJ(2000) Phage Display, a Laboratory Manual, Cold Spring Harbor Laboratory Press, New York.

Barbas CF III, Kang AS, Lerner RA, and Benkovic SJ(1991) Assembly of combinatorial antibody libraries on phage surfaces: the gene III site. Proc Natl Acad Sci USA 88:7978-7982.

Beaudette P, Popp O, and Dittmar G(2016) Proteomic techniques to probe the ubiquitin landscape. Proteomics 16:273-287.

Bedford L, Lowe J, Dick LR, Mayer RJ, and Brownell JE(2011) Ubiquitin-like protein conjugation and the ubiquitin-proteasome system as drug targets. Nat Rev Drug Discov 10:29-46.

Behrends C and Harper JW(2011) Constructing and decoding unconventional ubiquitin chains. Nat Struct Mol Biol 18:520-528.

Bence NF, Bennett EJ, and Kopito RR(2005) Application and analysis of the GFPu family of ubiquitin-proteasome system reporters. Methods Enzymol 399: 481-490.

Benirschke RC, Thompson JR, Nominé Y, Wasielewski E, Juranić N, Macura S, Hatakeyama S, Nakayama KI, Botuyan MV, and Mer G(2010) Molecular basis for the association of human E4B U box ubiquitin ligase with E2-conjugating enzymes UbcH5c and Ubc4. Structure 18:955-965.

Bhuripanyo K, Wang Y, Liu X, Zhou L, Liu R, Duong D, Zhao B, Bi Y, Zhou H, Chen G, et al.(2018) Identifying the substrate proteins of U-box E3s E4B and CHIP by orthogonal ubiquitin transfer. Sci Adv 4:e1701393.

Borodovsky A, Kessler BM, Casagrande R, Overkleeft HS, Wilkinson KD, and Ploegh HL(2001) A novel active site-directed probe specific for deubiquitylating enzymes reveals proteasome association of USP14. EMBO J 20:5187-5196.

Braxton CN, Quartner E, Pawloski W, Fushman D, and Cropp TA(2019) Ubiquitin chains bearing genetically encoded photo-cross-linkers enable efficient covalent capture of (poly)ubiquitin-binding domains. Biochemistry 58:883-886.

Bremm A and Komander D(2012) Synthesis and analysis of K11-linked ubiquitin chains. Methods Mol Biol 832:219-228.

Brown NG, VanderLinden R, Watson ER, Weissmann F, Ordureau A, Wu KP, Zhang W, Yu S, Mercredi PY, Harrison JS, et al.(2016) Dual RING E3 architectures regulate multiubiquitination and ubiquitin chain elongation by APC/C. Cell 165: 1440-1453.

Brownell JE, Sintchak MD, Gavin JM, Liao H, Bruzzese FJ, Bump NJ, Soucy TA, Milhollen MA, Yang X, Burkhardt AL, et al.(2010) Substrate-assisted inhibition of ubiquitin-like protein-activating enzymes: the NEDD8 E1 inhibitor MLN4924 forms a NEDD8-AMP mimetic in situ. Mol Cell 37:102-111.

Byrne R, Mund T, and Licchesi JDF(2017) Activity-based probes for HECT E3 ubiquitin ligases. ChemBioChem 18:1415-1427. 
Castañeda C, Liu J, Chaturvedi A, Nowicka U, Cropp TA, and Fushman D(2011) Nonenzymatic assembly of natural polyubiquitin chains of any linkage composition and isotopic labeling scheme. J Am Chem Soc 133:17855-17868.

Castañeda CA, Chaturvedi A, Camara CM, Curtis JE, Krueger S, and Fushman $\mathrm{D}(2016)$ Linkage-specific conformational ensembles of non-canonical polyubiquitin chains. Phys Chem Chem Phys 18:5771-5788.

Castañeda CA, Kashyap TR, Nakasone MA, Krueger S, and Fushman D(2013) Unique structural, dynamical, and functional properties of k11-linked polyubiquitin chains. Structure 21:1168-1181.

Chalker JM, Lercher L, Rose NR, Schofield CJ, and Davis BG(2012) Conversion of cysteine into dehydroalanine enables access to synthetic histones bearing diverse post-translational modifications. Angew Chem Int Ed Engl 51:1835-1839.

Chang LH and Strieter ER(2018) Reprogramming a deubiquitinase into a transamidase. ACS Chem Biol 13:2808-2818.

Chao G, Lau WL, Hackel BJ, Sazinsky SL, Lippow SM, and Wittrup KD(2006) Isolating and engineering human antibodies using yeast surface display. Nat Protoc 1 $755-768$.

Chen J, Ai Y, Wang J, Haracska L, and Zhuang Z(2010) Chemically ubiquitylated PCNA as a probe for eukaryotic translesion DNA synthesis. Nat Chem Biol 6 $270-272$

Chen K and Arnold FH(1993) Tuning the activity of an enzyme for unusual environments: sequential random mutagenesis of subtilisin $\mathrm{E}$ for catalysis in dimethylformamide. Proc Natl Acad Sci USA 90:5618-5622.

Chen K, Huang X, Kan SBJ, Zhang RK, and Arnold FH(2018) Enzymatic construction of highly strained carbocycles. Science 360:71-75.

Ciechanover A, Heller H, Elias S, Haas AL, and Hershko A(1980) ATP-dependent conjugation of reticulocyte proteins with the polypeptide required for protein degradation. Proc Natl Acad Sci USA 77:1365-1368.

Ciechanover A, Hod Y, and Hershko A(1978) A heat-stable polypeptide component of an ATP-dependent proteolytic system from reticulocytes. Biochem Biophys Res Commun 81:1100-1105.

Clackson T, Hoogenboom HR, Griffiths AD, and Winter G(1991) Making antibody fragments using phage display libraries. Nature 352:624-628.

Cohen MM, Amiott EA Day AR, Leboucher GP, Pryce EN, Glickman MH, McCaffery JM, Shaw JM, and Weissman AM(2011) Sequential requirements for the GTPase domain of the mitofusin Fzo1 and the ubiquitin ligase SCFMdm30 in mitochondrial outer membrane fusion. J Cell Sci 124:1403-1410.

Cohen MM, Leboucher GP, Livnat-Levanon N, Glickman MH, and Weissman $\operatorname{AM}(2008)$ Ubiquitin-proteasome-dependent degradation of a mitofusin, a critical regulator of mitochondrial fusion. Mol Biol Cell 19:2457-2464.

Colby DW, Kellogg BA, Graff CP, Yeung YA, Swers JS, and Wittrup KD(2004) Engineering antibody affinity by yeast surface display. Methods Enzymol 388: 348-358.

Cong L, Ran FA, Cox D, Lin S, Barretto R, Habib N, Hsu PD, Wu X, Jiang W, Marraffini LA, et al.(2013) Multiplex genome engineering using CRISPR/Cas systems. Science 339:819-823.

Dantuma NP, Lindsten K, Glas R, Jellne M, and Masucci MG(2000) Short-lived green fluorescent proteins for quantifying ubiquitin/proteasome-dependent proteolysis in living cells. Nat Biotechnol 18:538-543.

Daviet L and Colland F(2008) Targeting ubiquitin specific proteases for drug discovery. Biochimie 90:270-283.

Debelouchina GT, Gerecht K, and Muir TW(2017) Ubiquitin utilizes an acidic surface patch to alter chromatin structure. Nat Chem Biol 13:105-110.

de Jong A, Witting K, Kooij R, Flierman D, and Ovaa H(2017) Release of enzymatically active deubiquitinating enzymes upon reversible capture by disulfide ubiquitin reagents. Angew Chem Int Ed Engl 56:12967-12970.

Deshaies RJ and Joazeiro CA(2009) RING domain E3 ubiquitin ligases. Annu Rev Biochem 78:399-434.

Dixit VM, Green S, Sarma V, Holzman LB, Wolf FW, O’Rourke K, Ward PA, Prochownik EV, and Marks RM(1990) Tumor necrosis factor-alpha induction of nove gene products in human endothelial cells including a macrophage-specific chemotaxin. J Biol Chem 265:2973-2978.

Dou H, Buetow L, Sibbet GJ, Cameron K, and Huang DT(2012) BIRC7-E2 ubiquitin conjugate structure reveals the mechanism of ubiquitin transfer by a RING dimer. Nat Struct Mol Biol 19:876-883.

Dou H, Buetow L, Sibbet GJ, Cameron K, and Huang DT(2013) Essentiality of a nonRING element in priming donor ubiquitin for catalysis by a monomeric E3. Nat Struct Mol Biol 20:982-986.

Eddins MJ, Carlile CM, Gomez KM, Pickart CM, and Wolberger C(2006) Mms2 Ubc13 covalently bound to ubiquitin reveals the structural basis of linkage-specific polyubiquitin chain formation. Nat Struct Mol Biol 13:915-920.

Eddins MJ, Varadan R, Fushman D, Pickart CM, and Wolberger C(2007) Crystal structure and solution NMR studies of Lys48-linked tetraubiquitin at neutral $\mathrm{pH}$. $J$ Mol Biol 367:204-211.

Eger S, Castrec B, Hübscher U, Scheffner M, Rubini M, and Marx A(2011) Generation of a mono-ubiquitinated PCNA mimic by click chemistry. ChemBioChem 12: $2807-2812$

Eger S, Scheffner M, Marx A, and Rubini M(2010) Synthesis of defined ubiquitin dimers. $J$ Am Chem Soc 132:16337-16339.

Eigen M(1992) Steps Towards Life, a Perspective on Evolution, Oxford University Press, Oxford, UK

Ekkebus R, Flierman D, Geurink PP, and Ovaa H(2014) Catching a DUB in the act: novel ubiquitin-based active site directed probes. Curr Opin Chem Biol 23: $63-70$

Ekkebus R, van Kasteren SI, Kulathu Y, Scholten A, Berlin I, Geurink PP, de Jong A, Goerdayal S, Neefjes J, Heck AJ, et al.(2013) On terminal alkynes that can react with active-site cysteine nucleophiles in proteases. J Am Chem Soc 135 $2867-2870$

Eletr ZM, Huang DT, Duda DM, Schulman BA, and Kuhlman B(2005) E2 conjugating enzymes must disengage from their E1 enzymes before E3-dependent ubiquitin and ubiquitin-like transfer. Nat Struct Mol Biol 12:933-934.
El Oualid F, Merkx R, Ekkebus R, Hameed DS, Smit JJ, de Jong A, Hilkmann H, Sixma TK, and Ovaa H(2010) Chemical synthesis of ubiquitin, ubiquitin-based probes, and diubiquitin. Angew Chem Int Ed Engl 49:10149-10153.

Emanuele MJ, Elia AE, Xu Q, Thoma CR, Izhar L, Leng Y, Guo A, Chen YN, Rush J, Hsu PW, et al.(2011) Global identification of modular cullin-RING ligase substrates. Cell 147:459-474.

Ernst A, Avvakumov G, Tong J, Fan Y, Zhao Y, Alberts P, Persaud A, Walker JR, Neculai AM, Neculai D, et al.(2013) A strategy for modulation of enzymes in the ubiquitin system. Science 339:590-595.

Faesen AC, Luna-Vargas MP, Geurink PP, Clerici M, Merkx R, van Dijk WJ, Hameed DS, El Oualid F, Ovaa H, and Sixma TK(2011) The differential modulation of USP activity by internal regulatory domains, interactors and eight ubiquitin chain types. Chem Biol 18:1550-1561.

Flavell RR and Muir TW(2009) Expressed protein ligation (EPL) in the study of signal transduction, ion conduction, and chromatin biology. Acc Chem Res 42 : $107-116$.

Flierman D, van der Heden van Noort GJ, Ekkebus R, Geurink PP, Mevissen TE, Hospenthal MK, Komander D, and Ovaa H(2016) Non-hydrolyzable diubiquitin probes reveal linkage-specific reactivity of deubiquitylating enzymes mediated by S2 pockets. Cell Chem Biol 23:472-482.

Fottner M, Brunner AD, Bittl V, Horn-Ghetko D, Jussupow A, Kaila VRI, Bremm A and Lang K(2019) Site-specific ubiquitylation and SUMOylation using genetic-code expansion and sortase. Nat Chem Biol 15:276-284.

Frescas D and Pagano M(2008) Deregulated proteolysis by the F-box proteins SKP2 and beta-TrCP. tipping the scales of cancer. Nat Rev Cancer 8:438-449.

Fulcher LJ, Macartney T, Bozatzi P, Hornberger A, Rojas-Fernandez A, and Sapkota GP(2016) An affinity-directed protein missile system for targeted proteolysis. Open Biol 6:160255.

Gabrielsen M, Buetow L, Nakasone MA, Ahmed SF, Sibbet GJ, Smith BO, Zhang W, Sidhu SS, and Huang DT(2017) A general strategy for discovery of inhibitors and activators of RING and U-box E3 ligases with ubiquitin variants. Mol Cell 68: 456-470.e10.

Gao Y, Li Y, Zhang C, Zhao M, Deng C, Lan Q, Liu Z, Su N, Wang J, Xu F, et al.(2016) Enhanced purification of ubiquitinated proteins by engineered tandem hybrid ubiquitin-binding domains (ThUBDs). Mol Cell Proteomics 15:1381-1396.

George S, Aguirre JD, Spratt DE, Bi Y, Jeffery M, Shaw GS, and O’Donoghue P(2016) Generation of phospho-ubiquitin variants by orthogonal translation reveals codon skipping. FEBS Lett 590:1530-1542.

Geurink PP, van Tol BD, van Dalen D, Brundel PJ, Mevissen TE, Pruneda JN, Elliott PR, van Tilburg GB, Komander D, and Ovaa H(2016) Development of diubiquitinbased FRET probes to quantify ubiquitin linkage specificity of deubiquitinating enzymes. ChemBioChem 17:816-820.

Gilbert W(1978) Why genes in pieces? Nature 271:501.

Gilon T, Chomsky O, and Kulka RG(1998) Degradation signals for ubiquitin system proteolysis in Saccharomyces cerevisiae. EMBO J 17:2759-2766.

Gilon T, Chomsky O, and Kulka RG(2000) Degradation signals recognized by the Ubc6p-Ubc7p ubiquitin-conjugating enzyme pair. Mol Cell Biol 20:7214-7219.

Gorelik M, Manczyk N, Pavlenco A, Kurinov I, Sidhu SS, and Sicheri F(2018) A structure-based strategy for engineering selective ubiquitin variant inhibitors of Skp1-Cul1-F-box ubiquitin ligases. Structure 26:1226-1236.e3

Gorelik M, Orlicky S, Sartori MA, Tang X, Marcon E, Kurinov I, Greenblatt JF, Tyers M, Moffat J, Sicheri F, et al.(2016) Inhibition of SCF ubiquitin ligases by engineered ubiquitin variants that target the Cul1 binding site on the Skp1-F-box interface. Proc Natl Acad Sci USA 113:3527-3532.

Gorelik M and Sidhu SS(2017) Specific targeting of the deubiquitinase and E3 ligase families with engineered ubiquitin variants. Bioeng Transl Med 2:31-42.

Groff D, Chen PR, Peters FB, and Schultz PG(2010) A genetically encoded epsilon-Nmethyl lysine in mammalian cells. ChemBioChem 11:1066-1068.

Haj-Yahya N, Haj-Yahya M, Castañeda CA, Spasser L, Hemantha HP, Jbara M, Penner M, Ciechanover A, Fushman D, and Brik A(2013) Modifying the vicinity of the isopeptide bond to reveal differential behavior of ubiquitin chains with interacting proteins: organic chemistry applied to synthetic proteins. Angew Chem Int Ed Engl 52:11149-11153.

Haj-Yahya N, Hemantha HP, Meledin R, Bondalapati S, Seenaiah M, and Brik A(2014) Dehydroalanine-based diubiquitin activity probes. Org Lett 16:540-543.

Hammer SC, Kubik G, Watkins E, Huang S, Minges H, and Arnold FH(2017) AntiMarkovnikov alkene oxidation by metal-oxo-mediated enzyme catalysis. Science 358:215-218.

Hann ZS, Ji C, Olsen SK, Lu X, Lux MC, Tan DS, and Lima CD(2019) Structural basis for adenylation and thioester bond formation in the ubiquitin E1. Proc Nat Acad Sci USA 116:15475-15484.

Harper JW and Tan MK(2012) Understanding cullin-RING E3 biology through proteomics-based substrate identification. Mol Cell Proteomics 11:1541-1550.

Hatakeyama S and Nakayama KI(2003) U-box proteins as a new family of ubiquitin ligases. Biochem Biophys Res Commun 302:635-645.

Hayes JD and McMahon M(2009) NRF2 and KEAP1 mutations: permanent activation of an adaptive response in cancer. Trends Biochem Sci 34:176-188.

Hemantha HP, Bavikar SN, Herman-Bachinsky Y, Haj-Yahya N, Bondalapati S, Ciechanover A, and Brik A(2014) Nonenzymatic polyubiquitination of expressed proteins. J Am Chem Soc 136:2665-2673.

Hemelaar J, Galardy PJ, Borodovsky A, Kessler BM, Ploegh HL, and Ovaa H(2004) Chemistry-based functional proteomics: mechanism-based activity-profiling tools for ubiquitin and ubiquitin-like specific proteases. J Proteome Res 3:268-276.

Hermann GJ, Thatcher JW, Mills JP, Hales KG, Fuller MT, Nunnari J, and Shaw $\mathrm{JM}(1998)$ Mitochondrial fusion in yeast requires the transmembrane GTPase Fzo1p. J Cell Biol 143:359-373.

Hershko A and Ciechanover A(1998) The ubiquitin system. Annu Rev Biochem 67: $425-479$

Hershko A, Ciechanover A, and Rose IA(1979) Resolution of the ATP-dependent proteolytic system from reticulocytes: a component that interacts with ATP. Proc Natl Acad Sci USA 76:3107-3110. 
Hewings DS, Flygare JA, Bogyo M, and Wertz IE(2017) Activity-based probes for the ubiquitin conjugation-deconjugation machinery: new chemistries, new tools, and new insights. FEBS $J$ 284:1555-1576.

Hjerpe R, Aillet F, Lopitz-Otsoa F, Lang V, England P, and Rodriguez MS(2009) Efficient protection and isolation of ubiquitylated proteins using tandem ubiquitinbinding entities. EMBO Rep 10:1250-1258.

Hochstrasser M(2006) Lingering mysteries of ubiquitin-chain assembly. Cell 124: $27-34$.

Hoeller D and Dikic I(2009) Targeting the ubiquitin system in cancer therapy. Nature 458:438-444.

Hofmann RM and Pickart CM(2001) In vitro assembly and recognition of Lys-63 polyubiquitin chains. J Biol Chem 276:27936-27943.

Hoppmann C, Wong A, Yang B, Li S, Hunter T, Shokat KM, and Wang L(2017) Sitespecific incorporation of phosphotyrosine using an expanded genetic code. Nat Chem Biol 13:842-844.

Huang DT, Miller DW, Mathew R, Cassell R, Holton JM, Roussel MF, and Schulman $\mathrm{BA}(2004)$ A unique E1-E2 interaction required for optimal conjugation of the ubiquitin-like protein NEDD8. Nat Struct Mol Biol 11:927-935.

Huang L, Kinnucan E, Wang G, Beaudenon S, Howley PM, Huibregtse JM, and Pavletich NP(1999) Structure of an E6AP-UbcH7 complex: insights into ubiquitination by the E2-E3 enzyme cascade. Science 286:1321-1326.

Husnjak K and Dikic I(2012) Ubiquitin-binding proteins: decoders of ubiquitinmediated cellular functions. Annu Rev Biochem 81:291-322.

Husnjak K, Elsasser S, Zhang N, Chen X, Randles L, Shi Y, Hofmann K, Walters KJ, Finley D, and Dikic I(2008) Proteasome subunit Rpn13 is a novel ubiquitin receptor. Nature 453:481-488.

Hwang YW and Miller DL(1987) A mutation that alters the nucleotide specificity of elongation factor Tu, a GTP regulatory protein. J Biol Chem 262:13081-13085.

Hyer ML, Milhollen MA, Ciavarri J, Fleming P, Traore T, Sappal D, Huck J, Shi J, Gavin J, Brownell J, et al.(2018) A small-molecule inhibitor of the ubiquitin activating enzyme for cancer treatment. Nat Med 24:186-193.

Iconomou M and Saunders DN(2016) Systematic approaches to identify E3 ligase substrates. Biochem J 473:4083-4101.

Islam K, Chen Y, Wu H, Bothwell IR, Blum GJ, Zeng H, Dong A, Zheng W, Min J, Deng H, et al.(2013) Defining efficient enzyme-cofactor pairs for bioorthogonal profiling of protein methylation. Proc Natl Acad Sci USA 110:16778-16783.

Ivan M, Kondo K, Yang H, Kim W, Valiando J, Ohh M, Salic A, Asara JM, Lane WS, and Kaelin WG Jr.(2001) HIFalpha targeted for VHL-mediated destruction by proline hydroxylation: implications for O2 sensing. Science 292:464-468.

Jaakkola P, Mole DR, Tian YM, Wilson MI, Gielbert J, Gaskell SJ, von Kriegsheim A, Hebestreit HF, Mukherji M, Schofield CJ, et al.(2001) Targeting of HIF-alpha to the von Hippel-Lindau ubiquitylation complex by O2-regulated prolyl hydroxylation. Science 292:468-472.

Jin B, Wang J, Liu X, Fang S, Jiang B, Hofmann K, Yin J, and Zhao B(2018) Ubiquitin-mimicking peptides transfer differentiates by E1 and E2 enzymes. BioMed Res Int 2018:6062520.

Jin J, Li X, Gygi SP, and Harper JW(2007) Dual E1 activation systems for ubiquitin differentially regulate E2 enzyme charging. Nature 447:1135-1138.

Johnsson N and Varshavsky A(1994) Split ubiquitin as a sensor of protein interactions in vivo. Proc Natl Acad Sci USA 91:10340-10344.

Jonnalagadda S, Ecker DJ, Sternberg EJ, Butt TR, and Crooke ST(1988) Ubiquitin carboxyl-terminal peptides: substrates for ubiquitin activating enzyme. $J$ Biol Chem 263:5016-5019.

Kamadurai HB, Qiu Y, Deng A, Harrison JS, Macdonald C, Actis M, Rodrigues P, Miller DJ, Souphron J, Lewis SM, et al.(2013) Mechanism of ubiquitin ligation and lysine prioritization by a HECT E3. eLife 2:e00828.

Kamadurai HB, Souphron J, Scott DC, Duda DM, Miller DJ, Stringer D, Piper RC, and Schulman BA(2009) Insights into ubiquitin transfer cascades from a structure of a UbcH5B approximately ubiquitin-HECT(NEDD4L) complex. Mol Cell $\mathbf{3 6}$ 1095-1102.

Kan SB, Lewis RD, Chen K, and Arnold FH(2016) Directed evolution of cytochrome c for carbon-silicon bond formation: bringing silicon to life. Science 354:1048-1051.

Kan SBJ, Huang X, Gumulya Y, Chen K, and Arnold FH(2017) Genetically programmed chiral organoborane synthesis. Nature 552:132-136.

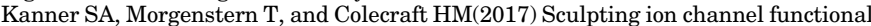
expression with engineered ubiquitin ligases. eLife 6:e29744

Kay BK, Winter J, and McCafferty J(1996) Phage Display of Peptides and Proteins, Academic Press, Boston.

Kim W, Bennett EJ, Huttlin EL, Guo A, Li J, Possemato A, Sowa ME, Rad R, Rush J, Comb MJ, et al.(2011) Systematic and quantitative assessment of the ubiquitinmodified proteome. Mol Cell 44:325-340.

Kobashigawa Y, Tomitaka A, Kumeta H, Noda NN, Yamaguchi M, and Inagaki $\mathrm{F}$ (2011) Autoinhibition and phosphorylation-induced activation mechanisms of human cancer and autoimmune disease-related E3 protein Cbl-b. Proc Natl Acad Sci USA 108:20579-20584.

Koduri V, McBrayer SK, Liberzon E, Wang AC, Briggs KJ, Cho H, and Kaelin WG Jr.(2019) Peptidic degron for IMiD-induced degradation of heterologous proteins Proc Natl Acad Sci USA 116:2539-2544.

Kolb HC, Finn MG, and Sharpless KB(2001) Click chemistry: diverse chemical function from a few good reactions. Angew Chem Int Ed Engl 40:2004-2021.

Komander D, Clague MJ, and Urbé S(2009) Breaking the chains: structure and function of the deubiquitinases. Nat Rev Mol Cell Biol 10:550-563.

Komander D and Rape M(2012) The ubiquitin code. Annu Rev Biochem 81:203-229.

Krönke J, Udeshi ND, Narla A, Grauman P, Hurst SN, McConkey M, Svinkina T, Heckl D, Comer E, Li X, et al.(2014) Lenalidomide causes selective degradation of IKZF1 and IKZF3 in multiple myeloma cells. Science 343:301-305.

Kumar KS, Bavikar SN, Spasser L, Moyal T, Ohayon S, and Brik A(2011) Total chemical synthesis of a 304 amino acid K48-linked tetraubiquitin protein. Angew Chem Int Ed Engl 50:6137-6141.

Kumar KS, Spasser L, Erlich LA, Bavikar SN, and Brik A(2010) Total chemical synthesis of di-ubiquitin chains. Angew Chem Int Ed Engl 49:9126-9131.
Kuo CL, Oyler GA, and Shoemaker CB(2011) Accelerated neuronal cell recovery from Botulinum neurotoxin intoxication by targeted ubiquitination. PLoS One 6:e20352. Kuslansky Y, Sominsky S, Jackman A, Gamell C, Monahan BJ, Haupt Y, RosinArbesfeld R, and Sherman L(2016) Ubiquitin ligase E6AP mediates nonproteolytic polyubiquitylation of $\beta$-catenin independent of the $\mathrm{E} 6$ oncoprotein. J Gen Virol 97: $3313-3330$

Lai AC and Crews CM(2017) Induced protein degradation: an emerging drug discovery paradigm. Nat Rev Drug Discov 16:101-114.

Lam YA, Lawson TG, Velayutham M, Zweier JL, and Pickart CM(2002) A proteasomal ATPase subunit recognizes the polyubiquitin degradation signal. Nature 416:763-767.

Lang K and Chin JW(2014) Cellular incorporation of unnatural amino acids and bioorthogonal labeling of proteins. Chem Rev 114:4764-4806.

Laser H, Bongards C, Schüller J, Heck S, Johnsson N, and Lehming N(2000) A new screen for protein interactions reveals that the Saccharomyces cerevisiae high mobility group proteins Nhp6A/B are involved in the regulation of the GAL1 promoter. Proc Natl Acad Sci USA 97:13732-13737.

Layfield R, Tooth D, Landon M, Dawson S, Mayer J, and Alban A(2001) Purification of poly-ubiquitinated proteins by S5a-affinity chromatography. Proteomics 1: $773-777$.

Lechtenberg BC, Rajput A, Sanishvili R, Dobaczewska MK, Ware CF, Mace PD and Riedl SJ(2016) Structure of a HOIP/E2 ubiquitin complex reveals RBR E3 ligase mechanism and regulation. Nature 529:546-550.

Lee I and Schindelin H(2008) Structural insights into E1-catalyzed ubiquitin activation and transfer to conjugating enzymes. Cell 134:268-278.

Lee S, Oh S, Yang A, Kim J, Söll D, Lee D, and Park HS(2013) A facile strategy for selective incorporation of phosphoserine into histones. Angew Chem Int Ed Engl 52:5771-5775.

Lee WH, Wang PY, Lin YH, Chou HY, Lee YH, Lee CK, and Pai LM(2014) Effects of RING-SH2Grb ${ }^{2}$, a chimeric protein containing the E3 ligase domain of $\mathrm{Cbl}$, on the EGFR pathway. Chin J Physiol 57:350-357.

Leto DE, Morgens DW, Zhang L, Walczak CP, Elias JE, Bassik MC, and Kopito RR(2019) Genome-wide CRISPR analysis identifies substrate-specific conjugation modules in ER-associated degradation. Mol Cell 73:377-389.e11.

Leung I, Dekel A, Shifman JM, and Sidhu SS(2016) Saturation scanning of ubiquitin variants reveals a common hot spot for binding to USP2 and USP21. Proc Nat Acad Sci USA 113:8705-8710.

Levin-Kravets O, Tanner N, Shohat N, Attali I, Keren-Kaplan T, Shusterman A Artzi S, Varvak A, Reshef Y, Shi X, et al.(2016) A bacterial genetic selection system for ubiquitylation cascade discovery. Nat Methods 13:945-952.

Li G, Liang Q, Gong P, Tencer AH, and Zhuang Z(2014) Activity-based diubiquitin probes for elucidating the linkage specificity of deubiquitinating enzymes. Chem Commun (Camb) 50:216-218.

Li X, Fekner T, Ottesen JJ, and Chan MK(2009) A pyrrolysine analogue for sitespecific protein ubiquitination. Angew Chem Int Ed Engl 48:9184-9187.

Li X, Shen L, Zhang J, Su J, Shen L, Liu X, Han H, Han W, and Yao L(2007) Degradation of HER2 by Cbl-based chimeric ubiquitin ligases. Cancer Res 67: $8716-8724$

Liang J, Zhang L, Tan XL, Qi YK, Feng S, Deng H, Yan Y, Zheng JS, Liu L, and Tian CL(2017) Chemical synthesis of diubiquitin-based photoaffinity probes for selectively profiling ubiquitin-binding proteins. Angew Chem Int Ed Engl 56 $2744-2748$

Lipkowitz S and Weissman AM(2011) RINGs of good and evil: RING finger ubiquitin ligases at the crossroads of tumour suppression and oncogenesis. Nat Rev Cancer 11:629-643.

Liu CC and Schultz PG(2010) Adding new chemistries to the genetic code. Annu Rev Biochem 79:413-444.

Liu X, Sun L, Gursel DB, Cheng C, Huang S, Rademaker AW, Khan SA, Yin J, and Kiyokawa $\mathrm{H}(2017 \mathrm{a})$ The non-canonical ubiquitin activating enzyme UBA6 suppresses epithelial-mesenchymal transition of mammary epithelial cells. Oncotarget 8:87480-87493.

Liu X, Zhao B, Sun L, Bhuripanyo K, Wang Y, Bi Y, Davuluri RV, Duong DM, Nanavati D, Yin J, et al.(2017b) Orthogonal ubiquitin transfer identifies ubiquitination substrates under differential control by the two ubiquitin activating enzymes. Nat Commun 8:14286.

Lorick KL, Jensen JP, Fang S, Ong AM, Hatakeyama S, and Weissman AM(1999) RING fingers mediate ubiquitin-conjugating enzyme (E2)-dependent ubiquitination. Proc Natl Acad Sci USA 96:11364-11369.

Love KR, Pandya RK, Spooner E, and Ploegh HL(2009) Ubiquitin C-terminal electrophiles are activity-based probes for identification and mechanistic study of ubiquitin conjugating machinery. ACS Chem Biol 4:275-287.

Lu G, Middleton RE, Sun H, Naniong M, Ott CJ, Mitsiades CS, Wong KK, Bradner JE, and Kaelin WG Jr.(2014) The myeloma drug lenalidomide promotes the cereblon-dependent destruction of Ikaros proteins. Science 343:305-309.

Lu J, Qian Y, Altieri M, Dong H, Wang J, Raina K, Hines J, Winkler JD, Crew AP, Coleman K, et al.(2015) Hijacking the E3 ubiquitin ligase cereblon to efficiently target BRD4. Chem Biol 22:755-763.

Lu X, Olsen SK, Capili AD, Cisar JS, Lima CD, and Tan DS(2010) Designed semisynthetic protein inhibitors of Ub/Ubl E1 activating enzymes. J Am Chem Soc 132 1748-1749.

Luo X, Fu G, Wang RE, Zhu X, Zambaldo C, Liu R, Liu T, Lyu X, Du J, Xuan W, et al.(2017) Genetically encoding phosphotyrosine and its nonhydrolyzable analog in bacteria. Nat Chem Biol 13:845-849.

MacDonald C, Winistorfer S, Pope RM, Wright ME, and Piper RC(2017) Enzyme reversal to explore the function of yeast E3 ubiquitin-ligases. Traffic 18:465-484. Madden MM, Song W, Martell PG, Ren Y, Feng J, and Lin Q(2008) Substrate properties of ubiquitin carboxyl-terminally derived peptide probes for protein ubiquitination. Biochemistry 47:3636-3644.

Madrzak J, Fiedler M, Johnson CM, Ewan R, Knebel A, Bienz M, and Chin JW(2015) Ubiquitination of the Dishevelled DIX domain blocks its head-to-tail polymerization. Nat Commun 6:6718. 
Mark KG, Loveless TB, and Toczyski DP(2016) Isolation of ubiquitinated substrates by tandem affinity purification of E3 ligase-polyubiquitin-binding domain fusions (ligase traps). Nat Protoc 11:291-301.

Mark KG, Simonetta M, Maiolica A, Seller CA, and Toczyski DP(2014) Ubiquitin ligase trapping identifies an SCF(Saf1) pathway targeting unprocessed vacuolar/ lysosomal proteins. Mol Cell 53:148-161.

Maspero E, Mari S, Valentini E, Musacchio A, Fish A, Pasqualato S, and Polo S(2011) Structure of the HECT:ubiquitin complex and its role in ubiquitin chain elongation. EMBO Rep 12:342-349.

Maspero E, Valentini E, Mari S, Cecatiello V, Soffientini P, Pasqualato S, and Polo S(2013) Structure of a ubiquitin-loaded HECT ligase reveals the molecular basis for catalytic priming. Nat Struct Mol Biol 20:696-701.

Matsumoto ML, Dong KC, Yu C, Phu L, Gao X, Hannoush RN, Hymowitz SG, Kirkpatrick DS, Dixit VM, and Kelley RF(2012) Engineering and structural characterization of a linear polyubiquitin-specific antibody. J Mol Biol 418: 134-144.

Matsumoto ML, Wickliffe KE, Dong KC, Yu C, Bosanac I, Bustos D, Phu L, Kirkpatrick DS, Hymowitz SG, Rape M, et al.(2010) K11-linked polyubiquitination in cell cycle control revealed by a K11 linkage-specific antibody. Mol Cell 39:477-484.

Mattern M, Sutherland J, Kadimisetty K, Barrio R, and Rodriguez MS(2019) Using ubiquitin binders to decipher the ubiquitin code. Trends Biochem Sci 44:599-615.

Maxwell PH, Wiesener MS, Chang GW, Clifford SC, Vaux EC, Cockman ME, Wykoff CC, Pugh CW, Maher ER, and Ratcliffe PJ(1999) The tumour suppressor protein VHL targets hypoxia-inducible factors for oxygen-dependent proteolysis. Nature 399:271-275.

Mayor T and Deshaies RJ(2005) Two-step affinity purification of multiubiquitylated proteins from Saccharomyces cerevisiae. Methods Enzymol 399:385-392.

McCafferty J, Griffiths AD, Winter G, and Chiswell DJ(1990) Phage antibodies: filamentous phage displaying antibody variable domains. Nature 348:552-554

McGouran JF, Gaertner SR, Altun M, Kramer HB, and Kessler BM(2013) Deubiquitinating enzyme specificity for ubiquitin chain topology profiled by di-ubiquitin activity probes. Chem Biol 20:1447-1455.

Meledin R, Mali SM, Kleifeld O, and Brik A(2018) Activity-based probes developed by applying a sequential dehydroalanine formation strategy to expressed proteins reveal a potential $\alpha$-globin-modulating deubiquitinase. Angew Chem Int Ed Engl 57:5645-5649.

Merchant AM, Zhu Z, Yuan JQ, Goddard A, Adams CW, Presta LG, and Carter $\mathrm{P}(1998)$ An efficient route to human bispecific IgG. Nat Biotechnol 16:677-681.

Metzger MB, Maurer MJ, Dancy BM, and Michaelis S(2008) Degradation of a cytosolic protein requires endoplasmic reticulum-associated degradation machinery. J Biol Chem 283:32302-32316.

Metzger MB, Pruneda JN, Klevit RE, and Weissman AM(2014) RING-type E3 ligases: master manipulators of E2 ubiquitin-conjugating enzymes and ubiquitination. Biochim Biophys Acta 1843:47-60.

Mevissen TET and Komander D(2017) Mechanisms of deubiquitinase specificity and regulation. Annu Rev Biochem 86:159-192.

Middleton AJ, Budhidarmo R, and Day CL(2014) Use of E2 ubiquitin conjugates for the characterization of ubiquitin transfer by RING E3 ligases such as the inhibitor of apoptosis proteins. Methods Enzymol 545:243-263.

Mulder MP, El Oualid F, ter Beek J, and Ovaa H(2014) A native chemical ligation handle that enables the synthesis of advanced activity-based probes: diubiquitin as a case study. ChemBioChem 15:946-949.

Mulder MP, Witting K, Berlin I, Pruneda JN, Wu KP, Chang JG, Merkx R, Bialas J, Groettrup M, Vertegaal AC, et al.(2016) A cascading activity-based probe sequentially targets E1-E2-E3 ubiquitin enzymes. Nat Chem Biol 12:523-530.

Müller J and Johnsson N(2008) Split-ubiquitin and the split-protein sensors: chessman for the endgame. ChemBioChem 9:2029-2038.

Nakayama KI and Nakayama K(2006) Ubiquitin ligases: cell-cycle control and cancer. Nat Rev Cancer 6:369-381.

Neumann H, Peak-Chew SY, and Chin JW(2008) Genetically encoding N(epsilon)acetyllysine in recombinant proteins. Nat Chem Biol 4.232-234.

Neumann H, Wang K, Davis L, Garcia-Alai M, and Chin JW(2010) Encoding multiple unnatural amino acids via evolution of a quadruplet-decoding ribosome. Nature 464:441-444

Newton K, Matsumoto ML, Wertz IE, Kirkpatrick DS, Lill JR, Tan J, Dugger D, Gordon N, Sidhu SS, Fellouse FA, et al.(2008) Ubiquitin chain editing revealed by polyubiquitin linkage-specific antibodies. Cell 134:668-678.

Nguyen DP, Garcia Alai MM, Kapadnis PB, Neumann H, and Chin JW(2009) Genetically encoding N(epsilon)-methyl-L-lysine in recombinant histones. J Am Chem Soc 131:14194-14195.

Nguyen DP, Garcia Alai MM, Virdee S, and Chin JW(2010) Genetically directing $\varepsilon-\mathrm{N}$, N-dimethyl-L-lysine in recombinant histones. Chem Biol 17:1072-1076.

Nicholson B, Kumar S, Agarwal S, Eddins MJ, Marblestone JG, Wu J, Kodrasov MP, LaRocque JP, Sterner DE, and Mattern MR(2014) Discovery of therapeutic deubiquitylase effector molecules: current perspectives. J Biomol Screen 19:989-999.

Nijman SM, Luna-Vargas MP, Velds A, Brummelkamp TR, Dirac AM, Sixma TK, and Bernards R(2005) A genomic and functional inventory of deubiquitinating enzymes. Cell 123:773-786.

O'Connor HF, Lyon N, Leung.JW, Agarwal P, Swaim CD, Miller KM, and Huibregtse $\mathrm{JM}(2015)$ Ubiquitin-activated interaction traps (UBAITs) identify E3 ligase binding partners. EMBO Rep 16:1699-1712.

Olsen SK, Capili AD, Lu X, Tan DS, and Lima CD(2010) Active site remodelling accompanies thioester bond formation in the SUMO E1. Nature 463:906-912.

Olsen SK and Lima CD(2013) Structure of a ubiquitin E1-E2 complex: insights to E1E2 thioester transfer. Mol Cell 49:884-896.

Ordureau A, Heo JM, Duda DM, Paulo JA, Olszewski JL, Yanishevski D, Rinehart J, Schulman BA, and Harper JW(2015) Defining roles of PARKIN and ubiquitin phosphorylation by PINK1 in mitochondrial quality control using a ubiquitin replacement strategy. Proc Natl Acad Sci USA 112:6637-6642.

Ordureau A, Paulo JA, Zhang W, Ahfeldt T, Zhang J, Cohn EF, Hou Z, Heo JM, Rubin LL, Sidhu SS, et al.(2018) Dynamics of PARKIN-dependent mitochondrial ubiquitylation in induced neurons and model systems revealed by digital snapshot proteomics. Mol Cell 70:211-227.e8.

Ovaa H, Kessler BM, Rolén U, Galardy PJ, Ploegh HL, and Masucci MG(2004) Activity-based ubiquitin-specific protease (USP) profiling of virus-infected and malignant human cells. Proc Natl Acad Sci USA 101:2253-2258.

Pao KC, Stanley M, Han C, Lai YC, Murphy P, Balk K, Wood NT, Corti O, Corvol JC, Muqit MM, et al.(2016) Probes of ubiquitin E3 ligases enable systematic dissection of parkin activation. Nat Chem Biol 12:324-331.

Pao KC, Wood NT, Knebel A, Rafie K, Stanley M, Mabbitt PD, Sundaramoorthy R, Hofmann K, van Aalten DMF, and Virdee S(2018) Activity-based E3 ligase profiling uncovers an E3 ligase with esterification activity. Nature 556:381-385.

Park HS, Hohn MJ, Umehara T, Guo LT, Osborne EM, Benner J, Noren CJ, Rinehart J, and Söll D(2011) Expanding the genetic code of Escherichia coli with phosphoserine. Science 333:1151-1154.

Park S, Foote PK, Krist DT, Rice SE, and Statsyuk AV(2017) UbMES and UbFluor: novel probes for ring-between-ring (RBR) E3 ubiquitin ligase PARKIN. J Biol Chem 292:16539-16553.

Parmley SF and Smith GP(1988) Antibody-selectable filamentous fd phage vectors: affinity purification of target genes. Gene 73:305-318.

Paudel P, Zhang Q, Leung C, Greenberg HC, Guo Y, Chern YH, Dong A, Li Y, Vedadi M, Zhuang Z, et al.(2019) Crystal structure and activity-based labeling reveal the mechanisms for linkage-specific substrate recognition by deubiquitinase USP9X. Proc Natl Acad Sci USA 116:7288-7297.

Pettersson M and Crews CM(2019) PROteolysis TArgeting Chimeras (PROTACs) Past, present and future. Drug Discov Today Technol 31:15-27.

Pickart CM(2001) Mechanisms underlying ubiquitination. Annu Rev Biochem 70 503-533.

Pickart CM and Raasi S(2005) Controlled synthesis of polyubiquitin chains. Methods Enzymol 399:21-36.

Piotrowski J, Beal R, Hoffman L, Wilkinson KD, Cohen RE, and Pickart CM(1997) Inhibition of the $26 \mathrm{~S}$ proteasome by polyubiquitin chains synthesized to have defined lengths. J Biol Chem 272:23712-23721.

Pratt MR, Schwartz EC, and Muir TW(2007) Small-molecule-mediated rescue of protein function by an inducible proteolytic shunt. Proc Natl Acad Sci USA 104: $11209-11214$

Pruneda JN, Littlefield PJ, Soss SE, Nordquist KA, Chazin WJ, Brzovic PS, and Klevit $\mathrm{RE}(2012)$ Structure of an E3:E2 Ub complex reveals an allosteric mechanism shared among RING/U-box ligases. Mol Cell 47:933-942.

Pruneda JN, Stoll KE, Bolton LJ, Brzovic PS, and Klevit RE(2011) Ubiquitin in motion: structural studies of the ubiquitin-conjugating enzyme $\sim$ ubiquitin conjugate. Biochemistry 50:1624-1633

Raasi S and Pickart CM(2005) Ubiquitin chain synthesis. Methods Mol Biol 301: $47-55$.

Rapaport D, Brunner M, Neupert W, and Westermann B(1998) Fzo1p is a mitochondrial outer membrane protein essential for the biogenesis of functional mitochondria in Saccharomyces cerevisiae. J Biol Chem 273:20150-20155.

Ravid T, Kreft SG, and Hochstrasser M(2006) Membrane and soluble substrates of the Doa10 ubiquitin ligase are degraded by distinct pathways. EMBO $J \mathbf{2 5}$ : 533-543.

Rayner SL, Morsch M, Molloy MP, Shi B, Chung R, and Lee A(2019) Using proteomics to identify ubiquitin ligase-substrate pairs: how novel methods may unvei therapeutic targets for neurodegenerative diseases. Cell Mol Life Sci $\mathbf{7 6}$ : 2499-2510.

Reyes-Turcu FE, Ventii KH, and Wilkinson KD(2009) Regulation and cellular roles of ubiquitin-specific deubiquitinating enzymes. Annu Rev Biochem 78:363-397.

Rösner D, Schneider T, Schneider D, Scheffner M, and Marx A(2015) Click chemistry for targeted protein ubiquitylation and ubiquitin chain formation. Nat Protoc 10: $1594-1611$

Rotin D and Kumar S(2009) Physiological functions of the HECT family of ubiquitin ligases. Nat Rev Mol Cell Biol 10:398-409.

Rougeulle C, Glatt $\mathrm{H}$, and Lalande M(1997) The Angelman syndrome candidate gene, UBE3A/E6-AP, is imprinted in brain. Nat Genet 17:14-15.

Ru Y, Wang Q, Liu X, Zhang M, Zhong D, Ye M, Li Y, Han H, Yao L, and Li X(2016) The chimeric ubiquitin ligase SH2-U-box inhibits the growth of imatinib-sensitive and resistant CML by targeting the native and T315I-mutant BCR-ABL. Sci Rep 6: 28352

Sakamoto KM, Kim KB, Kumagai A, Mercurio F, Crews CM, and Deshaies RJ(2001) Protacs: chimeric molecules that target proteins to the Skp1-Cullin-F box complex for ubiquitination and degradation. Proc Natl Acad Sci USA 98:8554-8559.

Salomons FA, Verhoef LG, and Dantuma NP(2005) Fluorescent reporters for the ubiquitin-proteasome system. Essays Biochem 41:113-128.

Sarraf SA, Raman M, Guarani-Pereira V, Sowa ME, Huttlin EL, Gygi SP, and Harper JW(2013) Landscape of the PARKIN-dependent ubiquitylome in response to mitochondrial depolarization. Nature 496:372-376.

Sato Y, Goto E, Shibata Y, Kubota Y, Yamagata A, Goto-Ito S, Kubota K, Inoue J, Takekawa M, Tokunaga F, et al.(2015) Structures of CYLD USP with Met1- or Lys63-linked diubiquitin reveal mechanisms for dual specificity. Nat Struct Mol Biol 22:222-229.

Sato Y, Yoshikawa A, Yamagata A, Mimura H, Yamashita M, Ookata K, Nureki O, Iwai K, Komada M, and Fukai S(2008) Structural basis for specific cleavage of Lys 63-linked polyubiquitin chains. Nature 455:358-362.

Schneekloth JS Jr., Fonseca FN, Koldobskiy M, Mandal A, Deshaies R, Sakamoto K and Crews $\mathrm{CM}(2004)$ Chemical genetic control of protein levels: selective in vivo targeted degradation. J Am Chem Soc 126:3748-3754.

Schneider T, Schneider D, Rösner D, Malhotra S, Mortensen F, Mayer TU, Scheffner M, and Marx A(2014) Dissecting ubiquitin signaling with linkagedefined and protease resistant ubiquitin chains. Angew Chem Int Ed Engl $\mathbf{5 3}$ 12925-12929.

Schulman BA and Harper JW(2009) Ubiquitin-like protein activation by E1 enzymes: the apex for downstream signalling pathways. Nat Rev Mol Cell Biol 10:319-331. 
Schwartz AL and Ciechanover A(2009) Targeting proteins for destruction by the ubiquitin system: implications for human pathobiology. Annu Rev Pharmacol Toxicol 49:73-96.

Scott D, Oldham NJ, Strachan J, Searle MS, and Layfield R(2015) Ubiquitin-binding domains: mechanisms of ubiquitin recognition and use as tools to investigate ubiquitin-modified proteomes. Proteomics 15:844-861.

Serniwka SA and Shaw GS(2009) The structure of the UbcH8-ubiquitin complex shows a unique ubiquitin interaction site. Biochemistry 48:12169-12179.

Shah K, Liu Y, Deirmengian C, and Shokat KM(1997) Engineering unnatural nucleotide specificity for Rous sarcoma virus tyrosine kinase to uniquely label its direct substrates. Proc Natl Acad Sci USA 94:3565-3570.

Shanmugham A, Fish A, Luna-Vargas MP, Faesen AC, El Oualid F, Sixma TK and Ovaa H(2010) Nonhydrolyzable ubiquitin-isopeptide isosteres as deubiquitinating enzyme probes. J Am Chem Soc 132:8834-8835.

Shimura H, Hattori N, Kubo S, Mizuno Y, Asakawa S, Minoshima S, Shimizu N, Iwai $\mathrm{K}$, Chiba T, Tanaka K, et al.(2000) Familial Parkinson disease gene product, parkin, is a ubiquitin-protein ligase. Nat Genet 25:302-305.

Sims JJ, Scavone F, Cooper EM, Kane LA, Youle RJ, Boeke JD, and Cohen RE(2012) Polyubiquitin-sensor proteins reveal localization and linkage-type dependence of cellular ubiquitin signaling. Nat Methods 9:303-309.

Singh SK, Sahu I, Mali SM, Hemantha HP, Kleifeld O, Glickman MH, and Brik A(2016) Synthetic uncleavable ubiquitinated proteins dissect proteasome deubiquitination and degradation, and highlight distinctive fate of tetraubiquitin. $J \mathrm{Am}$ Chem Soc 138:16004-16015.

Smith GP(1985) Filamentous fusion phage: novel expression vectors that display cloned antigens on the virion surface. Science 228:1315-1317.

Smith GP and Petrenko VA(1997) Phage display. Chem Rev 97:391-410.

Sokratous K, Hadjisavvas A, Diamandis EP, and Kyriacou K(2014) The role of ubiquitinbinding domains in human pathophysiology. Crit Rev Clin Lab Sci 51:280-290.

Sommer S, Weikart ND, Linne U, and Mootz HD(2013) Covalent inhibition of SUMO and ubiquitin-specific cysteine proteases by an in situ thiol-alkyne addition. Bioorg Med Chem 21:2511-2517.

Soucy TA, Smith PG, Milhollen MA, Berger AJ, Gavin JM, Adhikari S, Brownell JE, Burke KE, Cardin DP, Critchley S, et al.(2009) An inhibitor of NEDD8-activating enzyme as a new approach to treat cancer. Nature 458:732-736.

Spasser L and Brik A(2012) Chemistry and biology of the ubiquitin signal. Angew Chem Int Ed Engl 51:6840-6862.

Spratt DE, Walden H, and Shaw GS(2014) RBR E3 ubiquitin ligases: new structures, new insights, new questions. Biochem $J$ 458:421-437.

Stagljar I, Korostensky C, Johnsson N, and te Heesen S(1998) A genetic system based on split-ubiquitin for the analysis of interactions between membrane proteins in vivo. Proc Natl Acad Sci USA 95:5187-5192.

Stanley M, Han C, Knebel A, Murphy P, Shpiro N, and Virdee S(2015) Orthogonal thiol functionalization at a single atomic center for profiling transthiolation activity of E1 activating enzymes. ACS Chem Biol 10:1542-1554.

Stanley M and Virdee S(2016) Genetically directed production of recombinant, isosteric and nonhydrolysable ubiquitin conjugates. ChemBioChem 17:1472-1480.

Stefanovic-Barrett S, Dickson AS, Burr SP, Williamson JC, Lobb IT, van den Boomen DJ, Lehner PJ, and Nathan JA(2018) MARCH6 and TRC8 facilitate the quality control of cytosolic and tail-anchored proteins. EMBO Rep 19:e45603.

Stringer DK and Piper RC(2011) A single ubiquitin is sufficient for cargo protein entry into MVBs in the absence of ESCRT ubiquitination. J Cell Biol 192:229-242.

Swatek KN, Aumayr M, Pruneda JN, Visser LJ, Berryman S, Kueck AF, Geurink PP Ovaa H, van Kuppeveld FJM, Tuthill TJ, et al.(2018) Irreversible inactivation of ISG15 by a viral leader protease enables alternative infection detection strategies. Proc Natl Acad Sci USA 115:2371-2376.

Swatek KN and Komander D(2016) Ubiquitin modifications. Cell Res 26:399-422.

Swatek KN, Usher JL, Kueck AF, Gladkova C, Mevissen TET, Pruneda JN, Skern T, and Komander $\mathrm{D}(2019)$ Insights into ubiquitin chain architecture using Ubclipping. Nature 572:533-537.

Tagwerker C, Flick K, Cui M, Guerrero C, Dou Y, Auer B, Baldi P, Huang L, and Kaiser $\mathrm{P}(2006) \mathrm{A}$ tandem affinity tag for two-step purification under fully denaturing conditions: application in ubiquitin profiling and protein complex identification combined with in vivo cross-linking. Mol Cell Proteomics 5:737-748.

Tan XD, Pan M, Gao S, Zheng Y, Shi J, and Li YM(2017) A diubiquitin-based photoaffinity probe for profiling K27-linkage targeting deubiquitinases. Chem Commun (Camb) 53:10208-10211.

Thrower JS, Hoffman L, Rechsteiner M, and Pickart CM(2000) Recognition of the polyubiquitin proteolytic signal. EMBO J 19:94-102.

Tian M, Zeng T, Liu M, Han S, Lin H, Lin Q, Li L, Jiang T, Li G, Lin H, et al.(2019) A cell-based high-throughput screening method based on a ubiquitin-reference technique for identifying modulators of E3 ligases. J Biol Chem 294:2880-2891.

Trang VH, Valkevich EM, Minami S, Chen YC, Ge Y, and Strieter ER(2012) Nonenzymatic polymerization of ubiquitin: single-step synthesis and isolation of discrete ubiquitin oligomers. Angew Chem Int Ed Engl 51:13085-13088.

Tsai YC, Maditz R, Kuo CL, Fishman PS, Shoemaker CB, Oyler GA, and Weissman $\mathrm{AM}(2010)$ Targeting botulinum neurotoxin persistence by the ubiquitinproteasome system. Proc Natl Acad Sci USA 107:16554-16559.

Valkevich EM, Guenette RG, Sanchez NA, Chen YC, Ge Y, and Strieter ER(2012) Forging isopeptide bonds using thiol-ene chemistry: site-specific coupling of ubiquitin molecules for studying the activity of isopeptidases. J Am Chem Soc 134: $6916-6919$.

van Wijk SJ, Fiskin E, Putyrski M, Pampaloni F, Hou J, Wild P, Kensche T, Grecco HE, Bastiaens P, and Dikic I(2012) Fluorescence-based sensors to monitor localization and functions of linear and K63-linked ubiquitin chains in cells. Mol Cell 47: 797-809.

Varadan R, Assfalg M, Raasi S, Pickart C, and Fushman D(2005) Structural determinants for selective recognition of a Lys48-linked polyubiquitin chain by a UBA domain. Mol Cell 18:687-698.

Varadan R, Walker O, Pickart C, and Fushman D(2002) Structural properties of polyubiquitin chains in solution. J Mol Biol 324:637-647.
Varshavsky A(1996) The N-end rule: functions, mysteries, uses. Proc Natl Acad Sci USA 93:12142-12149.

Virdee S, Kapadnis PB, Elliott T, Lang K, Madrzak J, Nguyen DP, Riechmann L, and Chin JW(2011) Traceless and site-specific ubiquitination of recombinant proteins. J Am Chem Soc 133:10708-10711.

Virdee S, Ye Y, Nguyen DP, Komander D, and Chin JW(2010) Engineered diubiquitin synthesis reveals Lys29-isopeptide specificity of an OTU deubiquitinase. Nat Chem Biol 6:750-757.

Walden H, Podgorski MS, Huang DT, Miller DW, Howard RJ, Minor DL Jr., Holton JM, and Schulman BA(2003) The structure of the APPBP1-UBA3-NEDD8-ATP complex reveals the basis for selective ubiquitin-like protein activation by an E1. Mol Cell 12:1427-1437.

Wang L, Brock A, Herberich B, and Schultz PG(2001) Expanding the genetic code of Escherichia coli. Science 292:498-500.

Wang L and Schultz PG(2004) Expanding the genetic code. Angew Chem Int Ed Engl 44:34-66.

Wang Y, Liu X, Zhou L, Duong D, Bhuripanyo K, Zhao B, Zhou H, Liu R, Bi Y, Kiyokawa H, et al.(2017a) Identifying the ubiquitination targets of E6AP by orthogonal ubiquitin transfer. Nat Commun 8:2232.

Wang ZA, Zeng Y, Kurra Y, Wang X, Tharp JM, Vatansever EC, Hsu WW, Dai S, Fang X, and Liu WR(2017b) A genetically encoded allysine for the synthesis of proteins with site-specific lysine dimethylation. Angew Chem Int Ed Engl 56: $212-216$

Weber A, Elliott PR, Pinto-Fernandez A, Bonham S, Kessler BM, Komander D, El Oualid F, and Krappmann D(2017) A linear diubiquitin-based probe for efficient and selective detection of the deubiquitinating enzyme OTULIN. Cell Chem Biol 24:1299-1313.e7.

Wehr MC and Rossner MJ(2016) Split protein biosensor assays in molecular pharmacological studies. Drug Discov Today 21:415-429.

Weikart ND, Sommer S, and Mootz HD(2012) Click synthesis of ubiquitin dimer analogs to interrogate linkage-specific UBA domain binding. Chem Commun (Camb) 48:296-298.

Weissman AM, Shabek N, and Ciechanover A(2011) The predator becomes the prey: regulating the ubiquitin system by ubiquitylation and degradation. Nat Rev Mol Cell Biol 12:605-620.

Weller CE, Huang W, and Chatterjee C(2014) Facile synthesis of native and protease-resistant ubiquitylated peptides. ChemBioChem 15:1263-1267.

Wenzel DM, Stoll KE, and Klevit RE(2011) E2s: structurally economical and functionally replete. Biochem $J$ 433:31-42.

Wertz IE, Newton K, Seshasayee D, Kusam S, Lam C, Zhang J, Popovych N, Helgason E, Schoeffler A, Jeet S, et al.(2015) Phosphorylation and linear ubiquitin direct A20 inhibition of inflammation. Nature 528:370-375.

Whedon SD, Markandeya N, Rana ASJB, Senger NA, Weller CE, Tureček F, Strieter ER, and Chatterjee C(2016) Selenocysteine as a latent bioorthogonal electrophilic probe for deubiquitylating enzymes. J Am Chem Soc 138:13774-13777.

Wilkinson KD, Urban MK, and Haas AL(1980) Ubiquitin is the ATP-dependent proteolysis factor I of rabbit reticulocytes. J Biol Chem 255:7529-7532.

Winter G, Griffiths AD, Hawkins RE, and Hoogenboom HR(1994) Making antibodies by phage display technology. Annu Rev Immunol 12:433-455.

Winter GE, Buckley DL, Paulk J, Roberts JM, Souza A, Dhe-Paganon S, and Bradner JE(2015) Drug development: Phthalimide conjugation as a strategy for in vivo target protein degradation. Science 348:1376-1381.

$\mathrm{Xu} \mathrm{G}$ and Jaffrey SR(2011) The new landscape of protein ubiquitination. Nat Biotechnol 29:1098-1100.

Yang B, Tang S, Ma C, Li ST, Shao GC, Dang B, DeGrado WF, Dong MQ, Wang PG, Ding S, et al.(2017) Spontaneous and specific chemical cross-linking in live cells to capture and identify protein interactions. Nat Commun 8:2240

Yang C, Mi J, Feng Y, Ngo L, Gao T, Yan L, and Zheng YG(2013) Labeling lysine acetyltransferase substrates with engineered enzymes and functionalized cofactor surrogates. J Am Chem Soc 135:7791-7794.

Yang K, Gong P, Gokhale P, and Zhuang Z(2014) Chemical protein polyubiquitination reveals the role of a noncanonical polyubiquitin chain in DNA damage tolerance. ACS Chem Biol 9:1685-1691.

Yau RG, Doerner K, Castellanos ER, Haakonsen DL, Werner A, Wang N, Yang XW, Martinez-Martin N, Matsumoto ML, et al.(2017) Assembly and function of heterotypic ubiquitin chains in cell-cycle and protein quality control. Cell 171: 918-933.e20.

Ye Y and Rape M(2009) Building ubiquitin chains: E2 enzymes at work. Nat Rev Mol Cell Biol 10:755-764.

Yen HC and Elledge SJ(2008) Identification of SCF ubiquitin ligase substrates by global protein stability profiling. Science $322: 923-929$.

Yen HC, Xu Q, Chou DM, Zhao Z, and Elledge SJ(2008) Global protein stability profiling in mammalian cells. Science 322:918-923.

Yi JJ and Ehlers MD(2007) Emerging roles for ubiquitin and protein degradation in neuronal function. Pharmacol Rev 59:14-39.

Yi JJ, Paranjape SR, Walker MP, Choudhury R, Wolter JM, Fragola G, Emanuele MJ, Major MB, and Zylka MJ(2017) The autism-linked UBE3A T485A mutant E3 ubiquitin ligase activates the Wnt/ $\beta$-catenin pathway by inhibiting the proteasome. $J$ Biol Chem 292:12503-12515.

Yin J, Mills JH, and Schultz PG(2004) A catalysis-based selection for peroxidase antibodies with increased activity. J Am Chem Soc 126:3006-3007.

Yoshida Y, Saeki Y, Murakami A, Kawawaki J, Tsuchiya H, Yoshihara H, Shindo M, and Tanaka $K(2015)$ A comprehensive method for detecting ubiquitinated substrates using TR-TUBE. Proc Natl Acad Sci USA 112:4630-4635.

Yunus AA and Lima CD(2006) Lysine activation and functional analysis of E2mediated conjugation in the SUMO pathway. Nat Struct Mol Biol 13:491-499.

Zeymer C and Hilvert D(2018) Directed evolution of protein catalysts. Annu Rev Biochem 87:131-157.

Zhang K, Li H, Bhuripanyo K, Zhao B, Chen TF, Zheng N, and Yin J(2013a) Engineering new protein-protein interactions on the $\beta$-propeller fold by yeast cell surface display. ChemBioChem 14:426-430. 
Zhang K, Nelson KM, Bhuripanyo K, Grimes KD, Zhao B, Aldrich CC, and Yin $\mathrm{J}(2013 \mathrm{~b})$ Engineering the substrate specificity of the DhbE adenylation domain by yeast cell surface display. Chem Biol 20:92-101.

Zhang MS, Brunner SF, Huguenin-Dezot N, Liang AD, Schmied WH, Rogerson DT, and Chin JW(2017a) Biosynthesis and genetic encoding of phosphothreonine through parallel selection and deep sequencing. Nat Methods 14:729-736.

Zhang N, Wang Q, Ehlinger A, Randles L, Lary JW, Kang Y, Haririnia A, Storaska AJ, Cole JL, Fushman D, et al.(2009) Structure of the s5a:k48-linked diubiquitin complex and its interactions with rpn13. Mol Cell 35:280-290.

Zhang W, Bailey-Elkin BA, Knaap RCM, Khare B, Dalebout TJ, Johnson GG, van Kasteren PB, McLeish NJ, Gu J, He W, et al.(2017b) Potent and selective inhibition of pathogenic viruses by engineered ubiquitin variants. PLoS Pathog 13 e1006372.

Zhang W and Sidhu SS(2014) Development of inhibitors in the ubiquitination cascade. FEBS Lett 588:356-367.

Zhang W, Wu KP, Sartori MA, Kamadurai HB, Ordureau A, Jiang C, Mercredi PY, Murchie R, Hu J, Persaud A, et al.(2016) System-wide modulation of HECT E3 ligases with selective ubiquitin variant probes. Mol Cell 62:121-136.

Zhang X, Smits AH, van Tilburg GB, Jansen PW, Makowski MM, Ovaa H, and Vermeulen $\mathrm{M}(2017 \mathrm{c})$ An interaction landscape of ubiquitin signaling. Mol Cell 65:941-955.e8.

Zhang X, Zhang H, and Wang Y(2014) Phosphorylation regulates VCIP135 function in Golgi membrane fusion during the cell cycle. J Cell Sci 127:172-181.

Zhang Y, Zhou L, Rouge L, Phillips AH, Lam C, Liu P, Sandoval W, Helgason E, Murray JM, Wertz IE, et al.(2013c) Conformational stabilization of ubiquitin yields potent and selective inhibitors of USP7. Nat Chem Biol 9:51-58.

Zhao B, Bhuripanyo K, Schneider J, Zhang K, Schindelin H, Boone D, and Yin $\mathrm{J}(2012 \mathrm{a})$ Specificity of the E1-E2-E3 enzymatic cascade for ubiquitin C-terminal sequences identified by phage display. ACS Chem Biol 7:2027-2035.

Zhao B, Bhuripanyo K, Zhang K, Kiyokawa H, Schindelin H, and Yin J(2012b) Orthogonal ubiquitin transfer through engineered E1-E2 cascades for protein ubiquitination. Chem Biol 19:1265-1277.
Zhao B, Choi CHJ, Bhuripanyo K, Villhauer EB, Zhang K, Schindelin H, and Yin $\mathrm{J}(2012 \mathrm{c})$ Inhibiting the protein ubiquitination cascade by ubiquitin-mimicking short peptides. Org Lett 14:5760-5763.

Zhao B, Villhauer EB, Bhuripanyo K, Kiyokawa H, Schindelin H, and Yin J(2014) SUMO-mimicking peptides inhibiting protein SUMOylation. ChemBioChem 15: 2662-2666.

Zhao B, Zhang K, Bhuripanyo K, Choi CH, Villhauer EB, Li H, Zheng N, Kiyokawa $\mathrm{H}$, Schindelin H, and Yin J(2013a) Profiling the cross reactivity of ubiquitin with the Nedd8 activating enzyme by phage display. PLoS One 8:e70312.

Zhao B, Zhang K, Villhauer EB, Bhuripanyo K, Kiyokawa H, Schindelin H, and Yin $\mathrm{J}(2013 \mathrm{~b})$ Phage display to identify Nedd8-mimicking peptides as inhibitors of the Nedd8 transfer cascade. ChemBioChem 14:1323-1330.

Zhao H, Giver L, Shao Z, Affholter JA, and Arnold FH(1998) Molecular evolution by staggered extension process (StEP) in vitro recombination. Nat Biotechnol 16 $258-261$.

Zhao X, Lutz J, Höllmüller E, Scheffner M, Marx A, and Stengel F(2017) Identification of proteins interacting with ubiquitin chains. Angew Chem Int Ed Engl 56: 15764-15768.

Zheng N and Shabek N(2017) Ubiquitin ligases: structure, function, and regulation. Annu Rev Biochem 86:129-157.

Zhong D, Ru Y, Wang Q, Zhang J, Zhang J, Wei J, Wu J, Yao L, Li X, and Li X(2015 Chimeric ubiquitin ligases inhibit non-small cell lung cancer via negative modulation of EGFR signaling. Cancer Lett 359:57-64.

Zhou L, Holt MT, Ohashi N, Zhao A, Müller MM, Wang B, and Muir TW(2016 Evidence that ubiquitylated $\mathrm{H} 2 \mathrm{~B}$ corrals $\mathrm{hDot} 1 \mathrm{~L}$ on the nucleosomal surface to induce H3K79 methylation. Nat Commun 7:10589.

Zhou P, Bogacki R, McReynolds L, and Howley PM(2000) Harnessing the ubiquitination machinery to target the degradation of specific cellular proteins. Mol Cell $\mathbf{6}$ : 751-756.

Zhuang M, Guan S, Wang H, Burlingame AL, and Wells JA(2013) Substrates of IAP ubiquitin ligases identified with a designed orthogonal E3 ligase, the NEDDylator. Mol Cell 49:273-282. 